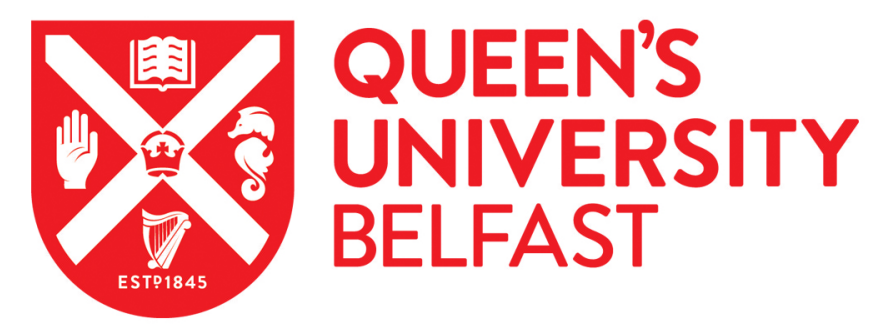

\title{
Pharmacological interventions for cognitive decline in people with Down syndrome
}

Livingstone, N., Hanratty, J., Mcshane, R., \& Macdonald, G. (2015). Pharmacological interventions for cognitive decline in people with Down syndrome. Cochrane Database of Systematic Reviews, 2015(10), [CD011546]. https://doi.org/10.1002/14651858.CD011546.pub2

Published in:

Cochrane Database of Systematic Reviews

Document Version:

Publisher's PDF, also known as Version of record

Queen's University Belfast - Research Portal:

Link to publication record in Queen's University Belfast Research Portal

Publisher rights

Copyright 2015, The Cochrane Collaboration.

This work is made available online in accordance with the publisher's policies. Please refer to any applicable terms of use of the publisher.

\section{General rights}

Copyright for the publications made accessible via the Queen's University Belfast Research Portal is retained by the author(s) and / or other copyright owners and it is a condition of accessing these publications that users recognise and abide by the legal requirements associated with these rights.

Take down policy

The Research Portal is Queen's institutional repository that provides access to Queen's research output. Every effort has been made to ensure that content in the Research Portal does not infringe any person's rights, or applicable UK laws. If you discover content in the Research Portal that you believe breaches copyright or violates any law, please contact openaccess@qub.ac.uk. 


\title{
(E) Cochrane Library
}

Cochrane Database of Systematic Reviews

\section{Pharmacological interventions for cognitive decline in people with Down syndrome (Review)}

Livingstone N, Hanratty J, McShane R, Macdonald G

\author{
Livingstone N, Hanratty J, McShane R, Macdonald G. \\ Pharmacological interventions for cognitive decline in people with Down syndrome. \\ Cochrane Database of Systematic Reviews 2015, Issue 10. Art. No.: CD011546. \\ DOI: 10.1002/14651858.CD011546.pub2.
}

www.cochranelibrary.com 
TABLE OF CONTENTS

HEADER

ABSTRACT

PLAIN LANGUAGE SUMMARY

OBJECTIVES

METHODS

RESULTS . . . . . . . . . . . . . . . . . . . . . . . . . . . . . . . . 10

Figure 1. . . . . . . . . . . . . . . . . . . . . . . . . . . . . . . . . . . . . 11

Figure 2. . . . . . . . . . . . . . . . . . . . . . . . . . . . . . . . . . . . . . 14

Figure 3. . . . . . . . . . . . . . . . . . . . . . . . . . . . . . . . . . . . . . 15

Figure 4. . . . . . . . . . . . . . . . . . . . . . . . . . . . . . . . . . . . . . 17

Figure 5. . . . . . . . . . . . . . . . . . . . . . . . . . . . . . . . . . . . . . 18

Figure 6. . . . . . . . . . . . . . . . . . . . . . . . . . . . . . . . . . . . . . 18

ADDITIONAL SUMMARY OF FINDINGS . . . . . . . . . . . . . . . . . . . . . . . . . . . . . 21

DISCUSSION . . . . . . . . . . . . . . . . . . . . . . . . . . . . . . . . . . . . . 24

AUTHORS' CONCLUSIONS . . . . . . . . . . . . . . . . . . . . . . . . . . . . . . . . 25

ACKNOWLEDGEMENTS . . . . . . . . . . . . . . . . . . . . . . . . . . . . . . . . . 25

REFERENCES . . . . . . . . . . . . . . . . . . . . . . . . . . . . . . . . . . . . . . . . . . 26

CHARACTERISTICS OF STUDIES . . . . . . . . . . . . . . . . . . . . . . . . . . . . . . . . . . . .

DATA AND ANALYSES . . . . . . . . . . . . . . . . . . . . . . . . . . . . . . . . . . . . . . . . . . . . . . . . . 48

Analysis 1.1. Comparison 1 Comparison 1: donepezil versus placebo, Outcome 1 Cognitive abilities (Severe Impairment

Battery) 12 to 24 weeks. . . . . . . . . . . . . . . . . . . . . . . . . . . . . . . 49

Analysis 1.2. Comparison 1 Comparison 1: donepezil versus placebo, Outcome 2 Behavioural problems (various scales) 12 to 24 weeks. . . . . . . . . . . . . . . . . . . . . . . . . . . . . . . . . . . . . . . . . . . . 50

Analysis 1.3. Comparison 1 Comparison 1: donepezil versus placebo, Outcome 3 Adverse events (12 to 24 weeks). . 51

Analysis 2.1. Comparison 2 Comparison 2: memantine versus placebo, Outcome 1 Cognitive abilities (various scales) 16 to

52 weeks.

Analysis 2.2. Comparison 2 Comparison 2: memantine versus placebo, Outcome 2 Behavioural problems (various scales)

16 to 52 weeks. . . . . . . . . . . . . . . . . . . . . . . . . 52

Analysis 2.3. Comparison 2 Comparison 2: memantine versus placebo, Outcome 3 Adverse events (16 to 52 weeks). 53

ADDITIONAL TABLES . . . . . . . . . . . . . . . . . . . . . . . . . . . . . . . . . . . . . . . . . . . 53

APPENDICES . . . . . . . . . . . . . . . . . . . . . . . . . . . . . . . . . . . . . . 55

HISTORY . . . . . . . . . . . . . . . . . . . . . . . . . . . . . . . . . . . . . . . 64

CONTRIBUTIONS OF AUTHORS . . . . . . . . . . . . . . . . . . . . . . . . . . . . . . . . . . 65

DECLARATIONS OF INTEREST . . . . . . . . . . . . . . . . . . . . . . . . . . . . . . . . . . 65

SOURCES OF SUPPORT . . . . . . . . . . . . . . . . . . . . . . . . . . . . . . . . . . . . 65

DIFFERENCES BETWEEN PROTOCOL AND REVIEW . . . . . . . . . . . . . . . . . . . . . . 66

INDEX TERMS . . . . . . . . . . . . . . . . . . . . . . . . . . . . . . . . . . . . . . . . . . . . . . . . . . . . . 66

Pharmacological interventions for cognitive decline in people with Down syndrome (Review)

Copyright $\odot 2015$ The Cochrane Collaboration. Published by John Wiley \& Sons, Ltd. 


\title{
[Intervention Review]
}

\section{Pharmacological interventions for cognitive decline in people with Down syndrome}

\author{
Nuala Livingstone ${ }^{1}$, Jennifer Hanratty ${ }^{1}$, Rupert McShane ${ }^{2}$, Geraldine Macdonald ${ }^{3}$ \\ ${ }^{1}$ School of Sociology, Social Policy and Social Work, Queen's University Belfast, Belfast, UK. ${ }^{2}$ Radcliffe Department of Medicine, \\ University of Oxford, Oxford, UK. ${ }^{3}$ School for Policy Studies, University of Bristol, Bristol, UK \\ Contact address: Nuala Livingstone, School of Sociology, Social Policy and Social Work, Queen's University Belfast, 6 College Park, \\ Belfast, BT7 1LP, UK. nuala.livingstone@qub.ac.uk. nlivingstone@cochrane.org.
}

Editorial group: Cochrane Developmental, Psychosocial and Learning Problems Group.

Publication status and date: New, published in Issue 10, 2015.

Review content assessed as up-to-date: 20 January 2015.

Citation: Livingstone N, Hanratty J, McShane R, Macdonald G. Pharmacological interventions for cognitive decline in people with Down syndrome. Cochrane Database of Systematic Reviews 2015, Issue 10. Art. No.: CD011546. DOI: 10.1002/14651858.CD011546.pub2.

Copyright (C) 2015 The Cochrane Collaboration. Published by John Wiley \& Sons, Ltd.

\begin{abstract}
A B S T R A C T
Background

People with Down syndrome are vulnerable to developing dementia at an earlier age than the general population. Alzheimer's disease and cognitive decline in people with Down syndrome can place a significant burden on both the person with Down syndrome and their family and carers. Various pharmacological interventions, including donepezil, galantamine, memantine and rivastigmine, appear to have some effect in treating cognitive decline in people without Down syndrome, but their effectiveness for those with Down syndrome remains unclear.
\end{abstract}

\section{Objectives}

To assess the effectiveness of anti-dementia pharmacological interventions and nutritional supplements for treating cognitive decline in people with Down syndrome.

\section{Search methods}

In January 2015, we searched CENTRAL, ALOIS (the Specialised Register of the Cochrane Dementia and Cognitive Improvement Group), Ovid MEDLINE, Embase, PsycINFO, seven other databases, and two trials registers. In addition, we checked the references of relevant reviews and studies and contacted study authors, other researchers and relevant drug manufacturers to identify additional studies.

\section{Selection criteria}

Randomised controlled trials (RCTs) of anti-dementia pharmacological interventions or nutritional supplements for adults (aged 18 years and older) with Down syndrome, in which treatment was administered and compared with either placebo or no treatment.

\section{Data collection and analysis}

Two review authors independently assessed the risk of bias of included trials and extracted the relevant data. Review authors contacted study authors to obtain missing information where necessary.

Pharmacological interventions for cognitive decline in people with Down syndrome (Review)

Copyright $\odot 2015$ The Cochrane Collaboration. Published by John Wiley \& Sons, Ltd. 


\section{Main results}

Only nine studies (427 participants) met the inclusion criteria for this review. Four of these (192 participants) assessed the effectiveness of donepezil, two (139 participants) assessed memantine, one (21 participants) assessed simvastatin, one study (35 participants) assessed antioxidants, and one study (40 participants) assessed acetyl-L-carnitine.

Five studies focused on adults aged 45 to 55 years, while the remaining four studies focused on adults aged 20 to 29 years. Seven studies were conducted in either the USA or UK, one between Norway and the UK, and one in Japan. Follow-up periods in studies ranged from four weeks to two years. The reviewers judged all included studies to be at low or unclear risk of bias.

Analyses indicate that for participants who received donepezil, scores in measures of cognitive functioning (standardised mean difference (SMD) 0.52 , 95\% confidence interval (CI) -0.27 to 1.13) and measures of behaviour (SMD 0.42, 95\% CI -0.06 to 0.89 ) were similar to those who received placebo. However, participants who received donepezil were significantly more likely to experience an adverse event (odds ratio (OR) 0.32 , 95\% CI 0.16 to 0.62 ). The quality of this body of evidence was low. None of the included donepezil studies reported data for carer stress, institutional/home care, or death.

For participants who received memantine, scores in measures of cognitive functioning (SMD 0.05, 95\% CI -0.43 to 0.52), behaviour (SMD $-0.17,95 \%$ CI -0.46 to 0.11 ), and occurrence of adverse events (OR 0.45, 95\% CI 0.18 to 1.17 ) were similar to those who received placebo. The quality of this body of evidence was low. None of the included memantine studies reported data for carer stress, institutional/home care, or death.

Due to insufficient data, it was possible to provide a narrative account only of the outcomes for simvastatin, antioxidants, and acetylL-carnitine. Results from one pilot study suggest that participants who received simvastatin may have shown a slight improvement in cognitive measures.

\section{Authors' conclusions}

Due to the low quality of the body of evidence in this review, it is difficult to draw conclusions about the effectiveness of any pharmacological intervention for cognitive decline in people with Down syndrome.

\section{PLAIN LANGUAGE SUMMARY}

\section{Medications for cognitive decline in people with Down syndrome}

People with Down syndrome often experience cognitive decline (a deterioration in memory, language, thinking and judgment that are greater than normal age-related changes) at a younger age and in greater numbers than the general population. Various medicines have been shown to improve, or at least slow down the progression of these symptoms in people without Down syndrome.

\section{Review question}

Do adults (18 years and older) with Down syndrome benefit from treatment with medicine to prevent cognitive decline, compared with other adults with Down syndrome who receive either fake medicine (placebos) or no medicine?

\section{Study characteristics}

In January 2015, we, a team of Cochrane researchers, searched for all medical studies that investigated the effect of any medicine or nutritional supplement on cognitive decline in adults with Down syndrome. We found nine relevant randomised controlled trials (this design produces the most reliable results) that we could include in this overview. These studies tested:

- donepezil, a medicine used to treat Alzheimer's disease (four studies);

- memantine, a medicine used to treat Alzheimer's disease (two studies);

- simvastatin, a (statin) medicine used to prevent heart disease (one study);

- a mixture of antioxidants, including forms of vitamins $\mathrm{C}$ and $\mathrm{E}$, and alpha-lipoic acid (one study); and

- acetyl-L-carnitine, a dietary supplement that has previously been used to treat dementia (one study).

Five of the studies focused on adults aged 45 to 55 years and four focused on adults aged 20 to 29 years. Seven studies were conducted in either the USA or UK, one took place in Norway and the UK, and one study was conducted in Japan.

Pharmacological interventions for cognitive decline in people with Down syndrome (Review)

Copyright @ 2015 The Cochrane Collaboration. Published by John Wiley \& Sons, Ltd. 


\section{Key results}

The nine studies we found examined the effects of five medicines that are, or have been, used to prevent cognitive decline. All the studies compared the medicine being tested with a placebo (a tablet or capsule that looked and tasted like the medicine, but which contained no medicine).

Generally, those who received the medicine did no better than those who received the placebo in any of the areas assessed in the studies. The areas assessed included general functioning (including memory and thinking, speech, mood and behaviour); cognitive functioning (including memory, following what's going on around you); adaptive behaviours (being able to do day-to-day tasks); or behaviour problems (such as being irritable or aggressive).

The only medicine to show any positive effect was the statin, simvastatin. Preliminary findings from a very small study showed that simvastin had some benefit on improving memory compared to placebo.

In the four donepezil studies, those participants given donepezil reported more headaches, dizziness, and nausea than participants given placebo. In the two memantine studies, there was no difference between participants given memantine or placebo for reports of headaches, dizziness, and nausea.

\section{Quality of the evidence}

Although the included studies were well conducted, most involved small numbers of participants and for many of the areas assessed we could not combine results from two or more studies. Overall, the quality of this evidence is low. We cannot be certain whether any of these medicines are effective. Running more trials with more people over a longer period of time would allow us answer this question with greater certainty.

We could not find any trials that investigated many of the medicines used to prevent cognitive decline, and so research is needed to explore the effectiveness of these medications in the Down syndrome population.

Pharmacological interventions for cognitive decline in people with Down syndrome (Review) 


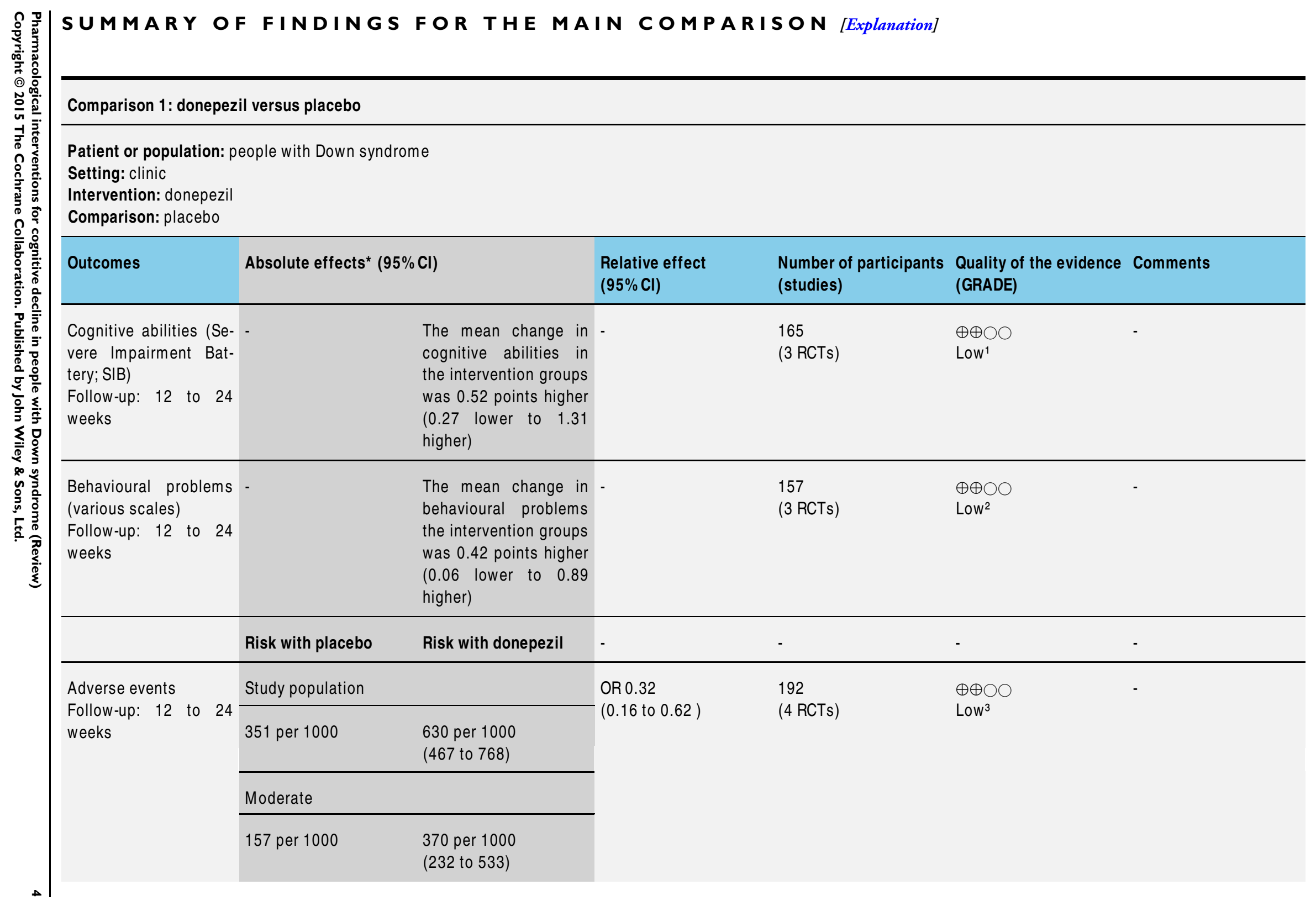




\begin{tabular}{llllll}
\hline Carer stress & No data available & No data available & - & - & - \\
\hline Institutional/home care & No data available & No data available & - & - & - \\
\hline Death & No data available & No data available & - & - & - \\
\hline
\end{tabular}

${ }^{*}$ The risk in the intervention group (and its $95 \%$ confidence interval) is based on the assumed risk in the comparison group and the relative effect of the intervention (and its $95 \% \mathrm{Cl})$.

$\mathrm{Cl}$ : confidence interval; GRADE: Grades of Recommendations, Assessment, Development and Evaluation; RR: risk ratio; OR: odds ratio

\section{GRADE Working Group grades of evidence}

High quality: We are very confident that the true effect lies close to that of the estimate of the effect

Moderate quality: We are moderately confident in the effect estimate: The true effect is likely to be close to the estimate of the effect, but there is a possibility that it is substantially different

Low quality: Our confidence in the effect estimate is limited: The true effect may be substantially different from the estimate of the effect

Very low quality: We have very little confidence in the effect estimate: The true effect is likely to be substantially different from the estimate of effect

${ }^{1}$ Downgraded two levels for imprecision (wide confidence interval) and inconsistency $\left(1^{2}=74 \%\right)$

2 Downgraded two levels for imprecision (wide confidence interval) and inconsistency $\left(I^{2}=36 \%\right.$ ).

${ }^{3}$ Downgraded two levels for serious imprecision (wide confidence interval) and small number of events. 


\section{B A C K G R O U N D}

\section{Description of the condition}

Down syndrome is the most common genetic disorder recognised at birth and is caused by an extra copy of chromosome 21 , or the translocation of part of chromosome 21, onto another chromosome (Loane 2014; Papalia 2001).

As the care and environment of people with Down syndrome has improved, so their life expectancy has improved (Bittles 2010; Yang 2002). Life expectancy is currently 58 years (Wu 2013), with $25 \%$ living beyond 63 years (Glasson 2002). Survival of babies with Down syndrome increased significantly in the 1950s, and there is currently a population bulge of those aged 40 to 55 (Wu 2013).

The extra copy of the amyloid precursor protein (APP) gene, which is located on chromosome 21, causes the early onset of Alzheimer's disease pathology: cerebral amyloid plaques are present in almost all cases, developing some 50 years earlier than in normal aging (Mann 1989; Rumble 1989). Consequently, people with Down syndrome are vulnerable to developing dementia at an earlier age: prevalence runs at $10 \%$ between the ages of 40 and 49 years, $40 \%$ between the ages of 50 and 59 years (Holland 1998), and 56\% in those over 60 (Janicki 2000). This is greater than the rate seen in other causes of neurodevelopmental delay, which runs at $2 \%$ to $3 \%$ at 40 years of age (Janicki 2000).

However, as in the general population, significant numbers of older people with Down syndrome and cerebral amyloid plaques do not develop dementia. Indeed, cerebral amyloid plaques may be unrelated to cognitive impairment in people with Down syndrome who do not have dementia (Hartley 2014), and neurofibrillary tangles develop considerably later than the amyloid deposition ( Hof 1995). Additional factors such as vascular pathology, cognitive reserve (Mullins 2013; Temple 2001), or additional genetic risks such as Apolipoprotein E (ApoE4; Jones 2013; Rohn 2014), may influence the development of cognitive decline and dementia.

Although progression from Alzheimer's disease to Alzheimer's dementia affects people with Down syndrome in similar ways to those without Down syndrome, there are some notable differences. Firstly, the rate of decline may be more rapid in people with Down syndrome. Secondly, diagnosis may be delayed because existing cognitive deficits may make changes in behaviour, confusion, and living skills more difficult to detect (Watchman 2013). Thirdly, behavioural changes of apathy and disinhibition are particularly common in pre-dementia decline in Down syndrome, and are suggestive of prominent frontal lobe impairment (Ball 2008).

Dementia and cognitive decline can cause significant distress and add to the burden of caring for people with Down syndrome. Changes in adaptive behaviour are common and 24-hour surveillance over a period of years is required, which places caregivers at a high risk of adverse health consequences (Bittles 2004; CSHAWG 2002).
Consideration of the performance of differing diagnostic criteria of dementia in Down syndrome is beyond the scope of this review and is reviewed elsewhere (Sheehan 2015).

\section{Description of the intervention}

There is no known cure for dementia, but psychological treatments have been found to be effective in helping people to cope with the symptoms (Forbes 2013; Woods 2012).

In addition, drugs from two classes are licensed for the treatment of Alzheimer's disease: the cholinesterase inhibitors (donepezil, galantamine and rivastigmine), and the $\mathrm{N}$-methyl-D-aspartate (NMDA) receptor antagonist, memantine. Trials of other interventions, such as vitamin $\mathrm{E}, \mathrm{B}$ vitamins and statins have provided conflicting evidence of benefit.

It is also not known whether there are interventions that might affect progression of cognitive decline in participants without a formal diagnosis of dementia.

\section{How the intervention might work}

A number of pharmacological interventions are currently available and operate through a range of mechanisms.

Donepezil, galantamine and rivastigmine work by inhibiting the enzyme acetylcholinesterase, thereby increasing the level of the neurotransmitter acetylcholine between nerve cells in the brain. They provide a modest symptomatic boost, improving cognitive and functional ability in those with mild to severe dementia. Over two years, this may be sufficient to reduce mortality, at least for galantamine (Hager 2014). The risks are considered to outweigh the benefits in mild cognitive impairment (Tricco 2013). The main side effects are loss of appetite, nausea, diarrhoea, headache, insomnia and slowed heart rate.

Memantine is an antagonist of the NMDA glutamate receptor. It has a small benefit, including in those already taking cholinesterase inhibitors. The benefit is confined to those with moderate or severe Alzheimer's disease and is consistent with the proposed mechanism of action: reduction of excitotoxicity and subsequent damage and death of neurons. It is a well tolerated drug (Gauthier 2013).

High dose vitamin E, an antioxidant, has been reported as showing benefit in trials of severe (Sano 1997), and mild-to-moderate Alzheimer's disease (Dysken 2014). The lack of effect on cognition, theoretical concerns about safety, and lack of industrial backing for marketing have, thus far, militated against widespread use (Corbett 2014).

A single study has indicated that high dose vitamin B12 and folate may reduce progression of brain atrophy in mild cognitive impairment, with cognitive benefit in those with high levels of the amino acid homocysteine (Douaud 2013).

Dual-specificity tyrosine-(Y)-phosphorylation regulated kinase 1A (DYRK1A) may be important in the pathophysiology of intellec- 
tual deficit in Down syndrome. Research has indicated that epigallocatechin-3-gallate reduces DYRK1A activity in the hippocampus (De la Torre 2014).

The incidence of dementia in the general population is reducing slightly. This raises the possibility that strategies that improve vascular health (Matthews 2013), such as statins and antihypertensives, may also reduce dementia, although this has not been securely established in randomised trials (Ligthart 2010; Power 2015). It remains unknown whether this applies to a Down syndrome population.

It is not known whether the benefits and risks seen in the general population would differ in those with Down syndrome.

\section{Why it is important to do this review}

In 2009, four Cochrane Reviews were published of the licensed treatments for Alzheimer's disease in people with Down syndrome (Mohan 2009a; Mohan 2009b; Mohan 2009c; Mohan 2009d). At that time, only one review identified a trial that met its inclusion criteria, namely a small randomised trial of donepezil. The reviews concluded that nothing was then known about the effectiveness of licensed treatments for Alzheimer's disease in this population. This review aimed to achieve three things:

1. to update the evidence base;

2. to bring together, in one place, the available evidence of both licensed treatments and other available treatments for this population; and

3. to examine the impact of these pharmacological interventions on cognitive impairment, which does not meet the criteria for dementia.

An up-to-date review of this kind is important, not least because people with learning disabilities (including Down syndrome) are often on a large amount of medication, despite limited evidence of its effectiveness and evidence of considerable harmful side effects (RCGP 2012).

\section{O B J E C T I VES}

To assess the effectiveness of anti-dementia pharmacological interventions and nutritional supplements for treating cognitive decline in people with Down syndrome.

\section{METHODS}

\section{Criteria for considering studies for this review}

\author{
Types of studies
}

Randomised controlled trials (RCTs) comparing one relevant antidementia pharmacological intervention or nutritional supplement with another, or with placebo or no treatment.

\section{Types of participants}

Adults (aged 18 years and older) with Down syndrome. Where we identified relevant studies that included participants younger than 18 years of age or participants that did not have Down syndrome, we contacted the study authors to request the subgroup data for participants with Down syndrome, aged 18 years and older only. If the authors were unable or unwilling to provide this data, the study was excluded from the review. Information from one such study is presented (Eisenburg 1984).

\section{Types of interventions}

Any anti-dementia pharmacological intervention or nutritional supplement that has a putative effect on cognitive function. Relevant interventions include, but are not limited to: donepezil, galantamine, memantine, rivastigmine, piracetem, acetyl-Lcarnitine, antioxidant supplementation, vitamin supplementation, and DYRK1A inhibitors (green tea extract).

\section{Types of outcome measures}

\section{Primary outcomes}

1. Improvement in:

i) cognitive abilities, as measured by standardised scales, for example, the Dementia Scale for Down Syndrome (DSDS; Jozsvai 2009), the Cambridge Cognitive Examination

(CAMCOG; Schmand 2000), or the Severe Impairment Battery (SIB; Panisset 1994; Saxon 1993);*

ii) global functioning, as measured by standardised scales, for example, the DSDS (Jozsvai 2009), or the International Classification of Functioning, Disability and Health (ICF) Scales (WHO 2001);

iii) behavioural problems, as measured by standardised scales, for example, the American Association on Mental Deficiency: Adaptive Behaviour Scale (AAMD: ABS; Nihira 1974), or the Neuropsychiatric Inventory (NPI; Cummings 1994);*

iv) daily living skills, including kitchen skills, laundry skills, self-care skills, etc. (as measured by carer report).

2. Adverse events, including headache, nausea, and dizziness.*

\section{Secondary outcomes}

1. Carer stress (as measured by interviews or self reports).*

2. Institutional/home care, including social care placement breakdown (as measured by administrative data).*

3. Death (as measured by administrative data).*

Pharmacological interventions for cognitive decline in people with Down syndrome (Review) 
4. Treatment adherence (as measured by administrative data and self report).

Had data been sufficient, we intended to make comparisons at the following specific follow-up periods:

1. short term (less than three months);

2. medium term (three to 12 months); and

3. long term (over one year).

Outcomes indicated by an asterisk $\left(^{*}\right)$ above are presented in two 'Summary of findings' tables (Summary of findings for the main comparison; Summary of findings 2).

\section{Search methods for identification of studies}

\section{Electronic searches}

The following databases were searched in January 2015.

1. Cochrane Central Register of Controlled Trials (CENTRAL; part of the Cochrane Library; 2014, Issue 12; includes the Specialised Register of the Cochrane Developmental, Psychosocial and Learning Problems Group).

2. ALOIS (Specialised Register of the Cochrane Dementia and Cognitive Improvement Group, up-to-date as of 1 January 2015).

3. Ovid MEDLINE(R) In-Process \& Other Non-Indexed Citations (1946 to January Week 2 2015).

4. Embase (Ovid; 1974 to 2015 Week 3).

5. PsycINFO (Ovid; 1806 to January Week 2 2015).

6. CINAHL (EBSCOhost; 1937 to 20 January 2015).

7. Science Citation Index (Web of Science; 1970 to 20 January 2015).

8. Social Sciences Citation Index (Web of Science; 1970 to 20 January 2015).

9. Conference Proceedings Citation Index - Science (Web of Science; 1970 to 20 January 2015).

10. Conference Proceedings Citation Index - Social Science \& Humanities (Web of Science; 1970 to 20 January 2015).

11. Cochrane Database of Systematic Reviews (CDSR; part of the Cochrane Library; 2015, Issue 1).

12. Database of Abstracts of Reviews of Effects (DARE; part of the Cochrane Library; 2014, Issue 4).

13. ClinicalTrials.gov (clinicaltrials.gov; 20 January 2015).

14. World Health Organisation (WHO) International Clinical Trials Registry Platform (ICTRP; apps.who.int/trialsearch; 20 January 2015).

The Trials Search Co-ordinator of the Cochrane Developmental, Psychosocial and Learning Problems Group searched 13 of the 14 databases. The final database (ALOIS) was searched by the Trials Search Co-ordinator of the Cochrane Dementia and Cognitive Improvement Group.
The exact search strategy and date of search for each database can be found in Appendix 1. We did not apply any language or date restrictions.

\section{Searching other resources}

We contacted relevant authors, key scholars, Down syndrome voluntary organisations and the manufacturers of all relevant drugs to ask about reports of unpublished or ongoing trials (see Appendix 2).

We scanned the bibliographies of relevant reviews, and of included and excluded studies for additional references of interest.

\section{Data collection and analysis}

\section{Selection of studies}

Two review authors (NL and JH) independently reviewed the titles and abstracts of all records located during the search process and assessed each study to determine whether it met the inclusion criteria for this review. Full text articles were retrieved for records that appeared to meet the inclusion criteria. Two review authors ( $\mathrm{NL}$ and $\mathrm{JH}$ ) then independently assessed these records. Any disagreements between the authors were discussed with the full review team until they were resolved.

\section{Data extraction and management}

Two review authors (NL and $\mathrm{JH}$ ) independently extracted and entered data into a piloted data extraction form. Any disagreements between the authors were discussed with the full review team until they were resolved.

We extracted the following data:

1. study characteristics (including study design, setting, recruitment procedures, details of attrition);

2. intervention characteristics (including type of drug, duration, dosage, frequency, age medication began, and concurrent interventions);

3. participants' characteristics (including number randomised, age distribution, gender, method of diagnosis, inclusion or exclusion criteria, number (total per group));

4. comparison characteristics (including duration, dosage, frequency); and

5. outcome data (including relevant details on all primary and secondary outcome measures used, loss to follow-up, length of follow-up, and summary data, including means, standard deviations (SDs), confidence intervals (CIs), and significance levels for continuous data and proportions for dichotomous data). 


\section{Assessment of risk of bias in included studies}

Two review authors (NL and $\mathrm{JH}$ ) assessed each included study for risk of bias, using the Cochrane 'Risk of bias' tool (Higgins 2011). Review authors judged each of the seven domains (below) assessed by the tool to be at either 'low risk of bias', 'high risk of bias', or 'unclear risk of bias':

1. sequence generation (was the method used to generate the allocation sequence adequate?);

2. allocation concealment (was the method of concealing the allocation sequence sufficient, both prior to, and during the recruitment process?);

3. blinding of participants and personnel (was knowledge of the allocated intervention adequately concealed from all participants and relevant personnel during the study?);

4. blinding of outcome assessors (was knowledge of the allocated intervention adequately concealed from all outcome assessors during the study?);

5. incomplete outcome data (did study authors address issues related to incomplete outcome data adequately?);

6. selective outcome reporting (are reports of the study free of suggestion of selective outcome reporting?); and

7. other sources of bias (was the study apparently free of other problems that could put it at a high risk of bias, for example, source of study funding?).

\section{Measures of treatment effect}

\section{Dichotomous data}

For dichotomous outcome data (e.g. institutionalisation or death), we calculated effect sizes as odds ratio (OR) with 95\% CIs. For studies with no events in a treatment arm, a fixed value of 0.5 was added to each 'zero event' cell of the contingency table to allow the calculation of an OR.

When an eligible study did not report data used to calculate summary measures, we made efforts to transform the data provided into the appropriate data. When necessary, we contacted study authors to request the required information.

\section{Continuous data}

When study authors used different measures to assess the same outcome, we converted continuous outcome data (e.g. cognitive abilities or behavioural problems) into standardised mean differences (SMDs) and presented these with 95\% CIs. More information on the protocol methods to be used in future updates of this review are detailed in Appendix 3 (Livingstone 2015).

\section{Time-to-event data}

No relevant time-to-event data were included in this review. In the event that future updated searches are able to locate reports of additional studies that meet the inclusion criteria for this review, any time-to-event data identified will be analysed using the methods detailed in Appendix 3.

\section{Multiple outcomes}

It was not necessary to combine multiple interchangeable continuous or dichotomous measures of the same construct at the same point in time in this review. In the event that this becomes necessary in future updates of this review, we will use the methods detailed in Appendix 3.

\section{Economic issues}

None of the included studies provided data on the cost of programmes within the studies under review. In the event that future updated searches are able to locate reports of eligible additional studies that address economic issues, they will be analysed using the methods detailed in Appendix 3.

\section{Unit of analysis issues}

No cluster randomised trials or studies with multiple treatment groups were identified in this review. One cross-over trial could not be included as the participants' ages ranged above and below 18 years, and individual participant data were not available from the authors (Eisenburg 1984). If unit of analysis issues arise in future updates of this review, they will be dealt with using the methods detailed in Appendix 3.

\section{Dealing with missing data}

We contacted authors and asked them to supply data missing from included studies where necessary.

It was not necessary to impute any missing participant data in this version of the review. if imputation of missing data is required in a future update, it will be done using the methods detailed in Appendix 3.

In the event of missing summary data, such as missing SDs, we obtained these using calculations provided in the Cochrane Handbook for Systematic Reviews of Interventions (Higgins 2011).

\section{Assessment of heterogeneity}

We examined clinical heterogeneity by inspecting variability in the participants, interventions and outcomes described in each included study within each comparison made. We examined methodological heterogeneity by inspecting variability in the study design and risk of bias of each included study within each comparison made. We assessed statistical heterogeneity using the Q statistic and its $P$ value (less than 0.10 suggesting statistical significance), the $\mathrm{I}^{2}$ statistic along with the $95 \%$ CI for heterogeneity variance, and by visual inspection of the forest plots. Due to 
the potential unreliability of the $\mathrm{I}^{2}$ statistic, we also presented the magnitude of the heterogeneity.

Where possible, we pooled data from studies that were sufficiently similar to minimise heterogeneity.

\section{Assessment of reporting biases}

There were insufficient studies $(<10)$ of any intervention to allow us to assess publication bias and other reporting biases using funnel plots. In the event that future updated searches are able to locate reports of additional studies that meet the inclusion criteria for this review, they will be analysed using the methods detailed in Appendix 3.

\section{Data synthesis}

We performed a meta-analysis on outcome data where we found at least two studies suitable for inclusion that studied the same intervention. We accounted for the expected heterogeneity among included studies by using a random-effects meta-analysis (DerSimonian 1986) in RevMan (Review Manager 2014). The random-effects model was used to incorporate the assumption that the different studies estimate different, yet related, intervention effects (Higgins 2011).

We converted continuous outcome data (i.e. cognitive abilities and behavioural problems) into SMDs and presented these with 95\% CIs using the inverse variance weighting method. For dichotomous outcome data (i.e. adverse events), we calculated effect sizes as ORs with 95\% CIs. We used the Mantel-Haenszel method for analysis of dichotomous outcomes, as It has been shown that this method has better statistical properties when few events are available.

When a meta-analysis was not possible due to an insufficient number of studies, we provided a narrative description of the study results.

For the purpose of this review, we extracted and synthesised summary data (i.e. means and SDs) primarily from journal publications. Individual patient data (IPD) were not available for any of the included studies in this review. In the event that future searches locate reports of additional studies that meet the inclusion criteria for this review, and such data are available, we will incorporate IPD using the methods detailed in Appendix 3.

\section{Summary of Findings Table}

For the identified outcomes (see above), we created 'Summary of findings' tables for the two main comparisons using the system and software developed by the Grading of Recommendations, Assessment, Development and Evaluation (GRADE) Working Group (GRADEpro GDT 2014; Review Manager 2014). For information regarding the GRADE approach and factors that influence the assessment, see Table 1, Table 2, and Table 3.

\section{Subgroup analysis and investigation of heterogeneity}

There were insufficient studies to allow for meaningful subgroup analyses. In the event that future searches locate reports of additional studies that meet the inclusion criteria for this review, and provide enough data for subgroup analyses, we will analyse the studies using the methods detailed in Appendix 3.

\section{Sensitivity analysis}

Similarly, there were insufficient studies to support meaningful sensitivity analyses in this review (see Appendix 3 for details of designated methods for sensitivity analyses).

\section{RES U L T S}

\section{Description of studies}

\section{Results of the search}

A systematic search, conducted in January 2015, identified 1220 unique records of potentially relevant trials. Of these, 1126 records were deemed irrelevant following inspection of their titles and abstracts. The full texts were obtained and read for the remaining 94 records. Following this, a further 65 irrelevant reports were excluded. We formally excluded another 11 reports (documented in Excluded studies).

Ten studies (with 16 reports) met our inclusion criteria for studies of pharmacological interventions for cognitive decline in people with Down syndrome.

Two additional reports were categorised as ongoing studies (Aisen 2005; NCT01791725; See Characteristics of ongoing studies). See Figure 1 for the study flow diagram. 
Figure I. Study flow diagram

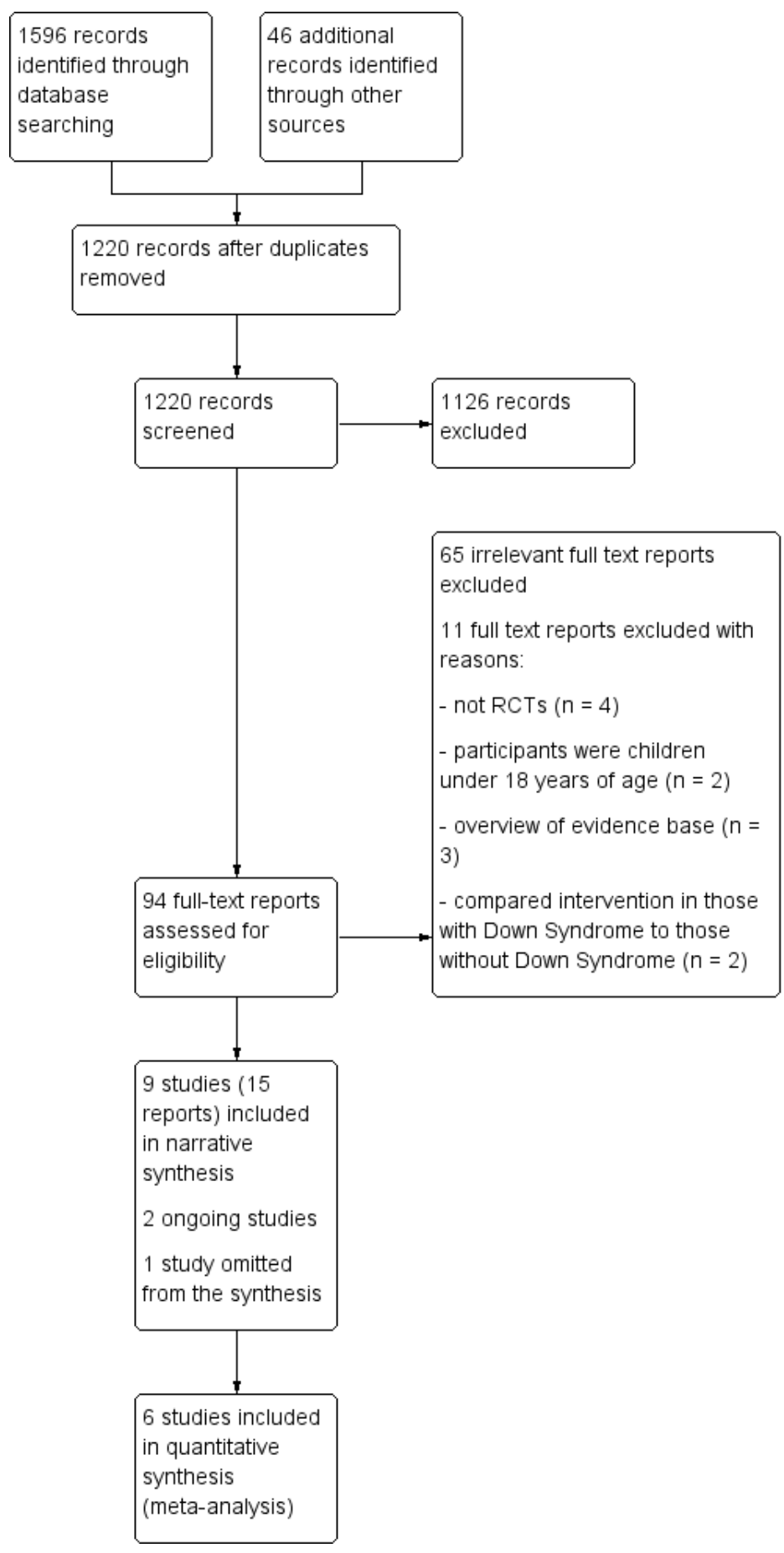




\section{Included studies}

In this review, we report on nine of the 10 studies that met the inclusion criteria for this review, six of which contribute data to meta-analyses. Four of these six studies assessed the effectiveness of donepezil (Johnson 2003; Kishnani 2009; Kondoh 2011; Prasher 2002), while the other two studies assessed the effectiveness of memantine (Boada 2012; Hanney 2012). The remaining three studies assessed the effectiveness of simvastatin (Cooper 2012), antioxidants (Lott 2011), and acetyl-L-carnitine (Pueschel 2006). The tenth study included participants aged 10 to 42 years (Eisenburg 1984). We contacted the authors of this study to request data for participants aged 18 to 42 years only. The author replied that it would not be possible to access any information beyond what was available in the published paper. Therefore, we adhered to the plan outlined in our original protocol (Livingstone 2015), and have not included this study in the results section of this review. We have included more details of this study in an additional table (Table 4).

See Characteristics of included studies for further information.

\section{Location in which studies conducted}

Five studies were conducted in the USA (Boada 2012; Johnson 2003; Kishnani 2009; Lott 2011; Pueschel 2006); two in the UK (Cooper 2012; Prasher 2002), and the remaining two studies in Norway and the UK (Hanney 2012), and Japan (Kondoh 2011).

\section{Study design}

All nine included studies were RCTs.

\section{Participants}

Participants in all included studies had a genetically karyotyped diagnosis of Down syndrome. In two of the studies (Hanney 2012; Prasher 2002), participants also had a diagnosis of mildto-moderate Alzheimer's disease, according to the International Classification of Diseases, 10th Revision (ICD-10) criteria (WHO 1992).

Four of the studies focused primarily on young adults with Down syndrome (Boada 2012; Johnson 2003; Kishnani 2009; Pueschel 2006); the mean age of participants in these studies ranged from 20.2 years to 29.5 years. The remaining five studies focused on middle-aged adults with Down syndrome (Cooper 2012; Hanney 2012; Kondoh 2011; Lott 2011; Prasher 2002); the mean age of participants in these studies ranged from 45.6 years to 55.07 years. The gender distribution of participants was relatively even ( $40 \%$ to 60\% male) in five studies (Cooper 2012; Hanney 2012; Johnson
2003; Lott 2011; Prasher 2002). One study focused predominantly on males (62\% male; Kishnani 2009), and another predominantly on females (37\% males; Boada 2012). One study focused exclusively on males (Pueschel 2006), and one exclusively on females (Kondoh 2011).

\section{Interventions}

Participants in three of the four donepezil studies received $5 \mathrm{mg}$ of donepezil per day for the first four to six weeks of the study, and $10 \mathrm{mg}$ per day thereafter (Johnson 2003; Kishnani 2009; Prasher 2002). Participants in the remaining donepezil study received 3 $\mathrm{mg} /$ day for 24 weeks (Kondoh 2011).

Participants in the Boada 2012 study received 5 mg memantine once daily in week one, $5 \mathrm{mg}$ twice daily $(10 \mathrm{mg})$ in week two, 5 $\mathrm{mg}$ per day and $10 \mathrm{mg}$ per day ( $15 \mathrm{mg}$; one divided dose) in week three, and $10 \mathrm{mg}$ twice daily $(20 \mathrm{mg})$ from week four to week 16. Participants in the Hanney 2012 memantine study received $5 \mathrm{mg}$ per day for eight weeks, which then increased to $10 \mathrm{mg}$ per day with fixed titration.

Participants in the antioxidant study received 900 IU of alphatocopherol with $200 \mathrm{mg}$ of ascorbic acid and $600 \mathrm{mg}$ of alphalipoic acid per day for 24 months (Lott 2011).

Participants in the Cooper 2012 study received 40 mg simvastatin once per day.

Participants in the Pueschel 2006 study received $10 \mathrm{mg} / \mathrm{kg}$ acetylL-carnitine per day during the first month, followed by $20 \mathrm{mg} / \mathrm{kg}$ per day in second month and $30 \mathrm{mg} / \mathrm{kg}$ per day for the rest of the study.

All studies used placebo tablets that were identical to the intervention tablet.

\section{Duration of follow-up}

The follow-up periods of the included studies ranged from four weeks to two years. The donepezil trials included follow-up at four weeks (Johnson 2003), after 12 weeks (Johnson 2003; Kishnani 2009), and after 24 weeks (Kondoh 2011; Prasher 2002). The two memantine trials had follow-up periods of 16 weeks (Boada 2012), and 52 weeks (Hanney 2012). The simvastatin study followed participants for up to 52 weeks (Cooper 2012). The antioxidant study included both one year (52-week) and two year (104-week) follow-ups (Lott 2011). Finally, the trial of acetyl-Lcarnitine followed up with participants after three and six months of treatment, and again following a three-month washout period (nine months after commencing treatment (Pueschel 2006).

\section{Outcomes}

Pharmacological interventions for cognitive decline in people with Down syndrome (Review) 
Primary outcomes

\section{Cognitive abilities}

Cognitive function was assessed in eight out of nine of the included studies using a range of different scales. Four studies, Johnson 2003, Kishnani 2009, Lott 2011 and Prasher 2002, assessed cognition using the Severe Impairment Battery (SIB; Panisset 1994; Saxon 1993).

Lott 2011 also assessed cognitive function using the Dementia Questionnaire for Mentally Retarded Persons (DMR; Evenhuis 1996) and the Brief Praxis Test (BPT; Dalton 1997).

Hanney 2012 assessed cognition using the Down syndrome Attention, Memory and Executive Functions Scales (DAMES; Margallo-Lana 2003), and Boada 2012 used the Differential Ability Scales-II Matrices (DAS-II; Elliott 2007; Elliott 2010).

Pueschel 1980 used the Stanford-Binet Intelligence Scale (Fourth Edition; Thorndike 1986), and Cooper 2012 used the Memory for Objects Test from the NADIID (Neuropsychological Assessment of Dementia in Intellectual Disabilities Battery; Oliver 1998).

\section{Global functioning}

Two studies reported on global functioning: Kondoh 2011 assessed this outcome using the International Classification of Functioning, Disability and Health (ICF) Scales (WHO 2001), while Lott 2011 assessed this outcome using the Sum of Social Scores on the DMR (DMR SOS; Evenhuis 1996).

\section{Behavioural problems}

Behaviour was assessed in seven of the nine included studies, using a range of scales. Boada 2012 and Johnson 2003 assessed behaviour using the Scales of Independent Behavior - Revised (SIB-R; Bruininks 1996). Kishnani 2009 and Lott 2011 used the Vineland Adaptive Behavior Scales (VABS; Sparrow 2006), and Hanney 2012 and Prasher 2002 used the American Association on Mental Deficiency: Adaptive Behavior Scale (AAMD ABS; Nihira 1974). Pueschel 2006 assessed behaviour using the Child Behavior Checklist (CBCL; Achenbach 1983).

\section{Daily living skills}

Three studies assessed daily living skills: Cooper 2012 reported this outcome using the American Association of Mental Retardation: Adaptive Behavior Scale (AAMR: ABS) - Residential and Community (Nihira 1993); Lott 2011 used the Bristol Activities of Daily Living Scale (BADLS; Bucks 1996); and Pueschel 2006 used the Daily Living Skills subtest of the VABS (Sparrow 2006).

\section{Adverse events}

All nine included studies reported data on adverse events.

\section{Secondary outcomes}

\section{Carer stress}

Cooper 2012 measured carer stress using the General Health Questionnaire-12 (GHQ-12; Goldberg 1988).

\section{Institutional/home care}

Pueschel 2006 summarised results of an analysis on living arrangements, but provided no numerical data for this outcome.

\section{Death}

None of the included studies assessed postintervention death rates.

\section{Treatment adberence}

Two of the included studies provided information on adherence to treatment (Cooper 2012; Lott 2011).

\section{Methodological heterogeneity}

There was no unexpected variability in the methodological heterogeneity in each included study. All included studies made use of a RCT design, and most had similar levels of low or unclear risk of bias.

\section{Clinical heterogeneity}

There was some clinical heterogeneity amongst the included studies. Whilst most of the participants across all studies were of a similar age (mean ages ranged from 45 to 55 years), four of the nine studies focused on younger adults (20 to 29 years).

The administration of all interventions followed a similar format. Similar outcomes were measured by all studies. We identified a total of five different interventions in this review and judged these to be too heterogenous to combine. We decided to compare each type of intervention separately, which led to a total of five comparisons in this review.

1. Comparison 1: donepezil versus placebo.

2. Comparison 2: memantine versus placebo.

3. Comparison 3: simvastatin versus placebo.

4. Comparison 4: antioxidants versus placebo.

5. Comparison 5: acetyl-L-carnitine versus placebo. 


\section{Statistical heterogeneity}

Since we found only one study for comparisons three, four and five, meta-analyses were only possible for the first two of the five comparisons listed above. For these two comparisons, statistical heterogeneity (as measured by the $\mathrm{I}^{2}$ ) ranged from $0 \%$ to $74 \%$ for the comparison of donepezil versus placebo, and $0 \%$ to $41 \%$ for the comparison of memantine versus placebo.

\section{Excluded studies}

We excluded 11 studies from this review: four because they were not RCTs (Boada-Rovira 2005; Gedye 1991; Schill 2005; Thase 1982); two because, although they were randomised trials, the participants were children under 18 years of age (Lobaugh 2001; Pueschel 1980); three because they only provided an overview of the current state of evidence, and did not provide an evaluation or any new data (Barr 1990; Breeze 2012; Shinagawa 2014); and two because they focused on comparing the effect of their intervention in participants with Down syndrome to those without Down syndrome (Arvat 1996; De Falco 1994). See Characteristics of excluded studies tables for further information.

\section{Risk of bias in included studies}

See: 'Risk of bias' tables (beneath the Characteristics of included studies tables), Figure 2, and Figure 3 for further information.

Figure 2. Risk of bias graph: review authors' judgements about each risk of bias item presented as percentages across all included studies

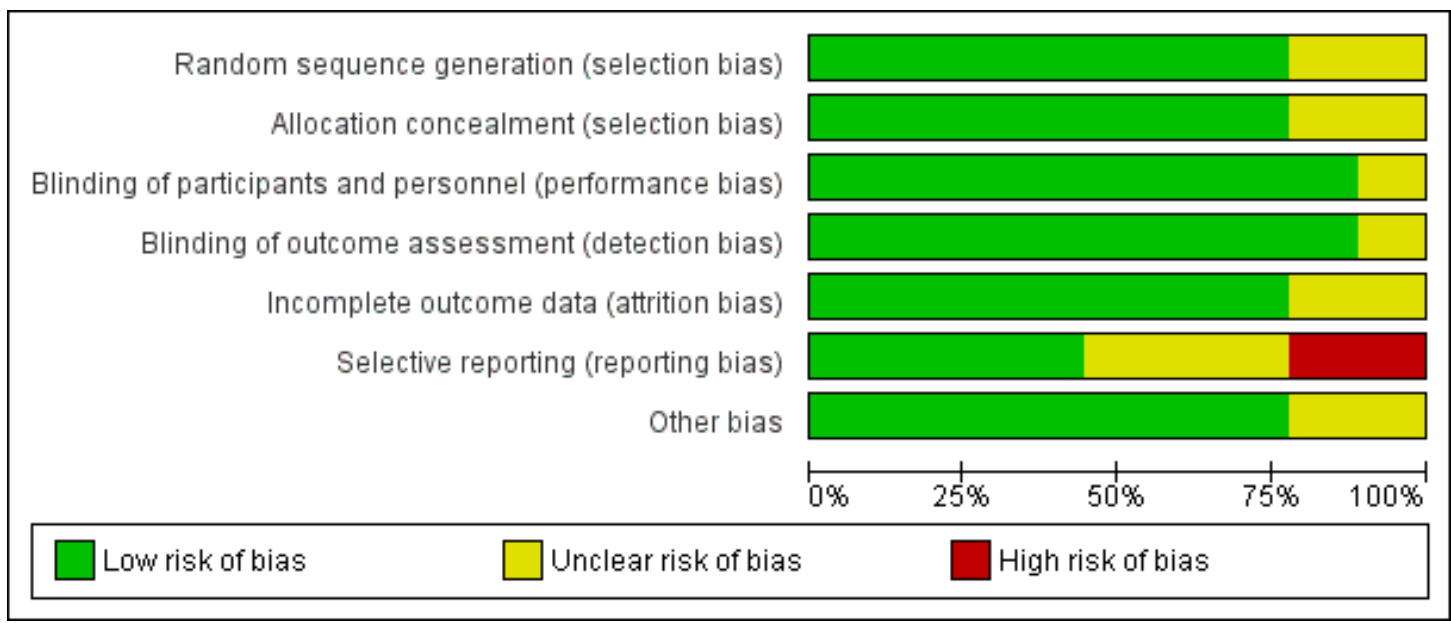

Pharmacological interventions for cognitive decline in people with Down syndrome (Review) 
Figure 3. Risk of bias summary: review authors' judgements about each risk of bias item for each included study

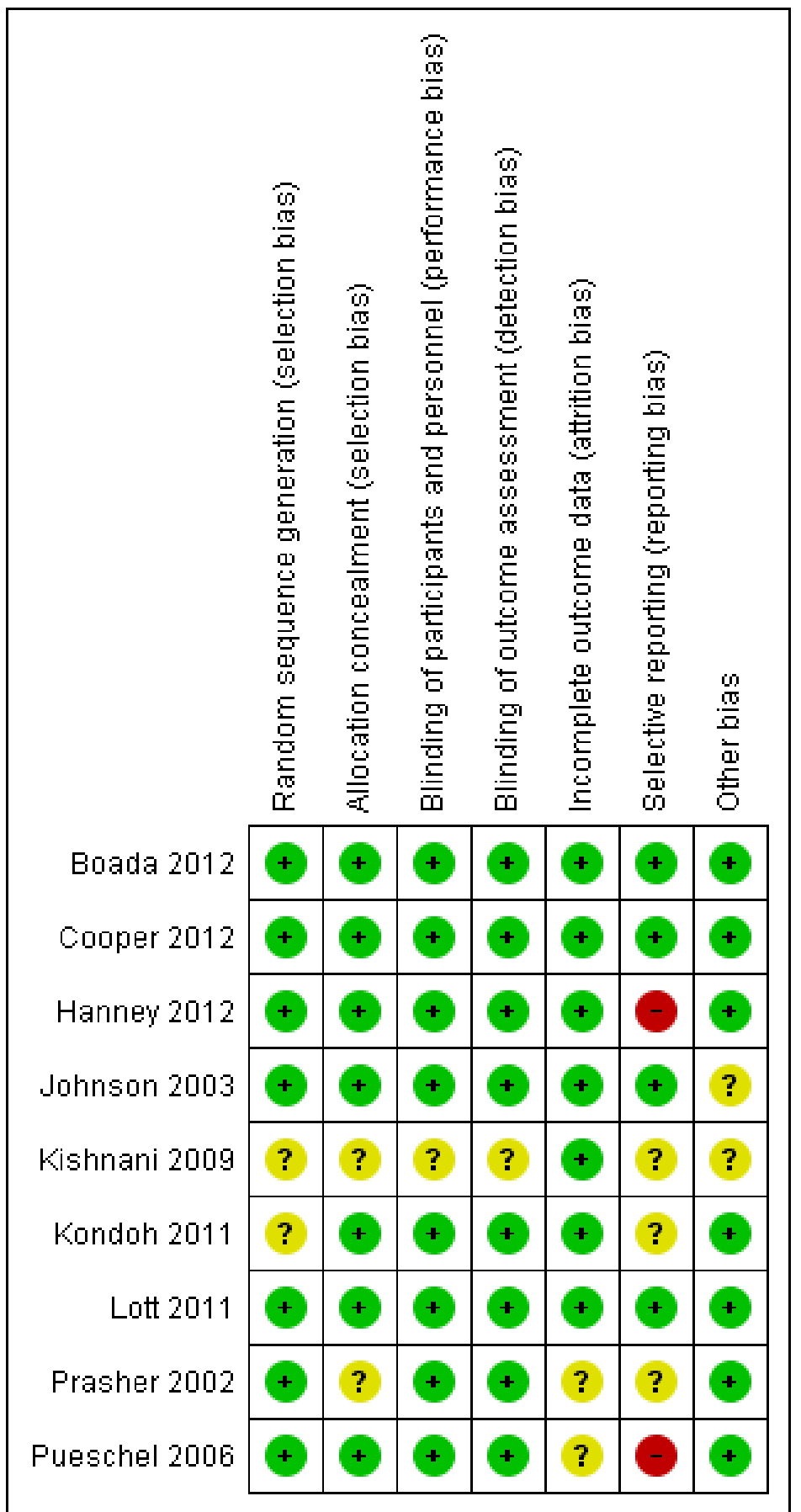

Pharmacological interventions for cognitive decline in people with Down syndrome (Review) 


\section{Allocation}

We judged the method of generating a random sequence to be adequate in seven of the nine included studies, resulting in a judgement of low risk of selection bias for those studies (Boada 2012; Cooper 2012; Hanney 2012; Johnson 2003; Lott 2011; Prasher 2002; Pueschel 2006). We judged the remaining two studies as being at unclear risk of bias due to insufficient reporting (Kishnani 2009; Kondoh 2011). We contacted the authors of both papers for more information, but none had replied at the time of publication.

We also judged the method of concealing the random allocation method to be adequate in seven of the nine included studies, resulting in a judgement of low risk of selection bias for those studies (Boada 2012; Cooper 2012; Hanney 2012; Johnson 2003; Kondoh 2011; Lott 2011; Pueschel 2006). We judged the remaining two studies as being at unclear risk of bias due to insufficient reporting (Kishnani 2009; Prasher 2002). We contacted the authors of both papers for more information. The authors of Kishnani 2009 have not yet replied, but the authors of Prasher 2002 sent their apologies and stated it would not be possible to obtain the necessary information.

\section{Blinding}

Blinding of participants, personnel, and outcome assessors was judged to be adequate in eight of the nine included studies, resulting in a judgement of low risk of performance bias and detection bias for those studies (Boada 2012; Cooper 2012; Hanney 2012; Johnson 2003; Kondoh 2011; Lott 2011; Prasher 2002; Pueschel 2006). The remaining study was judged as being at unclear risk of bias due to insufficient reporting (Kishnani 2009). We contacted the authors of this paper for more information, but they have not yet replied.

\section{Incomplete outcome data}

The reported analyses of five of the nine included studies accounted for all participants appropriately, resulting in a judgement of low risk of attrition bias for those studies (Boada 2012; Hanney 2012; Johnson 2003; Kondoh 2011; Lott 2011). In Prasher 2002, it was unclear whether the analyses were based on the 30 participants randomised or the 27 available at follow-up. In response to a request for further information, the authors informed us that it would not be possible to obtain the necessary information. In Pueschel 2006, it was also unclear how many of the original 40 participants randomised were included in the final analysis. The remaining two studies were judged to be at low risk of attrition bias for attrition bias (Cooper 2012; Kishnani 2009): although a small number of participants in these studies were lost to follow-up and not included in the final analyses, the dropouts were balanced across the arms of the studies, so it is unlikely that this introduced bias.

\section{Selective reporting}

We judged outcome reporting to be sufficient in four studies, as all outcomes planned in the protocol were reported; this resulted in judgements of low risk of reporting bias for these studies (Boada 2012; Cooper 2012; Johnson 2003; Lott 2011). We were unable to locate the protocols of three studies, either through searching or through contacting the authors (Kishnani 2009; Kondoh 2011; Prasher 2002). Therefore, we judged these studies to be at an unclear risk of reporting bias. The overall reporting of the results for the remaining two studies was poor and there were discrepancies between what was measured according to the methodology and what was presented in the results (Hanney 2012; Pueschel 2006). Specifically, the trial authors did not report on outcomes that they had listed as outcome measures, and did report on outcomes they had not mentioned in the methods section. We judged these studies to be at a high risk of reporting bias.

\section{Other potential sources of bias}

Two studies were funded by the drug manufacturer (Johnson 2003; Kishnani 2009). As these reports did not state whether the funder was involved in any aspect of the study, we judged them to be at unclear risk of other bias. We judged the remaining seven studies to be at a low risk of other bias (Boada 2012; Cooper 2012; Hanney 2012; Kondoh 2011; Lott 2011; Prasher 2002; Pueschel 2006).

\section{Effects of interventions}

See: Summary of findings for the main comparison Comparison 1: donepezil versus placebo; Summary of findings 2 Comparison 2: memantine versus placebo

\section{Comparison I: donepezil versus placebo}

See Summary of findings for the main comparison.

\section{Primary outcomes}

\section{Cognitive abilities}

Three studies (165 participants) looked at the impact of donepezil on cognitive function in people with Down syndrome using the SIB (Johnson 2003; Kishnani 2009; Prasher 2002). When combined in a meta-analysis, there was no difference between donepezil and control groups at 12 to 24 weeks postintervention 
Figure 5. Forest plot of comparison: I Comparison I: Donepezil versus placebo, outcome: I.3 Adverse events ( 12 to 24 weeks)

\begin{tabular}{|c|c|c|c|c|c|c|c|c|c|c|}
\hline \multirow[b]{2}{*}{ Study or Subgroup } & \multicolumn{2}{|c|}{ Donepezil } & \multicolumn{2}{|c|}{ Placebo } & \multicolumn{2}{|c|}{ Odds Ratio (Non-event) } & \multirow{2}{*}{\multicolumn{3}{|c|}{$\begin{array}{c}\text { Odds Ratio (Non-event) } \\
\text { M-H, Random, } 95 \% \mathrm{Cl}\end{array}$}} & Risk of Bias \\
\hline & Events & Total & Events & Total & Weight & M-H, Random, $95 \% \mathrm{Cl}$ & & & & A B C D E F G \\
\hline Kishnani 2009 & 46 & 62 & 29 & 61 & $76.4 \%$ & $0.32[0.15,0.67]$ & & & & ????†? ? \\
\hline Prasher 2002 & 8 & 16 & 3 & 14 & $17.0 \%$ & $0.27[0.05,1.36]$ & & & & ๑? ?૯? ?† \\
\hline Total $(95 \% \mathrm{Cl})$ & & 98 & & 94 & $100.0 \%$ & $0.32[0.16,0.62]$ & & & & \\
\hline Total events & 56 & & 33 & & & & & & & \\
\hline
\end{tabular}

\author{
Risk of bias legend \\ (A) Random sequence generation (selection bias) \\ (B) Allocation concealment (selection bias) \\ (C) Blinding of participants and personnel (performance bias) \\ (D) Blinding of outcome assessment (detection bias) \\ (E) Incomplete outcome data (attrition bias) \\ (F) Selective reporting (reporting bias) \\ G) Other bias
}

\section{Secondary outcomes}

None of the four included donepezil studies reported data on the secondary outcomes of carer stress, institutional/home care (including social care placement breakdown), death, or treatment adherence.

\section{Comparison 2: memantine versus placebo}

See Summary of findings 2 .

\section{Primary outcomes}

\section{Cognitive abilities}

Two studies (184 participants) looked at the impact of memantine on cognitive function in people with Down syndrome using various scales (DAMES; DAS-II; Boada 2012; Hanney 2012). When combined in a meta-analysis, there was no significant difference between memantine and control groups at 16 to 52 weeks postintervention (SMD 0.05, 95\% CI -0.43 to $0.52 ; \mathrm{I}^{2}=48 \%$; P value for heterogeneity $0.16 ; \tau^{2}=0.06$; Analysis 2.1 ; Figure 6 ). Using the GRADE approach, this outcome was downgraded from high to low quality evidence due to imprecision of the effect and inconsistency of the result.

Figure 6. Forest plot of comparison: 2 Comparison 2: Memantine versus placebo, outcome: 2.I Cognitive abilities (various scales) 16 to 52 weeks

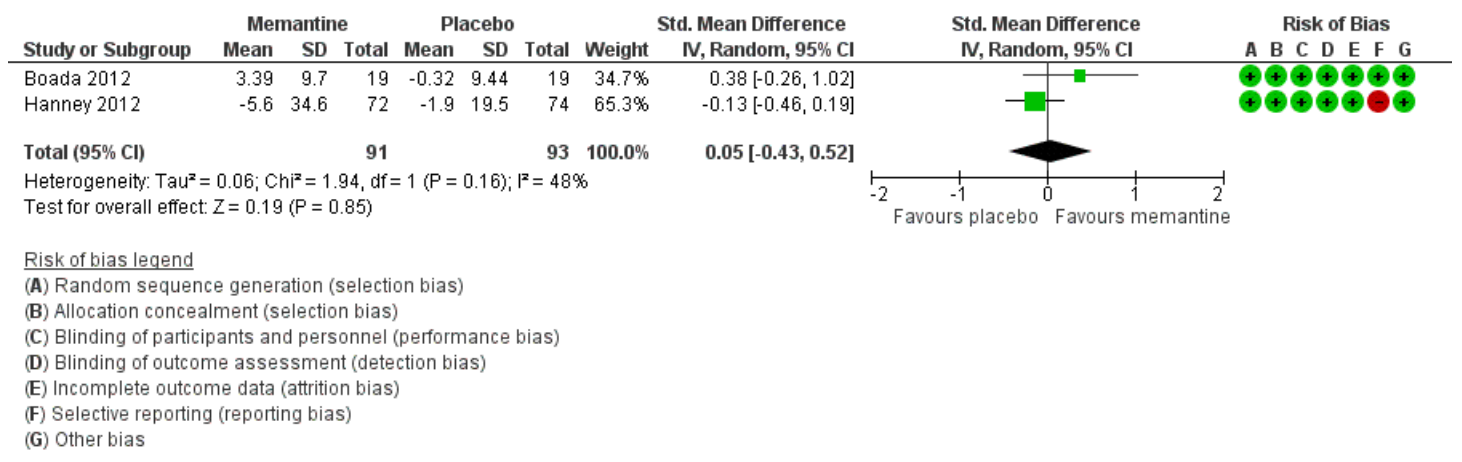




\section{Global functioning}

None of the included memantine studies reported data on global functioning.

\section{Behavioural problems}

Two studies (186 participants) looked at the impact of memantine on behaviour in people with Down syndrome using different scales (SIB-R; ABS; Boada 2012; Hanney 2012). When combined in a meta-analysis, there was no significant difference between memantine and control groups at 16 to 52 weeks postintervention (SMD $-0.17,95 \%$ CI -0.46 to $0.11 ; \mathrm{I}^{2}=0 \%$; P value for heterogeneity $0.33 ; \tau^{2}=0.00$; Analysis 2.2). Using the GRADE approach, this outcome was downgraded from high to low quality evidence due to serious imprecision of the effect.

\section{Daily living skills}

None of the included memantine studies reported data on daily living skills.

\section{Adverse events}

Two studies (211 participants) looked at the impact of memantine on occurrence of adverse events in people with Down's syndrome (Boada 2012; Hanney 2012). When combined in a meta-analysis, there was no significant difference between donepezil and control groups at 16 to 52 weeks postintervention (OR 0.45, 95\% CI 0.18 to $1.17 ; \mathrm{I}^{2}=0 \%$; P value for heterogeneity $0.47 ; \tau^{2}=0.00$; Analysis 2.3). Using the GRADE approach, this outcome was downgraded from high to low quality evidence due to serious imprecision of the effect.

\section{Secondary outcomes}

Neither of the two included memantine studies reported data on the secondary outcomes of carer stress, institutional/home care (including social care placement breakdown), death, or treatment adherence.

\section{Comparison 3: simvastatin versus placebo}

One study assessed the effectiveness of simvastatin (Cooper 2012). Study authors presented results in this study with 90\% CIs; a positive effect size shows benefit from the intervention.

\section{Primary outcomes}

\section{Cognitive abilities}

As this study was a feasibility and pilot trial, it used an unusually large number of measurement tools in order to identify the most appropriate and sensitive measure for use in a full scale trial. Here we summarize the outcomes from the cognitive test chosen as the primary measure for a future trial, the Memory for Objects test from the NADIID battery. The authors choose this as the primary measure as it had the highest completion rates and was sensitive to change over time.

Most participants (all but one at baseline and 12-month assessments) completed the measure. Scores at baseline and 12 months were near the middle of the possible range (zero to 10). Comparison of the baseline and 12-month scores showed a difference between groups, with improved scores for those in the intervention group (mean change 1.3; SD 2.7) and a deterioration in scores in the control group (mean change -0.08; SD 1.2). The effect size, adjusted for baseline scores, was 0.9 (90\% CI 0.4 to 1.4$)$ and adjusted for baseline and stratification variables, was $1.0(90 \% \mathrm{CI}$ 0.4 to 1.6$)$.

Other cognitive measures piloted were: Selective Attention Cancellation Task; Pattern Recognition Memory from the Cambridge Neuropsychological Test Automated Battery (CANTAB); The Cats and Dogs Test; Tower of London Test; Cued Recall Test; Category Fluency; Story Recall (adapted from the Rivermead Behavioural Memory Test for Children). These measures had a lower completion rate.

\section{Global functioning}

Cooper 2012 did not assess global functioning.

\section{Behavioural problems}

Cooper 2012 did not assess behavioural problems.

\section{Daily living skills}

The AAMR: ABS was used to assess adaptive function; this includes activities of daily living as well as social and conceptual skills, such as concepts of time and money. The mean change in the control group was 10 (SD 12), while in the intervention group, the mean change was 2.0 (SD 3.4) with an effect size adjusted for baseline scores of 0.7 ( $90 \%$ CI -0.1 to 1.3$)$ and adjusted for baseline and stratification variables of 0.7 (90\% CI 0.0 to 1.4 ).

\section{Adverse events}

There were no serious adverse events in the Cooper 2012 trial. Four participants withdrew from each arm of the trial. The authors' account of the reasons for withdrawal in the simvastatin group indicated that all but one withdrawal was due to pre-existing symptoms (history of episodic diarrhoea, pretrial weight loss), or withdrawal prior to commencement of medication. One participant in the simvastatin group withdrew because of a skin rash.

\section{Secondary outcomes}

\section{Carer stress}

Only eight of a possible 21 carers completed the GHQ-12 measure of carer strain, and so these results were not reported by the study authors. 


\section{Institutional/home care (including social care placement breakdown)}

Cooper 2012 did not assess institutional/home care (including social care placement breakdown).

\section{Death}

No deaths occurred in this trial.

\section{Treatment adherence}

Two-thirds of participants took the medication for 12 months, but no information about treatment adherence was provided.

\section{Comparison 4: antioxidants versus placebo}

One study assessed the effectiveness of antioxidants (Lott 2011).

\section{Primary outcomes}

\section{Cognitive abilities}

Changes in cognitive abilities between the intervention and control groups were very small and indicated that antioxidant supplementation had no effect on the cognitive abilities of participants in this study. Cognitive abilities were measured using the DMR sum of cognitive scores (DMR SOC), the SIB, and the BPT. The estimated change in the population trajectory (slope) of DMR SOC in intervention relative to control groups was a negligible 0.34 points per half-year ( $95 \%$ CI -1.39 to 2.07 ). Adjusting for baseline DMR SOC score made no difference, with one-year change in DMR SOC in treatment relative to controls of 1.69 points $(95 \% \mathrm{CI}-2.92$ to $6.31, \mathrm{P}$ value $=0.47)$. There was no difference in the average two-year change (3.71 points, $95 \% \mathrm{CI}$ 4.81 to 12.22 , $\mathrm{P}$ value $=0.39$ ) .

The estimated change in the population trajectory of the SIB in the intervention relative to control groups was also very small at 1.10 points per half-year (95\% CI -3.40 to 5.59$)$ and was not statistically significant $(P$ value $=0.63$ ). Adjusting for baseline SIB score made no difference with one-year change in the intervention relative to control groups estimated to be -9.08 points (95\% CI 23.86 to $5.70, \mathrm{P}$ value $=0.23)$ and two-year change estimated to be -1.51 points $(95 \% \mathrm{CI}-13.65$ to 10.63 , $\mathrm{P}$ value $=0.81)$. Neither change was statistically significant.

The BPT also detected no statistically significant difference between intervention and control groups. The estimated change in the population trajectory (slope) of BPT in intervention relative to control groups was -1.96 per half-year (95\% CI -4.97 to 1.05$)$ and was not statistically significant $(P$ value $=0.20)$.

\section{Global functioning}

There was no effect of antioxidant supplementation on DMR SOC scores, which measure the functional domains of speech, practical skills, mood, activity and interest, as well as behavioural disturbance over time. Change in the population trajectory in the intervention group relative to the control group was 0.45 points per half-year (95\% CI -1.67 to 2.56, P value $=0.68)$, 4.24 for one year $(95 \%$ CI -2.10 to $10.58, \mathrm{P}$ value $=0.19)$, and $4.03(95 \% \mathrm{CI}$ -5.10 to 13.16 , P value $=0.39)$ over two years.

\section{Behavioural problems}

The authors did not report results for the maladaptive behaviour scale of the VABS.

\section{Daily living skills}

The Lott 2011 trial found no effect of antioxidant supplementation on daily living skills. The trial reported that there were no statistically significant differences between intervention and control groups on either measure of daily living skills.

Change in the population trajectory of the BADLS score in the treatment group relative to the control group was 0.46 points per half-year $(95 \% \mathrm{CI}-1.87$ to 2.80 ; P value $=0.70), 3.14$ for one year $(95 \% \mathrm{CI}-6.26$ to 12.54 ; P value $=0.51)$, and $4.82(95 \% \mathrm{CI}$ -4.55 to 14.18 ; $\mathrm{P}$ value $=0.31)$ over two years.

Change in the population trajectory of the VABS daily living score in the treatment group relative to the control group was -1.93 points per half-year (95\% CI -7.13 to 3.44; P value $=0.48), 0.20$ for one year (95\% CI-14.01 to 14.40 ; P value $=0.98)$, and -13.22 $(95 \% \mathrm{CI}-32.17$ to 5.72 ; $\mathrm{P}$ value $=0.17)$ over two years

\section{Adverse events}

Fifty-two per cent (14 out of 26) of those in the intervention group, and $41 \%$ (11 out of 27 ) in the control group experienced a serious adverse event (estimated difference was 0.096 , 95\% CI -0.210 to $0.402 ; \mathrm{P}$ value $<0.05)$. These differences were not significant, and the authors reported that the serious adverse events were not attributable to the treatment.

A breakdown of the serious adverse events recorded indicated that seizures were somewhat more common in the intervention group (12 participants; 44\%) versus control group (seven participants; $26 \%$ ), but the authors attributed this to the higher proportion of participants with Alzheimer's disease-associated seizure disorder in the intervention group (12 out of 27) compared to the control group (7 out of 26).

\section{Secondary outcomes}

Lott 2011 reported no data on the secondary outcomes of carer stress, institutional/home care (including social care placement breakdown), or death.

\section{Treatment adherence}

Mean treatment adherence from pill counts was $91.9 \%$ in the treatment group and $90.4 \%$ in the control group. Elevated plasma levels of vitamin $\mathrm{E}$ after year one and year two in the intervention group (increase of $103.7 \%$ and $87.4 \%$ from baseline) compared 
to the control group (increase of $12.6 \%$ and $14.9 \%$ from baseline) indicated compliance with the regimen.

\section{Comparison 5: acetyl-L-carnitine versus placebo}

One study assessed the effectiveness of acetyl-L-carnitine (Pueschel 2006).

\section{Primary outcomes}

This study only provided data on the primary outcomes of cognitive abilities and daily living skills.

\section{Cognitive abilities}

Despite listing multiple measures of cognitive functioning, Pueschel 2006 reported outcomes sparsely, did not provide summary data, and only mentioned statistical significance at the $\mathrm{P}$ value $<0.05$ level. Those outcome measures reported indicated no statistically significant difference between the intervention and control groups. The Stanford-Binet Intelligence Scale: Fourth Edition test of short-term memory, verbal reasoning, abstract/visual reasoning, quantitative reasoning, and total test score indicated "no "drug" effect" (p 602). Neither the Mazes and Coding nor the comprehension subtests from the Wechsler Intelligence Scale for Children-Revised (WISC-R) showed a "statistically significant difference between the study and control groups at the end of the study" (p 602).

The authors reported using the Hiskey-Nebraska Visual Attention Span and Matching Familiar Figure tests, Seguin Formboard and the Riddles subtest from the Kaufman Assessment Battery for Children, but did not report any results that directly related to these measures. They did, however, indicate that the 'computer battery' showed no statistically significant differences between intervention and control groups at the end of the study; this com- puter battery consisted of tests of continuous performance, verbal attention span, nonverbal attention span, verbal serial learning, and paired associates.

\section{Daily living skills}

The Daily Living Skills subtest of the VABS self-care skills indicated "no statistically significant difference between the study and control groups at the end of the study" (p 602).

\section{Adverse events}

The authors did not measure adverse events explicitly, but did state that there were no differences between intervention and control groups in a general physical examination and neurological assessment either at the beginning of the trial or at six months. There was no indication that these tests were repeated at the nine-month follow-up.

Authors also stated that all participants tolerated the initial small doses and "no undue reactions or side effects were observed". In addition the authors described a general deterioration in scores on the Emotional Disorder Rating Scale (EDRS; which was not listed in the methodology section but was reported in results) in both groups over time, but with no between-group differences. The performance of all participants deteriorated over time.

\section{Secondary outcomes}

Pueschel 2006 only provided data on the secondary outcome 'institutional/home care (including social care placement breakdown)'. The authors reported that there were no statistically significant between-group differences in living arrangements, but provided no quantitative data.

The authors provided no data on the remaining secondary outcomes: carer stress, death and adherence to treatment. 


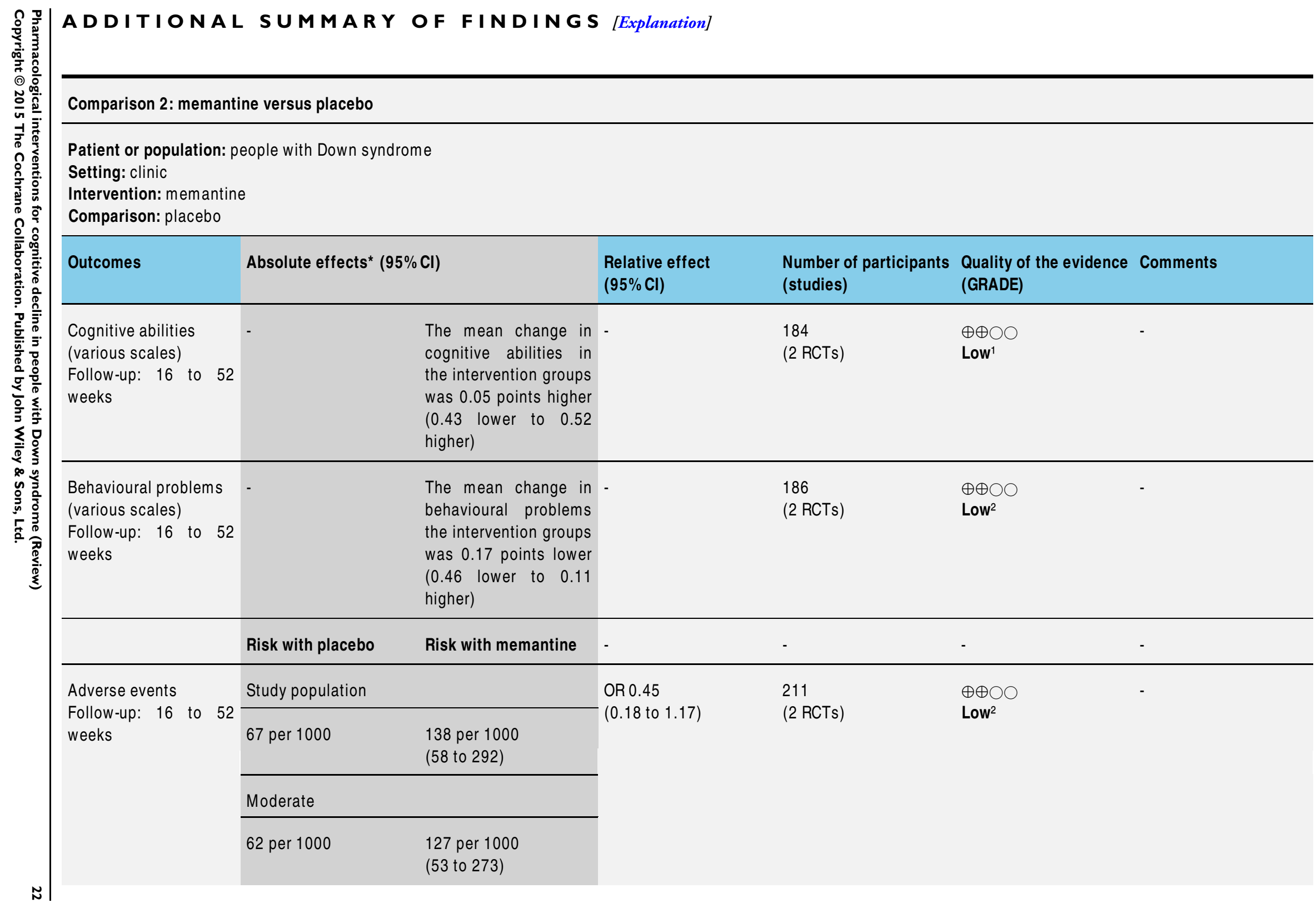




\begin{tabular}{llllll}
\hline Carer stress & No data available & No data available & - & - & - \\
\hline Institutional/home care & No data available & No data available & - & - & - \\
\hline Death & No data available & No data available & - & - & - \\
\hline
\end{tabular}

${ }^{*}$ The risk in the intervention group (and its $95 \%$ confidence interval) is based on the assumed risk in the comparison group and the relative effect of the intervention (and its $95 \% \mathrm{Cl})$

Cl: confidence interval; GRADE: Grades of Recommendations, Assessment, Development and Evaluation; OR: odds ratio; RCT: randomised controlled trial; RR: risk ratio

\section{GRADE Working Group grades of evidence}

High quality: We are very confident that the true effect lies close to that of the estimate of the effect

Moderate quality: We are moderately confident in the effect estimate: The true effect is likely to be close to the estimate of the effect, but there is a possibility that it is substantially different

Low quality: Our confidence in the effect estimate is limited: The true effect may be substantially different from the estimate of the effect

Very low quality: We have very little confidence in the effect estimate: The true effect is likely to be substantially different from the estimate of effect

${ }^{1}$ Downgraded two levels due to imprecision (wide confidence intervals) and inconsistency $\left(I^{2}=48 \%\right)$.

${ }^{2}$ Downgraded two levels for serious imprecision (wide confidence interval) and small number of events. 


\section{ISCUSSIO N}

\section{Summary of main results}

Following an extensive systematic search, we identified only nine studies that met the eligibility criteria for this review. These studies assessed five different types of pharmacological interventions, each against placebo:

1. donepezil;

2. memantine;

3. simvastatin;

4. antioxidants;

5. acetyl-L-carnitine.

\section{Donepezil}

There is currently insufficient evidence to determine whether donepezil is effective in treating cognitive decline in people with Down syndrome.

Results suggest that scores in measures of cognitive functioning and measures of behaviour were similar for participants regardless of whether they received donepezil or placebo. There is limited evidence that those who received donepezil may have shown a slightly greater improvement in their global functioning. Furthermore, participants who received donepezil were significantly more likely to experience an adverse event. This indicates that this intervention may be associated with a lack of any clear benefit, as well as a risk of side effects.

We found the evidence for most outcomes to be of low quality, primarily due to imprecise results and statistical heterogeneity.

\section{Memantine}

There is currently insufficient evidence to determine whether memantine is effective in treating cognitive decline in people with Down syndrome.

Results suggest that scores in measures of cognitive functioning and measures of behaviour were similar for participants regardless of whether they received memantine or placebo. There was also no difference in the rate of adverse events experienced by participants who received memantine and those who received placebo.

We found the evidence for most outcomes to be of low quality, primarily due to imprecise results and statistical heterogeneity.

\section{Simvastatin}

There is currently insufficient evidence to determine whether simvastatin is effective in treating cognitive decline in people with Down syndrome.

Only one eligible study was found that assessed the effectiveness of this intervention. Results from this feasibility study suggest that the six participants who received simvastatin experienced a slight improvement on cognitive measures, whereas the seven participants in the control group experienced a slight decline in cognitive measures, but little can be concluded from this small trial. There were no serious adverse events reported for any participant.

\section{Antioxidants}

There is currently insufficient evidence to determine whether antioxidants are effective in treating cognitive decline in people with Down syndrome.

We found only one eligible study that assessed the effectiveness of this intervention. Results from this study suggested that there was no difference between groups for cognition, global functioning, daily living skills, or occurrence of adverse events.

\section{Acetyl-L-carnitine}

There is currently insufficient evidence to determine whether acetyl-L-carnitine is effective in treating cognitive decline in people with Down syndrome.

We found only one eligible study that assessed the effectiveness of this intervention. Results from this study suggest that there was no difference between participants who received acetyl-L-carnitine and those who received placebo on measures of cognitive abilities, behavioural problems, daily living skills, occurrence of adverse events, or living arrangements.

\section{Overall completeness and applicability of evidence}

Our extensive search for RCTs for pharmacological interventions for cognitive decline in people with Down syndrome identified only four studies of donepezil, two studies of memantine, and one study each of simvastatin, antioxidants, and acetyl-L-carnitine.

We found no relevant studies that assessed the effectiveness of galantamine, rivastigmine, piracetem, or DYRK1A inhibitors (green tea extract) in people with Down syndrome. Therefore, this review is not able to provide any indication of whether these interventions are effective forms of treatment for cognitive decline in people with Down syndrome. We identified two ongoing studies that are assessing the effectiveness of vitamin supplementation, and ELND005 (scyllo-inositol) treatment. It is likely that the effectiveness of these interventions will be included in the next update of this review.

Eight of the nine included studies were conducted (entirely or partially) in either the UK, or the USA, which may limit the extent to which these results can be applied internationally.

The authors of Hanney 2012 (memantine trial) noted that when recruiting for this trial, they specifically excluded people with severe dementia. Since memantine is thought to deliver the greatest benefit in people with moderate-to-severe dementia, it is possible that it could provide a benefit for individuals with Down syndrome who have more severe dementia. However this possibility requires further exploration in clinical trials before any reliable conclusions can be drawn. 


\section{Quality of the evidence}

All of the included studies were at a relatively low risk of bias. Most were clear and explicit in their methods of allocation and blinding. However, their risks of bias across a number of other domains were difficult to judge on the basis of the information provided in the published paper only. Their selection of outcomes and presentation of outcome data in particular may have been subject to bias, but without confirmation from the study authors, we could only judge them as being at 'unclear' risk of bias.

The overall quality of the evidence of this review was judged to be low. This was primarily due to the small number of participants and events that could be incorporated into any pooled analysis, leading to imprecise results, and the high levels of statistical heterogeneity indicated across many of the pooled analyses.

\section{Potential biases in the review process}

We made every attempt to follow the protocol of this review, thus minimising our risk of bias in the review process. Despite an extensive systematic search, we identified only nine studies that met the inclusion criteria and could be included in the synthesis. Although one study did appear to fit the eligibility criteria for this review (Eisenburg 1984), the decision was made to omit it from the overall synthesis of the review, as data could not be obtained for participants aged 18 years and older only. Also, we judged a small number of domains in the 'Risk of bias' assessment for some included studies as 'unclear'. We have contacted study authors and asked for clarification on these issues, but we have not received any confirmation prior to publication.

\section{Agreements and disagreements with other studies or reviews}

To date, there have been four published Cochrane Systematic Reviews that have focused on the use of various pharmacological interventions in Down syndrome, including donepezil (Mohan 2009a), galantamine (Mohan 2009b), memantine ( Mohan 2009c), and rivastigmine (Mohan 2009d). Across all four reviews, the review authors found only one small randomised trial of donepezil that was eligible for inclusion. This study is included in our review, together with a study of memantine (Hanney 2012), which was listed as an 'Ongoing study' in the previous memantine review (Mohan 2009c). No ongoing studies were identified in the earlier galantamine (Mohan 2009b), or rivastigmine reviews (Mohan 2009d), and this situation remains unchanged.

Overall, the results of our review are in agreement with the findings of these four previous review, in that there continues to be insufficient evidence that any one of these drugs could slow the rate of cognitive decline in this population.

\section{A U THORS' CONCLUSIONS}

\section{Implications for practice}

Due to the low sample size of the included studies in this review, it is difficult to state with certainty the implications for the continued practice of pharmacological interventions for cognitive decline in people with Down syndrome. Donepezil may be associated with a lack of any clear benefit, as well as a risk of adverse events. There is limited and inconclusive evidence for memantine, antioxidants and acetyl-L-carnitine. The results from Cooper 2012 suggest there may be a positive trend for participants receiving simvastatin, but this suggestion is based only on preliminary results from a small feasibility study. There are no data available to consider the impact of galantamine, rivastigmine, piracetem, or DYRK1A inhibitors for cognitive decline in people with Down syndrome.

\section{Implications for research}

This review highlights the need for further research in this area. More RCTs are needed before any conclusions can be drawn about the effectiveness of any pharmacological intervention for treating cognitive decline in people with Down syndrome. Future research should also provide clear details regarding the inclusion criteria for participants, and in particular, the level of dementia they consider eligible and ineligible for their studies. It is also important to consider the reasons why this review identified so few eligible RCTs, and why these RCTs have such small sample sizes. This could be a reflection of the fact that it is difficult to conduct research in this population. Scoping of potential sample size should be an important priority for commissioning of future research in this area. Furthermore, future research should consider the choice of outcomes to be measured carefully. For example, only two of the included studies reported global functioning, which some consider a more reliable measure of outcome in this population than cognitive function. In addition, researchers must ensure that any measurement tools selected are likely to be completed by participants, sufficiently sensitive to detect relevant changes, harmonised so that meta-analysis can be undertaken and sufficiently powered.

\section{ACK NOW LEDGEMENTS}

We are grateful for the support and advice provided to us by the Cochrane Developmental, Psychosocial and Learning Problems Group (CDPLPG), in particular, the Managing Editor (Joanne Wilson), and the Trials Search Co-ordinator (Margaret Anderson). We are also very grateful for the support and advice provided to us by the Cochrane Dementia and Cognitive Improvement Group, in particular, the Co-ordinating Editors (Rupert McShane and Jenny McCleery), Deputy Co-ordinating Editor (Sascha Koepke), Managing Editor (Sue Marcus), and Trials Search Co-ordinator 
(Anna Noel-Storr). We would like to thank all the authors who responded to us and particularly to those of included studies who took the time to provide us with additional data.

\section{R E F E R E N C E S}

\section{References to studies included in this review}

Boada 2012 \{published data only\}

* Boada R, Hutaff-Lee C, Schrader A, Weitzenkamp D, Benke TA, Goldson EJ, et al. Antagonism of NMDA receptors as a potential treatment for Down syndrome: a pilot randomized controlled trial. Translational Psychiatry 2012;2:e141. [PUBMED: 22806212]

Costa ACS. On the promise of pharmacotherapies targeted at cognitive and neurodegenerative components of Down syndrome. Developmental Neuroscience 2011;33(5):414-27. Costa ACS. Query re Memantine and Down syndrome [personal communication]. Email to: N Livingstone 17 August 2015.

NCT01112683. Efficacy and safety of memantine hydrochloride in enhancing the cognitive abilities of young adults with Down syndrome. clinicaltrials.gov/ct2/show/ NCT01112683 (accessed 20 September 2015).

Cooper 2012 \{published data only\}

Cooper SA. TOP-COG study [personal communication]. Email to: R McShane 12 March 2015.

* Cooper SA, Caslake M, Evans J, Hassiotis A, Jahoda A, McConnachie A, et al. Toward onset prevention of cognitive decline in adults with Down syndrome (the TOP-COG study): study protocol for a randomized controlled trial. Trials 2014;15(1):202. [DOI: 10.1186/ 1745-6215-15-202]

ISRCTN67338640. Towards Onset Prevention of COGnition decline in adults with Down syndrome (the TOP-COG study). controlled-trials.com/ ISRCTN67338640 (accessed 20 September 2015). [DOI: 10.1186/ISRCTN67338640]

Hanney 2012 \{published data only\}

* Hanney M, Prasher V, Williams N, Jones EL, Aarsland D, Corbett A, et al. Memantine for dementia in adults older than 40 years with Down's syndrome (MEADOWS): a randomised, double-blind, placebo-controlled trial. Lancet 2012;379(9815):528-36. [PUBMED: 22236802] ISRCTN47562898. Efficacy and safety of memantine hydrochloride, a low affinity antagonist to N-Methyl-DAspartate (NMDA) type receptors, in the prevention of cognitive decline and disease progression in older people with Down's syndrome, with and without dementia. isrctn.com/ISRCTN47562898 (accessed 20 September 2015). [DOI: 10.1186/ISRCTN47562898]

NCT00240760. Efficacy and safety of memantine hydrochloride, a low affinity antagonist to N-methyl$\mathrm{D}$-aspartate (NMDA) type receptors, in the prevention of cognitive decline and disease progression in Down's syndrome. clinicaltrials.gov/ct2/show/NCT00240760 (accessed 20 September 2015).

Johnson 2003 \{published data only\}

* Johnson N, Fahey C, Chicoine B, Chong G, Gitelman D. Effects of donepezil on cognitive functioning in Down syndrome. American Journal on Mental Retardation 2003; 108(6):367-72. [PUBMED: 14561111 ]

Kennedy N. Effects of donepezil on cognitive functioning in Down syndrome [personal communication]. Email to: N Livingstone 11 September 2015.

\section{Kishnani 2009 \{published data only\}}

Kishnani PS, Sommer BR, Handen BL, Seltzer B, Capone GT, Spiridigliozzi GA, et al. The efficacy, safety, and tolerability of donepezil for the treatment of young adults with Down syndrome. American Journal of Medical Genetics. Part A 2009;149A(8):1641-54. [PUBMED: 19606472 ]

\section{Kondoh 2011 \{published data only\}}

Kondoh T, Kanno A, Itoh H, Nakashima M, Honda R, Kojima M, et al. Donepezil significantly improves abilities in daily lives of female Down syndrome patients with severe cognitive impairment: a 24-week randomized, doubleblind, placebo-controlled trial. International Journal of Psychiatry in Medicine 2011;41(1):71-89. [PUBMED: 21495523 ]

Lott 2011 \{published data only\}

Lott IT, Doran E, Nguyen VQ, Tournay A, Head E, Gillen DL. Down syndrome and dementia: a randomized, controlled trial of antioxidant supplementation. American Journal of Medical Genetics. Part A 2011;155A(8):1939-48. [DOI: 10.1002/ajmg.a.34114]

Prasher 2002 \{published data only\}

Prasher VP. Query re donepezil in Down syndrome [personal communication]. Email to: N Livingstone 9 September 2015.

Prasher VP, Adams C, Holder R. Long term safety and efficacy of donepezil in the treatment of dementia in Alzheimer's disease in adults with Down syndrome: open label study. International Journal of Geriatric Psychiatry 2003;18(6):549-51. [PUBMED: 12789681]

* Prasher VP, Huxley A, Haque MS. A 24-week, doubleblind, placebo-controlled trial of donepezil in patients with Down syndrome and Alzheimer's disease - pilot study. International Journal of Geriatric Psychiatry 2002; Vol. 17, issue 3:270-8. [PUBMED: 11921156]

Pueschel 2006 \{published data only\}

Pueschel SM. The effect of acetyl-L-carnitine administration on persons with Down syndrome. Research in Developmental 
Disabilities 2006;27(6):599-604. [DOI: 10.1016/ j.ridd.2004.07.009]

\section{References to studies excluded from this review}

Arvat 1996 \{published data only\}

Arvat E, Gianotti L, Ragusa L, Valetto MR, Cappa M, Aimaretti G, et al. The enhancing effect of pyridostigmine on the GH response to GHRH undergoes an accelerated age-related reduction in Down syndrome. Dementia 1996;7 (5):288-92. [DOI: 10.1159/000106894]

Barr 1990 \{published data only\}

Barr O. Down's syndrome and Alzheimer's disease -- what is the link?. Professional Nurse 1990;5(9):465-8.

Boada-Rovira 2005 \{published data only\} Boada-Rovira M, Hernández-Ruiz I, Badenas-Homiar S, Buendía-Torras M, Tárraga-Mestre L. Clinical-therapeutic study of dementia in people with Down syndrome and the effectiveness of donepezil in this population [Estudio clinicoterapéutico de la demencia en las personas con síndrome de Down y eficacia del donepecilo en esta población]. Revista de Neurologia 2005;41(3):129-36.

Breeze 2012 \{published data only\}

Breeze S. News in brief: potential memory treatment for those with Down's syndrome. Expert Review of Clinical Pharmacology 2012;5(5):497. [DOI: 10.1586/ecp.12.66]

De Falco 1994 \{published data only\}

De Falco FA, D’Angelo E, Grimaldi G, Scafuro F, Sachez F, Caruso G. Effect of the chronic treatment with Lacetylcarnitine in Down's syndrome [Effetti del trattamento cronico con L-acetilcarnitina nella sindrome di Down]. Clinica Terapeutica 1994;144(2):123-7. [PUBMED: 8181206

Gedye 1991 \{published data only\}

Gedye A. Serotonergic treatment for aggression in a Down's syndrome adult showing signs of Alzheimers disease. Journal of Mental Deficiency Research 1991;35:247-58.

Lobaugh 2001 \{published data only\}

Lobaugh NJ, Karaskov V, Rombough V, Rovet J, Bryson S, Greenbaum R, et al. Piracetam therapy does not enhance cognitive functioning in children with Down syndrome. Archives of Pediatrics \& Adolescent Medicine 2001;155(4): 442-8. [PUBMED: 11296070 ]

Pueschel 1980 \{published data only\} Pueschel SM, Reed RB, Cronk CE, Goldstein BI. 5hydroxytryptophan and pyridoxine. Their effects in young children with Down's syndrome. American Journal of Diseases of Children 1980;134(9):838-44. [PUBMED: 6447999]

Schill 2005 \{published data only\}

Schill D. Dementia of trisomy 21. Improvement with donepezil [Demenz bei Trisomie 21. Zustandsbesserung mit donepezil]. Medizinische Monatsschrift fur Pharmazeuten 2005;28(10):371-2.

Shinagawa 2014 \{published data only\} Shinagawa S, Shigeta M. Acetylcholinesterase inhibitors for treatment of Alzheimer's disease
[アルツハイマー病の治療]. Brain \& Nerve/Shinkei Kenkyu no Shinpo 2014;66(5):507-16.

Thase 1982 \{published data only\}

Thase ME. Reversible dementia in Down's syndrome. Journal of Intellectual Disability Research 1982;26(2):111-3. [DOI: 10.1111/j.1365-2788.1982.tb00135.x]

\section{References to ongoing studies}

\section{Aisen 2005 \{published data only\}}

Aisen PS, Dalton AJ, Sano M, Lott IT, Andrews HF, Tsai WY, International Down Syndrome and Alzheimer's Disease Consortium. Design and implementation of a multicenter trial of vitamin $\mathrm{E}$ in aging individuals with Down syndrome. Journal of Policy and Practice in Intellectual Disabilities 2005; 2(2):86-93. [DOI: 10.1111/j.1741-1130.2005.00020.x] NCT01594346. Multicenter vitamin E trial in aging persons with Down syndrome. clinicaltrials.gov/ct2/show/ NCT01594346 (accessed 20 September 2015).

NCT01791725 \{published data only\} NCT01791725. A 4-Week Randomized, Double-Blind, Placebo-Controlled, Phase 2a Safety and PK Study of Oral ELND005 in Young Adults With Down Syndrome Without Dementia. clinicaltrials.gov/ct2/show/NCT01791725 (accessed 20 September 2015).

\section{Additional references}

\section{Achenbach 1983}

Achenbach TM, Edelbrock C. Manual for the Child Behavior Checklist and Revised Child Behavior Profile. Queen City Printers, Cincinnati 1983.

\section{Ball 2008}

Ball SL, Holland AJ, Treppner P, Watson PC, Huppert FA. Executive dysfunction and its association with personality and behaviour changes in the development of Alzheimer's disease in adults with Down syndrome and mild to moderate learning disabilities. British Journal of Clinical Psychology 2008;47(Pt 1):1-29. [PUBMED: 17681112]

\section{Begg 1994}

Begg CB, Mazumdar M. Operating characteristics of a rank correlation test for publication bias. Biometrics 1994;50(4): 1088-101. [DOI: 10.2307/2533446]

Bittles 2004

Bittles AH, Glasson EJ. Clinical, social, and ethical implications of changing life expectancy in Down syndrome. Developmental Medicine \& Child Neurology 2004;46(4): 282-6. [DOI: 10.1111/j.1469-8749.2004.tb00483.x]

Bittles 2010

Bittles AH, Glasson EJ. Increased longevity and the comorbidities associated with intellectual and developmental disability. In: Bax M, Gillberg C editor(s). Comorbidities in Developmental Disorders. London: Mac Keith Publishers, 2010:125-41.

\section{Borenstein 2009}

Borenstein M, Hedges LV, Higgins JPT, Rothstein HR. Chapter 24: Multiple outcomes or time-points within a 
study. Introduction to Meta-Analysis. Chichester: John Wiley \& Sons, 2009:225-38.

\section{Bruininks 1996}

Bruininks RH, Woodcock RW, Weatherman RE, Hill BK. Scales of Independent Behavior-Revised (SIB-R). Chicago: Riverside 1996.

\section{Bucks 1996}

Bucks R, Ashworth D, Wilcock G, Siegfried K. Assessment of activities of daily living in dementia: development of the Bristol Activities of Daily Living Scale. Age and Ageing 1996;25(2):113-20. [DOI: 10.1093/ageing/25.2.113]

\section{Corbett 2014}

Corbett A, Ballard C. Randomised controlled trial: the value of vitamin $\mathrm{E}$ as a treatment for Alzheimer's disease remains unproven despite functional improvement, due to a lack of established effect on cognition or other outcomes from RCTs. Evidence-Based Medicine 2014;19(4):140. [DOI: 1136/eb-2014-101741]

\section{CSHAWG 2002}

Canadian Study of Health and Aging Working Group. Patterns and health effects of caring for people with dementia: the impact of changing cognitive and residential status. Gerontologist 2002;42(5):643-52. [DOI: 10.1093/ geront/42.5.643]

\section{Cummings 1994}

Cummings JL, Mega M, Gray K, Rosenberg-Thompson S, Carusi DA, Gornbein J. The Neuropsychiatric Inventory: comprehensive assessment of psychopathology in dementia. Neurology 1994;44(12):2308-14. [PUBMED: 7991117]

\section{Dalton 1997}

Dalton A, Fedor B. DYSPRAXIA Scale for Adults with Down Syndrome. Staten Island, NY: NYS Institute for Basic Research in Developmental Disabilities, 1997.

\section{De la Torre 2014}

De la Torre R, De Sola S, Pons M, Duchon A, De Lagran MM, Farré M, et al. Epigallocatechin-3-gallate, a DYRK1A inhibitor, rescues cognitive deficits in Down syndrome mouse models and in humans. Molecular Nutrition \& Food Research 2014;58(2):278-88. [DOI: 10.1002/ mnfr.201300325]

\section{DerSimonian 1986}

DerSimonian R, Laird N. Meta-analysis in clinical trials. Controlled Clinical Trials 1986;7(3):177-88. [PUBMED: 3802833]

\section{Douaud 2013}

Douaud G, Refsum H, De Jager CA, Jacoby R, Nichols TE, Smith SM, et al. Preventing Alzheimer's disease-related gray matter atrophy by B-vitamin treatment. Proceedings of the National Academy of Sciences of the United States of America 2013;110(23):9523-8. [DOI: 10.1073/pnas.1301816110]

\section{Dysken 2014}

Dysken MW, Sano M, Asthana S, Vertrees JE, Pallaki M, Llorente $\mathrm{M}$, et al. Effect of vitamin $\mathrm{E}$ and memantine on functional decline in Alzheimer disease: the TEAM-AD VA cooperative randomized trial. JAMA 2014;311(1):33-44. [PUBMED: 24381967]

\section{Egger 1997}

Egger M, Davey Smith G, Schneider M, Minder C. Bias in meta-analysis detected by a simple, graphical test. BMJ 1997;315(7109):629-34. [PUBMED: 9310563]

\section{Eisenburg 1984}

Eisenberg J, Hamburger-Bar R, Belmaker RH. The effect of vasopressin treatment on learning in Down's syndrome. Journal of Neural Transmission 1984;60(2):143-7.

Elliott 2007

Elliott, C D. Differential Ability Scales-Second edition (DASII). San Antonio, TX: Harcourt, 2007.

Elliott 2010

Elliott CD, Hale JB, Fiorello CA, Dorvil C, Moldovan J. Differential Ability Scales-II prediction of reading performance: global scores are not enough. Psychology in the Schools 2010;47(7):698-720. [DOI: 10.1002/pits.20499]

\section{Evenhuis 1996}

Evenhuis H. Further evaluation of the dementia questionnaire for persons with mental retardation (DMR). Journal of Intellectual Disability Research 1996;40(4): 369-73. [DOI: 10.1046/j.1365-2788.1996.786786.x]

Forbes 2013

Forbes D, Thiessen EJ, Blake CM, Forbes SC, Forbes S. Exercise programs for people with dementia. Cochrane Database of Systematic Reviews 2013, Issue 12. [DOI: 10.1002/14651858.CD006489.pub3]

\section{Gauthier 2013}

Gauthier S, Molinuevo JL. Benefits of combined cholinesterase inhibitor and memantine treatment in moderate-severe Alzheimer's disease. Alzheimer's \& Dementia 2013;9(3):326-31. [DOI: http://dx.doi.org/ 10.1016/j.jalz.2011.11.005]

\section{Glasson 2002}

Glasson EJ, Sullivan SG, Hussain R, Petterson BA, Montgomery PD, Bittles AH. The changing survival profile of people with Down's syndrome: implications for genetic counselling. Clinical Genetics 2002;62(5):390-3. [PUBMED: 12431254]

\section{Goldberg 1988} Goldberg DP, Williams P. A user's guide to the general health questionnaire. NFER-Nelson: Windsor, UK 1988.

\section{GRADEpro GDT 2014 [Computer program]} McMaster University. GRADEpro GDT: GRADEpro Guideline Development Tool. McMaster University, 2015 (developed by Evidence Prime, Inc). Available from www.gradepro.org.

\section{Hager 2014}

Hager K, Baseman AS, Nye JS, Brashear HR, Han J, Sano M, et al. Effects of galantamine in a 2-year, randomized, placebo-controlled study in Alzheimer's disease. Neuropsychiatric Disease and Treatment 2014;10: 391-401. [DOI: 10.2147/NDT.S57909] 
Hartley 2014

Hartley SL, Handen B, Devenny DA, Hardison R, Mihaila I, Price JC, et al. Cognitive functioning in relation to brain amyloid- $\beta$ in healthy adults with Down syndrome. Brain 2014;137(9):2556-63. [DOI: 10.1093/brain/awu173]

Higgins 2011

Higgins JPT, Green S (editors). Cochrane Handbook for Systematic Reviews of Interventions Version 5.1.0 [updated March 2011]. The Cochrane Collaboration, 2011. Available from www.cochrane-handbook.org.

Higgins 2014 [pers comm]

Higgins JPT. Averaging across multiple outcomes [personal communication]. Email to: G Macdonald 27 October 2014.

Hof 1995

Hof PR, Bouras C, Perl DP, Sparks DL, Mehta N, Morrison $\mathrm{JH}$. Age-related distribution of neuropathologic changes in the cerebral cortex of patients with Down's syndrome. Quantitative regional analysis and comparison with Alzheimer's disease. Archives of Neurology 1995;52(4):37991. [DOI: 10.1001/archneur.1995.00540280065020]

\section{Holland 1998}

Holland AJ, Hon J, Huppert FA, Stevens F, Watson P. Population-based study of the prevalence and presentation of dementia in adults with Down's syndrome. British Journal of Psychiatry 1998;172:493-8. [PUBMED: 9828989 ]

\section{Janicki 2000}

Janicki MP, Dalton A. Prevalence of dementia and impact on intellectual disability services. Mental Retardation 2000; 38(3):276-88. [PUBMED: 10900935]

Jones 2013

Jones EL, Mok K, Hanney M, Harold D, Sims R, Williams $\mathrm{J}$, et al. Evidence that PICALM affects age at onset of Alzheimer's dementia in Down syndrome. Neurobiology of Aging 2013;34(10):2441.e1-5. [DOI: 10.1016/ j.neurobiolaging.2013.03.018]

\section{Jozsvai 2009}

Jozsvai E, Kartakis P, Gedye A. Dementia scale for Down syndrome. Neuropsychological Assessments of Dementia in Down Syndrome and Intellectual Disabilities. London: Springer, 2009:53-66.

\section{Ligthart 2010}

Ligthart SA, Moll van Charante EP, Van Gool WA, Richard E. Treatment of cardiovascular risk factors to prevent cognitive decline and dementia: a systematic review. Vascular Health and Risk Management 2010;6:775-85. [PUBMED: 20859546 ]

\section{Livingstone 2015}

Livingstone N, Hanratty J, Macdonald G, McShane R. Pharmacological interventions for cognitive decline in people with Down syndrome. Cochrane Database of Systematic Reviews 2015, Issue 2. [DOI: 10.1002/ 14651858.CD011546]

\section{Loane 2014}

Loane M, Morris JK, Addor MC, Arriola L, Budd J, Doray B, et al. Twenty-year trends in the prevalence of
Down syndrome and other trisomies in Europe: impact of maternal age and prenatal screening. European Journal of Human Genetics 2013;21(1):27-33. [PUBMED: 22713804 ]

\section{Mann 1989}

Mann DM, Esiri MM. The pattern of acquisition of plaques and tangles in the brains of patients under 50 years of age with Down's syndrome. Journal of the Neurological Sciences 1989;89(2-3):169-79. [PUBMED: 2522541]

Margallo-Lana 2003 Margallo-Lana ML, Ballard C, Morris C, Kay D, Tyrer $\mathrm{S}$, Moore B. Cognitive decline in Down syndrome. Archives of Neurology 2003;60(7):1024. [DOI: 10.1001/ archneur.60.7.1024-a.]

\section{Matthews 2013}

Matthews FE, Arthur A, Barnes LE, Bond J, Jagger C, Robinson L, et al. A two-decade comparison of prevalence of dementia in individuals aged 65 years and older from three geographical areas of England: results of the Cognitive Function and Ageing Study I and II. Lancet 2013;82(9902): 1405-12. [PUBMED: 23871492]

\section{Mohan 2009a}

Mohan M, Carpenter PK, Bennett C. Donepezil for dementia in people with Down syndrome. Cochrane Database of Systematic Reviews 2009, Issue 1. [DOI: 10.1002/14651858.CD007178.pub2]

\section{Mohan 2009b}

Mohan M, Bennett C, Carpenter PK. Galantamine for dementia in people with Down syndrome. Cochrane Database of Systematic Reviews 2009, Issue 1. [DOI: 10.1002/14651858.CD007656]

\section{Mohan 2009c}

Mohan M, Bennett C, Carpenter PK. Memantine for dementia in people with Down syndrome. Cochrane Database of Systematic Reviews 2009, Issue 1. [DOI: 10.1002/14651858.CD007657]

\section{Mohan 2009d}

Mohan M, Bennett C, Carpenter PK. Rivastigmine for dementia in people with Down syndrome. Cochrane Database of Systematic Reviews 2009, Issue 1. [DOI: 10.1002/14651858.CD007658]

\section{Mullins 2013}

Mullins D, Daly E, Simmons A, Beacher F, Foy CML, Lovestone $S$, et al. Dementia in Down's syndrome: an MRI comparison with Alzheimer's disease in the general population. Journal of Neurodevelopmental Disorders 2013;5 (1):19-32. [DOI: 10.1186/1866-1955-5-19]

\section{Nihira 1974}

Nihira K, Foster R, Shellhaas M, Leland H. AAMD Adaptive Behaviour Scale 1974 Revision. Washington DC: American Association on Mental Deficiency, 1974.

\section{Nihira 1993}

Nihira K, Leland H, Lambert N. AAMR Adaptive Behavior Scale-Residential andCommunity. 2nd Edition. Austin, TX: PRO-ED, 1993. 
Oliver 1998

Oliver C, Crayton L, Holland A, Hall S, Bradbury J. A four year prospective study of age-related cognitive change in adults with Down's syndrome. Psychological Medicine 1998; 28(6):1365-77.

\section{Panisset 1994}

Panisset M, Roudier M, Saxton J, Boiler F. Severe impairment battery: a neuropsychological test for severely demented patients. Archives of Neurology 1994;51(1):41-5. [DOI: 10.1001/archneur.1994.00540130067012]

\section{Papalia 2001}

Papalia DE, Olds SW, Feldman RD, Gross DL. Human Development. 8th Edition. Boston: McGraw Hill, 2001.

\section{Power 2015}

Power MC, Weuve J, Sharrett AR, Blacker D, Gottesman RF. Statins, cognition, and dementia - systematic review and methodological commentary. National Reviews. Neurology 2015;11(4):220-9. [PUBMED: 25799928]

RCGP 2012

Royal College of General Practitioners (RCGP). Improving the Health and Well being of People with Learning Disabilities: An Evidence-Based Commissioning Guide for Clinical Commissioning Groups. London: RCGP, 2012.

Review Manager 2014 [Computer program] The Nordic Cochrane Centre, The Cochrane Collaboration. Review Manager (RevMan). Version 5.3. Copenhagen: The Nordic Cochrane Centre, The Cochrane Collaboration, 2014.

Rohn 2014

Rohn TT, McCarty KL, Love JE, Head E. Is apolipoprotein E4 an important risk factor for dementia in persons with Down syndrome?. Journal of Parkinson's Disease and Alzheimer's Disease 2014;8(1):7. [PUBMED: 25594074]

\section{Rumble 1989}

Rumble B, Retallack R, Hilbich C, Simms G, Multhaup G, Martins R, et al. Amyloid A4 protein and its precursor in Down's syndrome and Alzheimer's disease. New England Journal of Medicine 1989;320:1446-52. [DOI: 10.1056/ NEJM198906013202203]

\section{Sano 1997}

Sano M, Ernesto C, Thomas RG, Klauber MR, Schafer K, Grundman M, et al. A controlled trial of selegiline, alphatocopherol, or both as treatment for Alzheimer's disease. The Alzheimer's Disease Cooperative Study. New England Journal of Medicine 1997;336(17):1216-22. [PUBMED: 9110909]

\section{Saxon 1993}

Saxon J, McGonigle KL, Swihard AA, Boller F. The Severe Impairment Battery (SIB). Thames Valley Test Company 1993; Vol. England, Bury St. Edmunds.

\section{Schmand 2000}

Schmand B, Walstra G, Lindeboom J, Teunisse S, Jonker C. Early detection of Alzheimer's disease using the Cambridge Cognitive Examination (CAMCOG). Psychological Medicine 2000;30(3):619-27. [PUBMED: 10883717]

\section{Schünemann 2011}

Schünemann HJ, Oxman AD, Vist GE, Higgins JPT, Deeks JJ, Glasziou P, et al. Chapter 12: Interpreting results and drawing conclusions. In: Higgins JPT, Green $S$ (editors). Cochrane Handbook for Systematic Reviews of Interventions Version 5.1.0 [updated March 2011]. The Cochrane Collaboration, 2011. Available from www.cochrane-handbook.org.

Sheehan 2015

Sheehan R, Sinai A, Bass N, Blatchford P, Bohnen I, Bonell $S$, et al. Dementia diagnostic criteria in Down syndrome. International Journal of Geriatric Psychiatry 2015;30(8): 857-63. [DOI: 10.1002/gps.4228]

Sparrow 2006 Sparrow SS, Cicchetti DV, Balla DA. Vineland Adaptive Behavior Scales: Second Edition. Livonia, MN: American Guidance Services, Inc 2006.

\section{Stewart 2015}

Stewart LA, Clarke M, Rovers M, Riley RD, Simmonds M, Stewart G, et al. Preferred reporting items for a systematic review and meta-analysis of individual participant data: the PRISMA-IPD statement. JAMA 2015;313(16):1657-65. [DOI: 10.1001/jama.2015.3656]

\section{Temple 2001}

Temple V, Jozsvai E, Konstantareas MM, Hewitt TA. Alzheimer dementia in Down's syndrome: the relevance of cognitive ability. Journal of Intellectual Disability Research 2001;45(Pt 1):47-55. [PUBMED: 11168776]

\section{Thorndike 1986}

Thorndike RL, Hagen EP, Sattler JM. Stanford-Binet Intelligence Scale. Fourth. Chicago: Riverside, 1986.

Tricco 2013

Tricco AC, Soobiah C, Berliner S, Ho JM, Ng CH, Ashoor $\mathrm{HM}$, et al. Efficacy and safety of cognitive enhancers for patients with mild cognitive impairment: a systematic review and meta-analysis. Canadian Medical Association Journal 2013;185(16):1393-401. [DOI: 10.1503/ cmaj.130451]

\section{Watchman 2013}

Watchman K. At a Crossroads in Care: The Experience of Individuals with Down Syndrome and Dementia [PhD thesis]. Edinburgh: University of Edinburgh, 2013.

\section{WHO 1992}

World Health Organisation (WHO). The ICD-10 Classification of Mental and Behavioural Disorders. The ICD-10 Classification of Mental and Behavioural Disorders. Geneva: WHO, 1992.

\section{WHO 2001}

World Health Organization. International Classification of Functioning, Disability and Health: ICF. Geneva: World Health Organization, 2001.

\section{Woods 2012}

Woods B, Aguirre E, Spector AE, Orrell M. Cognitive stimulation to improve cognitive functioning in people with 
dementia. Cochrane Database of Systematic Reviews 2012, Issue 2. [DOI: 10.1002/14651858.CD005562.pub2]

\section{Wu 2013}

Wu J, Morris JK. The population prevalence of Down's syndrome in England and Wales in 2011. European Journal of Human Genetics 2013;21(9):1016-9. [PUBMED: 23321618 ]

\section{Yang 2002}

Yang Q, Rasmussen SA, Friedman JM. Mortality associated with Down's syndrome in the USA from 1983 to 1997: a population-based study. Lancet 2002;359(9311):1019-25.

[PUBMED: 11937181]

\section{References to other published versions of this review}

\section{Livingstone 2015a}

Livingstone N, Hanratty J, Macdonald G, McShane

R. Pharmacological interventions for cognitive decline

in people with Down syndrome. Cochrane Database

of Systematic Reviews 2015, Issue 2. [DOI: 10.1002/

14651858.CD011546]

* Indicates the major publication for the study 


\section{CHARACTERISTICS OF STUDIES}

\section{Characteristics of included studies [ordered by study ID]}

\section{Boada 2012}

\begin{tabular}{|c|c|}
\hline Methods & Randomised, double-blinded, placebo-controlled trial \\
\hline Participants & $\begin{array}{l}\text { - } 40 \text { participants randomised (20 intervention, } 20 \text { control) } \\
\text { - } \bigcirc 1 \text { (control) participant declined participation for personal reasons } \\
\circ 1 \text { (intervention) participant discontinued due to adverse events } \\
\circ 1 \text { (intervention) participant excluded from analyses due to adverse events } \\
\text { - } 37 \text { participants included in primary analysis } \\
\text { - Mean age of participants: } 23.27 \text { years intervention, } 22.60 \text { years control } \\
\text { - Gender of participants: } 14 \text { males ( } 7 \text { intervention, } 7 \text { control), } 24 \text { females (12 } \\
\text { intervention, } 12 \text { control) }\end{array}$ \\
\hline Interventions & $\begin{array}{l}\text { Intervention group } \\
\text { - Memantine: } 5 \mathrm{mg} \text { once daily during week } 1,5 \mathrm{mg} \text { twice daily during week } 2,5 \\
\text { and } 10 \mathrm{mg} \text { daily (divided dose = } 15 \mathrm{mg} \text { ) during week } 3 \text {, and } 10 \mathrm{mg} \text { twice daily from } \\
\text { week } 4 \text { to week } 16 \\
\text { Control group } \\
\text { - "placebo tablets (containing the same fillers and binders as the memantine tablets, } \\
\text { but no active ingredients)" }\end{array}$ \\
\hline Outcomes & $\begin{array}{l}\text { - Cognitive function (DAS II Matrices) } \\
\text { - Behaviour (SIB-R) } \\
\text { Duration of follow-up: } 16 \text { weeks }\end{array}$ \\
\hline
\end{tabular}

Notes

Although 3 participants were missing from the primary analysis, the review authors agreed that because Boada used repeated measures mixed models, which already takes account of dropouts (which were balanced in the 2 arms), it was not necessary to impute these missing data into our pooled analyses

Clinical Trials.Gov Identifier: NCT01112683

Funded by: Forest Research Institute Investigator Initiated Grant NAM-58

Study start date: July 2008

Study end date: August 2011

\section{Risk of bias}

\section{Bias}

Authors' judgement

\section{Support for judgement}

Random sequence generation (selection Low risk bias)

No information was provided beyond "participants were randomized". Authors were contacted for further information, and they replied confirming "Assignment of subjects to memantine or placebo was performed according to a computerized randomization schedule commissioned to Jason Child, PharmD., then, the head phar- 
Boada 2012 (Continued)

macist at the Investigational Drug Services at the Children's Hospital Colorado" (Costa 2015, pers comm in Boada 2012)

Allocation concealment (selection bias) Low risk

Quote: "Dr. Child was the only one with access to the key for the double-blind labels" "Dr. Child had no direct contact with any of the physicians or psychologists performing safety or efficacy assessments during this trial" (Costa 2015, pers comm in Boada 2012)

Blinding of participants and personnel Low risk (performance bias)

All outcomes

Blinding of outcome assessment (detection Low risk bias)

All outcomes

Incomplete outcome data (attrition bias) Low risk All outcomes

Other bias

Low risk
Quote: “participants, caregivers and all other investigators were blind to the treatment allocation"

Quote: “participants, caregivers and all other investigators were blind to the treatment allocation"

This study used repeated measures mixed models, which already takes account of dropouts (which were balanced in the 2 arms)

All outcomes specified in the protocol were reported

Quote: “This trial was funded by Forest Research Institute Investigator Initiated Grant NAM-58. ACSC was also supported in part by NIH Grant RO1-HD056235, the Linda Crnic Institute and the Coleman Institute for Cognitive Disabilities. The funding sources had no role in the design and conduct of the study; in the collection, analysis and interpretation of the data; or in the preparation, review or approval of the manuscript"

Cooper 2012

\begin{tabular}{l|l} 
Methods & Randomised, double-blinded, placebo-controlled trial \\
\hline Participants & $\begin{aligned}-21 \text { participants randomised (10 Intervention, } 11 \text { control) } \\
\quad 4 \text { participants lost from each arm }\end{aligned}$ \\
$\begin{aligned} \text { - } 13 \text { participants included in final analysis }(6 \text { Intervention, } 7 \text { control) } \\
\text { - Mean age of participants: } 54.68 \text { years intervention, } 53.67 \text { years control }\end{aligned}$
\end{tabular}

Pharmacological interventions for cognitive decline in people with Down syndrome (Review) 
- Gender of participants: 11 males (5 intervention, 6 control), 10 females (5 intervention, 5 control)

\begin{tabular}{l|l}
\hline Interventions & $\begin{array}{l}\text { Intervention group } \\
\text { Simvastatin } 40 \mathrm{mg} \text { once daily } \\
\text { Control group } \\
\bullet\end{array}$ \\
\hline Outcomes & $\begin{array}{l}\text { Placebo } \\
\text { - Cognitive decline (NADIID) } \\
\text { - Caily living skills (AAMR: ABS) }\end{array}$ \\
\hline Duration of follow-up: 52 weeks
\end{tabular}

\section{Risk of bias}

\begin{tabular}{l|l|l} 
Bias & Authors judgement & Support for judgement \\
\hline $\begin{array}{l}\text { Random sequence generation (selection } \\
\text { bias) }\end{array}$ & Low risk & $\begin{array}{l}\text { Participants randomly assigned by Robert- } \\
\text { son Centre for Biostatistics (RCB) }\end{array}$ \\
\hline Allocation concealment (selection bias) & Low risk & $\begin{array}{l}\text { Randomisation was carried out by Robert- } \\
\text { son Centre for Biostatistics (RCB), who in- } \\
\text { formed the pharmacy of each participant's } \\
\text { medication pack number assigned }\end{array}$
\end{tabular}

Blinding of participants and personnel Low risk (performance bias)

All outcomes

Blinding of outcome assessment (detection Low risk bias)

All outcomes

Incomplete outcome data (attrition bias) Low risk All outcomes

Selective reporting (reporting bias)

Low risk
Quote: "The research team will therefore remain blinded to group allocation status, as will the participants and their caregivers"

Quote: "The research team will therefore remain blinded to group allocation status, as will the participants and their caregivers"

4 participants lost to follow-up from each $\operatorname{arm}(4 / 11$ and 4/10). Given that the dropouts were balanced, it is unlikely that this introduced bias

All outcomes specified in the protocol were reported 
Other bias $\quad$ Low risk
Quote: "This study is funded by the Chief Scientist Office, Scottish Government Health Department (reference: CZH/4/ 626). JS is funded by the NHS Lothian R\& D Directorate"

Hanney 2012

\begin{tabular}{l|l} 
Methods & Randomised, double-blinded, placebo-controlled trial \\
\hline Participants & $\begin{array}{c}173 \text { participants randomised (88 intervention; } 85 \text { control) } \\
\text { o Of these, } 31(35 \%) \text { intervention participants and } 30(35 \%) \text { control }\end{array}$ \\
$\begin{array}{c}\text { participants had a baseline diagnosis of dementia } \\
\text { - Mean age of participants: } 51.7 \text { years intervention, } 51.0 \text { years control } \\
\text { - Gender of participants: } 98 \text { males (50 intervention, } 48 \text { control), } 75 \text { females (38 } \\
\text { intervention, } 37 \text { control) }\end{array}$
\end{tabular}

Interventions

\section{Intervention group}

- Memantine: 2 tablets per day for 52 weeks; dosage began at $5 \mathrm{mg}$ for 8 weeks, then increased to $10 \mathrm{mg}$ with fixed titration

\section{Control group}

- Placebo as identical scored tablets

Outcomes

Outcomes

- Attention, memory and executive function, as measured by DAMES

- Adaptive behaviour, as measured by AAMR: ABS

Duration of follow-up: 52 weeks

\begin{tabular}{ll} 
Notes & Clinical Trials.Gov Identifier: NCT00240760 \\
ICTRP Identifier: ISRCTN47562898 \\
Funded by: Lundbeck (Valby, Denmark) \\
Study start date: July 2005 \\
Study end date: July 2006 \\
\hline
\end{tabular}

\section{Risk of bias}

\begin{tabular}{|c|c|c|}
\hline Bias & Authors' judgement & Support for judgement \\
\hline $\begin{array}{l}\text { Random sequence generation (selection } \\
\text { bias) }\end{array}$ & Low risk & $\begin{array}{l}\text { Randomly allocated using a "computer- } \\
\text { generated allocation sequence" }\end{array}$ \\
\hline Allocation concealment (selection bias) & Low risk & $\begin{array}{l}\text { Quote: "Randomisation was done by a } \\
\text { statistician (NW) at the Centre for Statis- } \\
\text { tics in Medicine (Oxford, UK) who allo- } \\
\text { cated treatment and distributed pack num- } \\
\text { bers to the pharmacist, ensuring masking } \\
\text { of participants and investigators and allo- } \\
\text { cation concealment" }\end{array}$ \\
\hline
\end{tabular}


Hanney 2012 (Continued)

\begin{tabular}{|c|c|c|}
\hline $\begin{array}{l}\text { Blinding of participants and personnel } \\
\text { (performance bias) } \\
\text { All outcomes }\end{array}$ & Low risk & $\begin{array}{l}\text { Quote: "Memantine and placebo were pro- } \\
\text { vided as identical scored tablets to ensure } \\
\text { that the memantine and placebo could not } \\
\text { be distinguished" }\end{array}$ \\
\hline $\begin{array}{l}\text { Blinding of outcome assessment (detection } \\
\text { bias) } \\
\text { All outcomes }\end{array}$ & Low risk & $\begin{array}{l}\text { Ethics committee was "the only body who } \\
\text { had access to unmasked data" }\end{array}$ \\
\hline $\begin{array}{l}\text { Incomplete outcome data (attrition bias) } \\
\text { All outcomes }\end{array}$ & Low risk & $\begin{array}{l}\text { Study analysed and presented the data } \\
\text { available for each outcome. Study also in- } \\
\text { cluded a "posthoc sensitivity analysis with } \\
\text { multiple imputation method to handle } \\
\text { missing data" }\end{array}$ \\
\hline Selective reporting (reporting bias) & High risk & $\begin{array}{l}\text { Quality of life (QOL-AD) and post-test in- } \\
\text { cidence of dementia planned in protocol } \\
\text { but not reported in paper. DAMES and } \\
\text { AAMR: ABS reported for dementia sub- } \\
\text { group only. Study authors were emailed to } \\
\text { clarify this issue - no reply as of } 15 \text { Septem- } \\
\text { ber } 2015\end{array}$ \\
\hline Other bias & Low risk & $\begin{array}{l}\text { Study was funded by Lundbeck (Valby, } \\
\text { Denmark) as an investigator-led trial }\end{array}$ \\
\hline
\end{tabular}

\section{Johnson 2003}

\begin{tabular}{l|l}
\hline Methods & Randomised, double-blinded, placebo-controlled study \\
\hline Participants & $\begin{array}{l}19 \text { participants randomised (10 intervention, } 9 \text { control) } \\
01 \text { participant lost to follow-up }\end{array}$ \\
& $\begin{array}{l}\text { - } 18 \text { participants in final analyses }(9 \text { intervention, } 9 \text { control) } \\
\text { - Mean age of participants: } 29.5 \text { years intervention, } 24.7 \text { years control } \\
\text { - Gender of participants: } 11 \text { males }(4 \text { intervention, } 7 \text { control), } 8 \text { females }(6\end{array}$ \\
\hline intervention, 2 control)
\end{tabular}

Pharmacological interventions for cognitive decline in people with Down syndrome (Review) 
Johnson 2003 (Continued)

\begin{tabular}{|c|c|c|}
\hline Notes & \multicolumn{2}{|c|}{$\begin{array}{l}\text { Funded by: Pfizer grant to N Johnson and Northwestern Alzheimer's Disease Center, } \\
\text { Grant AG } 13854 \text { from NIA } \\
\text { Study start/end date: } 2002\end{array}$} \\
\hline \multicolumn{3}{|l|}{ Risk of bias } \\
\hline Bias & Authors' judgement & Support for judgement \\
\hline $\begin{array}{l}\text { Random sequence generation (selection } \\
\text { bias) }\end{array}$ & Low risk & Randomised by medical school pharmacy \\
\hline Allocation concealment (selection bias) & Low risk & Randomised by medical school pharmacy \\
\hline $\begin{array}{l}\text { Blinding of participants and personnel } \\
\text { (performance bias) } \\
\text { All outcomes }\end{array}$ & Low risk & $\begin{array}{l}\text { Quote: "neither the researchers nor the par- } \\
\text { ticipants were aware of subject group mem- } \\
\text { bership (donepezil vs. placebo) until the } \\
\text { study was completed" }\end{array}$ \\
\hline $\begin{array}{l}\text { Blinding of outcome assessment (detection } \\
\text { bias) } \\
\text { All outcomes }\end{array}$ & Low risk & $\begin{array}{l}\text { Quote: "neither the researchers nor the par- } \\
\text { ticipants were aware of subject group mem- } \\
\text { bership (donepezil vs. placebo) until the } \\
\text { study was completed" }\end{array}$ \\
\hline $\begin{array}{l}\text { Incomplete outcome data (attrition bias) } \\
\text { All outcomes }\end{array}$ & Low risk & $\begin{array}{l}\text { All participants were accounted for in anal- } \\
\text { yses }\end{array}$ \\
\hline Selective reporting (reporting bias) & Low risk & $\begin{array}{l}\text { All relevant measures appear to have been } \\
\text { reported }\end{array}$ \\
\hline Other bias & Unclear risk & $\begin{array}{l}\text { Quote: "This work was supported by the } \\
\text { following sources: Pfizer grant to N. John- } \\
\text { son and Northwestern Alzheimer's Disease } \\
\text { Center, Grant AG } 13854 \text { from NIA". Re- } \\
\text { port did not state whether the funder was } \\
\text { involved in any aspect of the study }\end{array}$ \\
\hline
\end{tabular}

Kishnani 2009

\begin{tabular}{|c|c|}
\hline Methods & Randomised, double-blinded, placebo-controlled study \\
\hline Participants & $\begin{array}{l}\text { - } 123 \text { participants randomised (62 intervention, } 61 \text { control) } \\
\text { o } 3 \text { participants discontinued treatment } \\
\text { - } 120 \text { participants in final analyses (59 intervention, } 61 \text { control) } \\
\text { - Mean age of participants: } 24.2 \text { years intervention, } 26.0 \text { years control } \\
\text { - Gender of participants: } 77 \text { males ( } 38 \text { intervention, } 39 \text { control), } 46 \text { females (24 } \\
\text { intervention, } 22 \text { control) }\end{array}$ \\
\hline
\end{tabular}


Kishnani 2009 (Continued)

\begin{tabular}{l|l}
\hline Interventions & $\begin{array}{l}\text { Intervention } \\
\text { - Donepezil: } 5 \mathrm{mg} / \mathrm{day} \text { for } 6 \text { weeks followed by } 10 \mathrm{mg} / \mathrm{day} \text { for } 6 \text { weeks } \\
\text { Control } \\
\text { - Placebo }\end{array}$ \\
\hline Outcomes & $\begin{array}{l}\text { - Cognitive functioning (SIB) } \\
\text { - Behaviour (VABS) } \\
\text { - Adverse events } \\
\text { Duration of follow-up: } 12 \text { weeks }\end{array}$ \\
\hline Notes & $\begin{array}{l}\text { A very small proportion of the participants }(3 / 123) \text { were not included in the final analyses. } \\
\text { Given that the dropouts were balanced, it is unlikely that this introduced bias. Therefore, } \\
\text { the review authors agreed it was not necessary to impute these missing data into our } \\
\text { pooled analyses } \\
\text { Funded by: Eisai, Inc and Pfizer, Inc } \\
\text { Study start/end date: unknown }\end{array}$ \\
\hline
\end{tabular}

Risk of bias

\begin{tabular}{|c|c|c|}
\hline Bias & Authors' judgement & Support for judgement \\
\hline $\begin{array}{l}\text { Random sequence generation (selection } \\
\text { bias) }\end{array}$ & Unclear risk & $\begin{array}{l}\text { No information provided beyond partici- } \\
\text { pants were "randomly assigned". Authors } \\
\text { were contacted for more information, but } \\
\text { have not yet replied as of } 15 \text { September } \\
2015\end{array}$ \\
\hline
\end{tabular}

Allocation concealment (selection bias) Unclear risk

No information provided beyond participants were "randomly assigned". Authors were contacted for more information, but have not yet replied as of 15 September 2015

Blinding of participants and personnel Unclear risk

Quote “double-blind”

(performance bias)

All outcomes

Blinding of outcome assessment (detection Unclear risk

bias)

Quote "double-blind”

All outcomes

Incomplete outcome data (attrition bias) Low risk

All outcomes

Selective reporting (reporting bias)

Unclear risk
Participants who discontinued treatment were not included in the analyses. Given that the dropouts were balanced, it is unlikely that this introduced bias

A protocol could not be obtained for this study. Authors were contacted for more information, but have not yet replied as of 15 
Kishnani 2009 (Continued)

September 2015

\begin{tabular}{|c|c|c|}
\hline Other bias & Unclear risk & $\begin{array}{l}\text { Quote: "This study was sponsored by Eisai, } \\
\text { Inc. and Pfizer, Inc". Report did not state } \\
\text { whether the funder was involved in any as- } \\
\text { pect of the study }\end{array}$ \\
\hline
\end{tabular}

Kondoh 2011

\begin{tabular}{|c|c|}
\hline Methods & Randomised, double-blinded, placebo-controlled study \\
\hline Participants & $\begin{array}{l}\text { - } 21 \text { participants randomised (11 intervention, } 10 \text { control) } \\
\text { - } 21 \text { participants in final analysis (11 intervention, } 10 \text { control) } \\
\text { - Mean age of participants: } 45.6 \text { years (breakdown for intervention and control } \\
\text { groups not provided) } \\
\text { - Gender of participants: } 100 \% \text { female }\end{array}$ \\
\hline Interventions & $\begin{array}{l}\text { Intervention group } \\
\text { - Donepezil: } 3 \mathrm{mg} / \text { day for } 24 \text { weeks } \\
\text { Control group } \\
\text { - Placebo: } 600 \mathrm{mg} \text { sucrose }\end{array}$ \\
\hline Outcomes & $\begin{array}{l}\text { - Global functioning (ICF) } \\
\text { - Adverse events } \\
\text { Duration of follow-up: } 24 \text { weeks }\end{array}$ \\
\hline
\end{tabular}

$\begin{array}{ll}\text { Notes } & \text { Funded by: unknown } \\ & \text { Study start date: } 2006 \\ & \text { Study end date: } 2007\end{array}$

\section{Risk of bias}

\begin{tabular}{|c|c|c|}
\hline Bias & Authors' judgement & Support for judgement \\
\hline $\begin{array}{l}\text { Random sequence generation (selection } \\
\text { bias) }\end{array}$ & Unclear risk & $\begin{array}{l}\text { No information provided beyond "sim- } \\
\text { ple random sampling". Authors were con- } \\
\text { tacted for more information, but have not } \\
\text { yet replied as of } 15 \text { September } 2015\end{array}$ \\
\hline Allocation concealment (selection bias) & Low risk & $\begin{array}{l}\text { Quote: "list of allocation kept securely in } \\
\text { the pharmacy ... not available to anyone } \\
\text { except Mna, who never had contact with } \\
\text { patients" }\end{array}$ \\
\hline
\end{tabular}

Blinding of participants and personnel Low risk (performance bias)

Quote: "placebo and drug identically supAll outcomes plied and formulated" 
Kondoh 2011 (Continued)

\begin{tabular}{|c|c|c|}
\hline $\begin{array}{l}\text { Blinding of outcome assessment (detection } \\
\text { bias) } \\
\text { All outcomes }\end{array}$ & Low risk & $\begin{array}{l}\text { Quote: "Code not disclosed until analysis } \\
\text { completed and fixed" }\end{array}$ \\
\hline $\begin{array}{l}\text { Incomplete outcome data (attrition bias) } \\
\text { All outcomes }\end{array}$ & Low risk & $\begin{array}{l}\text { All participants were accounted for in the } \\
\text { analyses }\end{array}$ \\
\hline Selective reporting (reporting bias) & Unclear risk & $\begin{array}{l}\text { A protocol could not be obtained for this } \\
\text { study. Authors were contacted for more in- } \\
\text { formation, but have not yet replied as of } 15 \\
\text { September } 2015\end{array}$ \\
\hline Other bias & Low risk & None known \\
\hline
\end{tabular}

\section{Lott 2011}

\begin{tabular}{|c|c|}
\hline Methods & Randomised, double-blinded, placebo-controlled study \\
\hline Participants & $\begin{array}{l}\text { - } 58 \text { participants randomised (29 intervention, } 29 \text { control) } \\
\text { o } 5 \text { participants discontinued treatment } \\
\text { - } 53 \text { participants in final analyses ( } 27 \text { intervention, } 26 \text { control) } \\
\text { - Mean age of participants: } 50.65 \text { years intervention, } 50.63 \text { years control } \\
\text { - Gender of participants: } 25 \text { males ( } 15 \text { intervention, } 10 \text { control), } 28 \text { females (11 } \\
\text { intervention, } 17 \text { control) }\end{array}$ \\
\hline
\end{tabular}

\begin{tabular}{ll} 
Interventions & $\begin{array}{l}\text { Intervention group } \\
\text { - Antioxidant: } 900 \text { IU of alpha-tocopherol, plus } 200 \mathrm{mg} \text { of asco } \\
\text { mg of alpha-lipoic acid. This daily dose was taken as } 1 \text { capsule at } \\
\text { capsules at the evening meal for } 24 \text { months } \\
\text { Control group } \\
\text { - Placebo }\end{array}$ \\
\hline Outcomes & $\begin{array}{l}\text { - Cognitive functioning (SIB) } \\
\text { - Behaviour (VABS) } \\
\text { - Daily living skills (BADLS) } \\
\text { - Adverse events } \\
\text { Duration of follow-up: 1-year interim and 2-year final follow-up }\end{array}$ \\
\hline
\end{tabular}

Notes

Grant sponsor: NIA; Grant numbers: AG-21912, ADRC P50-AG16573; "My Brother Joey" Neuroscience Fund

Study start date: June 2003

Study end date: May 2008

\section{Risk of bias}

Bias

Authors' judgement

Support for judgement 


\section{Lott 2011 (Continued)}

\begin{tabular}{l|l}
$\begin{array}{l}\text { Random sequence generation (selection Low risk } \\
\text { bias) }\end{array}$ & $\begin{array}{l}\text { Quote: "(computerized random numbers) } \\
\text { was used to assign participants to either the } \\
\text { treatment or placebo group" }\end{array}$
\end{tabular}

\begin{tabular}{l|l}
\hline Allocation concealment (selection bias) $\quad$ Low risk & $\begin{array}{l}\text { Quote: "The allocation sequence was con- } \\
\text { cealed from participants and all members } \\
\text { of the research team for the entire duration } \\
\text { of the study" }\end{array}$ \\
\hline
\end{tabular}

Blinding of participants and personnel Low risk (performance bias)

Quote: "The antioxidant supplements for All outcomes the treatment group were manufactured in capsule form and were identical in appearance to the placebo capsules"

Blinding of outcome assessment (detection Low risk bias)

All outcomes

Quote: "The allocation sequence was concealed from participants and all members of the research team for the entire duration of the study"

Incomplete outcome data (attrition bias) Low risk All outcomes

All participants were accounted for in the analyses

\begin{tabular}{l|l|l}
\hline Selective reporting (reporting bias) & Low risk & $\begin{array}{l}\text { A protocol was obtained from the authors } \\
\text { of this study. All expected outcomes were } \\
\text { reported }\end{array}$ \\
\hline Other bias & Low risk & None known \\
\hline
\end{tabular}

Prasher 2002

Methods $\quad$ Randomised, double-blinded, placebo-controlled trial

Participants

- 31 participants randomised (16 intervention; 15 control)

$\circ 1$ control participant went into hospital at the point of randomisation and therefore did not begin the intervention

- In total, 16 intervention and 14 control participants began treatment

- All participants had an ICD-10 diagnosis of dementia

- Mean age of participants: 53.06 years intervention, 55.07 years control

- Gender of participants: 15 males (10 intervention, 5 control), 15 females (6 intervention, 9 control)

Interventions

\section{Intervention group}

- Donepezil: 1 tablet per day for 24 weeks; dosage began at $5 \mathrm{mg}$ for 4 weeks, then increased to $10 \mathrm{mg}$ ( 3 in drug group remained at $5 \mathrm{mg}$ per day due to side effects)

\section{Control group}

- Placebo tablets similar in colour, shape, and size 
Prasher 2002 (Continued)

$\begin{array}{ll}\text { Outcomes } & \text { Global functioning (intellectual, social and behavioural; DMR) } \\ \text { - Cognitive function (SIB) } & \text { - Non-cognitive and behavioural psychopathology (NPI) } \\ \text { - Adaptive behaviour (AAMR: ABS) } & \text { - Adverse events } \\ \text { - Caregiver views, as measured by a qualitative questionnaire designed by the } \\ \text { authors specifically for the study } \\ \text { Duration of follow-up: } 24 \text { weeks }\end{array}$

Notes

A very small proportion of the participants (3/30) may not have been included in the final analyses. Given that the dropouts were balanced, it is unlikely that this introduced bias. Therefore, the review authors agreed it was not necessary to impute these missing data into our pooled analyses. A follow-up open label study to this trial was conducted using a cross-over design and published in 2003 (Prasher 2003). We have not analysed data for the follow-up period because this study was carried out on an open-label basis. All risk of bias judgements are based on the original randomised, double-blinded, placebocontrolled trial

Clinical Trials.Gov Identifier: NCT00240760

Funded by: Pfizer and Eisai

Study start date: October 2005

Study end date: not provided

Risk of bias

Bias

Random sequence generation (selection Low risk bias)
Authors' judgement

Allocation concealment (selection bias)

Unclear risk

Blinding of participants and personnel Low risk (performance bias)

All outcomes

Blinding of outcome assessment (detection Low risk bias)

All outcomes

\section{Support for judgement}

Quote: "Names of individuals were put into separate sealed envelopes, shuffled and then the first envelope (one person) was allocated to the active group, and the next to the placebo group ... and so on until all individuals were allocated"

Quote: "Names of individuals were put into separate sealed envelopes". Study authors emailed to confirm that envelopes were opaque and sequentially numbered. Authors replied (9 September 2015) stating it would not be possible to obtain the information requested

Quote: "patients, carers and the researcher undertaking data collection were blind throughout the study period"

Quote: "patients, carers and the researcher undertaking data collection were blind throughout the study period”. VP (Princi- 
Prasher 2002 (Continued)

\begin{tabular}{|c|c|c|}
\hline & & $\begin{array}{l}\text { ple investigator) had to break the alloca- } \\
\text { tion code after some patients suffered side } \\
\text { effects but was not involved in outcome } \\
\text { assessment. Quote: "other researchers, pa- } \\
\text { tients, cares and data analysis remained } \\
\text { blind until the study was completed" }\end{array}$ \\
\hline $\begin{array}{l}\text { Incomplete outcome data (attrition bias) } \\
\text { All outcomes }\end{array}$ & Unclear risk & $\begin{array}{l}\text { Unclear whether analyses based on } 30 \text { ran- } \\
\text { domised or } 27 \text { at follow-up. We emailed } \\
\text { the authors to request confirmation. Au- } \\
\text { thors replied ( } 9 \text { September } 2015 \text { ) stating it } \\
\text { would not be possible to obtain the infor- } \\
\text { mation requested }\end{array}$ \\
\hline Selective reporting (reporting bias) & Unclear risk & $\begin{array}{l}\text { No protocol available. We emailed the } \\
\text { authors to request confirmation that all } \\
\text { planned outcomes were measured and } \\
\text { reported. Authors replied ( } 9 \text { September } \\
\text { 2015) stating it would not be possible to } \\
\text { obtain the information requested }\end{array}$ \\
\hline Other bias & Low risk & $\begin{array}{l}\text { Sponsored by Pfizer and Eisai via an "un- } \\
\text { restricted educational grant". This implies } \\
\text { that the sponsor did not have involvement } \\
\text { in the trial or influence over the content of } \\
\text { reports }\end{array}$ \\
\hline
\end{tabular}

Pueschel 2006

\begin{tabular}{l|l}
\hline Methods & Randomised, double-blinded, placebo-controlled trial \\
\hline Participants & - 40 participants randomised ( 20 intervention; 20 control) \\
& - Number included in final analysis not known \\
& - Mean age of participants: 20.2 years intervention, 21.5 years control \\
& - Gender of participants: $100 \%$ male \\
\hline
\end{tabular}

Interventions

\section{Intervention group}

- Acetyl-L-carnitine: $10 \mathrm{mg} / \mathrm{kg} / \mathrm{day}$ divided into 3 doses during the first month. Increased to $20 \mathrm{mg} / \mathrm{kg} / \mathrm{day}$ in second month and afterwards to $30 \mathrm{mg} / \mathrm{kg} / \mathrm{day}$ for the rest of the study

\section{Control group}

- Placebo tablet, with similar appearance and taste

Outcomes

- Cognitive function (SBIS)

- Behavioural problems (CBCL)

- Daily living skills (VABS)

- Adverse events

Duration of follow-up: baseline, 3, 6 and at 9 months, after a 3-month 'washout' period 
Pueschel 2006 (Continued)

\begin{tabular}{|c|c|c|}
\hline Notes & \multicolumn{2}{|c|}{$\begin{array}{l}\text { Authors were contacted to enquire about final numbers analysed. No response at time } \\
\text { of publication } \\
\text { Funded by: unknown } \\
\text { Study start/end date: unknown }\end{array}$} \\
\hline \multicolumn{3}{|l|}{ Risk of bias } \\
\hline Bias & Authors' judgement & Support for judgement \\
\hline $\begin{array}{l}\text { Random sequence generation (selection } \\
\text { bias) }\end{array}$ & Low risk & $\begin{array}{l}\text { Quote: "An independent statistical consul- } \\
\text { tant randomly assigned the persons with } \\
\text { Down syndrome to either the study or con- } \\
\text { trol group" }\end{array}$ \\
\hline Allocation concealment (selection bias) & Low risk & $\begin{array}{l}\text { Quote: "An independent statistical consul- } \\
\text { tant randomly assigned the persons with } \\
\text { Down syndrome to either the study or con- } \\
\text { trol group" }\end{array}$ \\
\hline $\begin{array}{l}\text { Blinding of participants and personnel } \\
\text { (performance bias) } \\
\text { All outcomes }\end{array}$ & Low risk & $\begin{array}{l}\text { Quote: "The evaluators, parents, and the } \\
\text { subjects with Down syndrome were blind } \\
\text { relative to group assignment" }\end{array}$ \\
\hline $\begin{array}{l}\text { Blinding of outcome assessment (detection } \\
\text { bias) } \\
\text { All outcomes }\end{array}$ & Low risk & $\begin{array}{l}\text { Quote: "The evaluators, parents, and the } \\
\text { subjects with Down syndrome were blind } \\
\text { relative to group assignment" }\end{array}$ \\
\hline $\begin{array}{l}\text { Incomplete outcome data (attrition bias) } \\
\text { All outcomes }\end{array}$ & Unclear risk & $\begin{array}{l}\text { No information given on final numbers } \\
\text { analysed }\end{array}$ \\
\hline Selective reporting (reporting bias) & High risk & $\begin{array}{l}\text { The overall reporting of the results was poor } \\
\text { and there were discrepancies between what } \\
\text { was measured according to the methodol- } \\
\text { ogy and what was presented in the results. } \\
\text { This paper provided little detail on out- } \\
\text { comes, published no numerical data at all, } \\
\text { and did not report on outcomes that au- } \\
\text { thors listed as outcome measures and did } \\
\text { report on outcomes not mentioned in the } \\
\text { methods section }\end{array}$ \\
\hline Other bias & Low risk & None known \\
\hline
\end{tabular}

AAMR: ABS - American Association of Mental Retardation: Adaptive Behavior Scale

BADLS - Bristol Activities of Daily Living Scale

CBCL - Child Behavior Checklist

CGIC - Clinical Global Impression of Change

Pharmacological interventions for cognitive decline in people with Down syndrome (Review)

Copyright $\odot 2015$ The Cochrane Collaboration. Published by John Wiley \& Sons, Ltd. 
DAMES - Down Syndrome Attention Memory and Executive Function Scale

DAS-II - Differential Ability Scales-II

DMR - Dementia Questionnaire for Persons with Mental Retardation

GHQ-12 - General Health Questionnaire 12

ICD-10 - International Classification of Diseases, 10th Revision

ICF - International Classification of Functioning, Disability and Health scales

NADIID - Neuropsychological Assessment of Dementia in Intellectual Disabilities Battery

NHS - National Health Service

NIH - National Institute of Health

NPI - Neuropsychiatric Inventory

QoL-AD - Quality of Life in Alzheimer's Disease

SBIS - Stanford-Binet Intelligence Scale: 4th Edition

SCIP - Severe Cognitive Impairment Profile

SIB - Severe Impairment Battery

SIB-R - Scales of Independent Behavior-Revised

VABS - Vineland Adaptive Behavior Scales

\section{Characteristics of excluded studies [ordered by study ID]}

\begin{tabular}{|c|c|}
\hline Study & Reason for exclusion \\
\hline Arvat 1996 & $\begin{array}{l}\text { Focus of the study was on comparing the effect of pyridostigmine in participants with Down syndrome to } \\
\text { those without Down syndrome }\end{array}$ \\
\hline Barr 1990 & Paper was an overview of the current state of evidence and provided no evaluation or new data \\
\hline Boada-Rovira 2005 & Paper was an overview of the current state of evidence and provided no evaluation or new data \\
\hline Breeze 2012 & Paper was an overview of the current state of evidence and provided no evaluation or new data \\
\hline De Falco 1994 & $\begin{array}{l}\text { Focus of the study was on comparing the effect of acetyl-L-carnitine treatment in participants with Down } \\
\text { syndrome to those without Down syndrome }\end{array}$ \\
\hline Gedye 1991 & Study made use of a single case study design, and its focus was on aggression rather than cognitive decline \\
\hline Lobaugh 2001 & Study on children under 18 years of age \\
\hline Pueschel 1980 & Study on children under 18 years of age \\
\hline Schill 2005 & Not a randomised controlled trial \\
\hline Shinagawa 2014 & Paper was an overview of the current state of evidence and provided no evaluation or new data \\
\hline Thase 1982 & Study made use of a single case study design, and its focus was on aggression rather than cognitive decline \\
\hline
\end{tabular}

Pharmacological interventions for cognitive decline in people with Down syndrome (Review) 
Characteristics of ongoing studies [ordered by study ID]

\section{Aisen 2005}

Trial name or title Multicenter vitamin E trial in aging persons with Down syndrome

\begin{tabular}{l|l}
\hline Methods & RCT \\
\hline Participants & $\begin{array}{l}\text { - } 349 \text { participants reported on clinical trial register } \\
\text { - In the } 2005 \text { publication, researchers indicated that at that time } 316 \text { participants (162 women, } 154 \\
\text { men) with Down syndrome had been recruited. Aged between } 33 \text { and } 77 \text { years (mean } 48.7 \text { years; SD } 6.2 \\
\text { years) } \\
\text { - Degree of intellectual disability was available for } 262 \text { participants } \\
\circ 39(15 \%) \text { classified as mild } \\
\circ 137(52 \%) \text { classified as moderate } \\
\circ 75(29 \%) \text { classified as severe } \\
\circ 11(4 \%) \text { classified as profound } \\
\text { - Information on dementia status was available for } 98 \text { participants } \\
\circ 57(58 \%) \text { recorded as 'no dementia' } \\
\circ 41(42 \%) \text { with a diagnosis of probable dementia }\end{array}$ \\
\hline
\end{tabular}

\section{Interventions Vitamin E (alpha-tocopherol)}

- 1000 IU synthetic vitamin E twice daily or identical placebo

Primary
Outcomes
Secondary
- CGIC
- New Dot Test
- Modified Fuld test
- Vocabulary Test
- Behavior and Function Questionnaire
- Time to diagnosis of Alzheimer's disease (in non-demented participants)

Starting date September 2000

Contact information mary.sano@mssm.edu

Notes According to ClinicalTrials.gov the primary completion date of this study was April 2010

Authors have been contacted for data and they responded advising that they are "in a revision" which they

"hope will be done soon"

ClinicalTrials.govidentifier: NCT01594346

\section{NCT01791725}

Trial name or title A 4-week randomized, double-blinded, placebo-controlled, phase 2a safety and PK study of oral ELND005 (scyllo-inositol) in young adults with Down syndrome without dementia

Methods

Randomised, double-blinded, placebo-controlled, parallel-group, 3-arm trial 


\section{NCT01791725 (Continued)}

\begin{tabular}{|c|c|}
\hline Participants & $\begin{array}{l}\text { Inclusion criteria } \\
\text { - } 18 \text { to } 45 \text { years of age } \\
\text { - IQ of > } 40 \text { (K-BIT) } \\
\text { - Able and willing to have a brain MRI } \\
\text { Exclusion criteria } \\
\text { - Symptoms of dementia or worsening cognition over the past year } \\
\text { - History of hepatitis B, hepatitis C, or HIV }\end{array}$ \\
\hline Interventions & $\begin{array}{l}\text { - Experimental (arm 1): ELND005 (scyllo-inositol) } 250 \text { mg, twice daily } \\
\text { - Experimental (arm 2): ELND005 (scyllo-inositol) } 250 \mathrm{mg} \text {, once daily } \\
\text { - Control (arm 3): placebo twice daily }\end{array}$ \\
\hline Outcomes & $\begin{array}{l}\text { - Incidence of adverse events } \\
\text { - Changes from baseline in physical and neurological examinations } \\
\text { - Plasma ELND005 concentrations } \\
\text { - ELND005 PK profile to optimise PK model, including patient population } \\
\text { - Cognitive outcome } \\
\text { - Rapid Assessment for Development Disabilities (RADD) functional outcomes } \\
\text { - Vineland Adaptive Behavior Scale, Second Edition (VABS-II) }\end{array}$ \\
\hline Starting date & September 2013 \\
\hline Contact information & None provided. Information provided by (Responsible Party): Transition Therapeutics Ireland Limited \\
\hline Notes & $\begin{array}{l}\text { According to ClinicalTrials.gov, the primary completion date of this study was June } 2014 \\
\text { The Responsible Party (Transition Therapeutics Ireland Limited) have been contacted for data and have not } \\
\text { yet replied } \\
\text { ClinicalTrials.gov identifier: NCT01791725 }\end{array}$ \\
\hline
\end{tabular}

BPT - Brief Praxis Test

CGIC - Clinical Global Impression of Change

HIV - human immunodeficiency virus

IQ - intelligence quotient

K-BIT-2 - Kaufman Brief Intelligence Test, 2nd Edition

MRI - magnetic resonance imaging

PK - pharmacokinetic

RCT - randomised controlled trial 
DATA ANDANALYSES

Comparison 1. Comparison 1: donepezil versus placebo

\begin{tabular}{lcccc} 
Outcome or subgroup title & $\begin{array}{c}\text { No. of } \\
\text { studies }\end{array}$ & $\begin{array}{c}\text { No. of } \\
\text { participants }\end{array}$ & Statistical method & Effect size \\
\hline $\begin{array}{l}1 \text { Cognitive abilities (Severe } \\
\text { Impairment Battery) } 12 \text { to 24 } \\
\text { weeks }\end{array}$ & 3 & 165 & Std. Mean Difference (IV, Random, 95\% CI) & $0.52[-0.27,1.31]$ \\
$\begin{array}{l}2 \text { Behavioural problems (various } \\
\text { scales) } 12 \text { to 24 weeks }\end{array}$ & 3 & 157 & Std. Mean Difference (IV, Random, 95\% CI) & $0.42[-0.06,0.89]$ \\
\begin{tabular}{l}
3 Adverse events (12 to 24 weeks) \\
\hline
\end{tabular} & 4 & 192 & Odds Ratio (M-H, Random, 95\% CI) & $0.32[0.16,0.62]$ \\
\hline
\end{tabular}

Comparison 2. Comparison 2: memantine versus placebo

\begin{tabular}{|c|c|c|c|c|}
\hline Outcome or subgroup title & $\begin{array}{l}\text { No. of } \\
\text { studies }\end{array}$ & $\begin{array}{c}\text { No. of } \\
\text { participants }\end{array}$ & Statistical method & Effect size \\
\hline $\begin{array}{l}1 \text { Cognitive abilities (various } \\
\text { scales) } 16 \text { to } 52 \text { weeks }\end{array}$ & 2 & 184 & Std. Mean Difference (IV, Random, 95\% CI) & $0.05[-0.43,0.52]$ \\
\hline $\begin{array}{l}2 \text { Behavioural problems (various } \\
\text { scales) } 16 \text { to } 52 \text { weeks }\end{array}$ & 2 & 186 & Std. Mean Difference (IV, Random, 95\% CI) & $-0.17[-0.46,0.11]$ \\
\hline 3 Adverse events ( 16 to 52 weeks) & 2 & 211 & Odds Ratio (M-H, Random, 95\% CI) & $0.45[0.18,1.17]$ \\
\hline
\end{tabular}


Analysis I.I. Comparison I Comparison I: donepezil versus placebo, Outcome I Cognitive abilities (Severe Impairment Battery) 12 to 24 weeks.

Review: Pharmacological interventions for cognitive decline in people with Down syndrome

Comparison: I Comparison I: donepezil versus placebo

Outcome: I Cognitive abilities (Severe Impairment Battery) 12 to 24 weeks

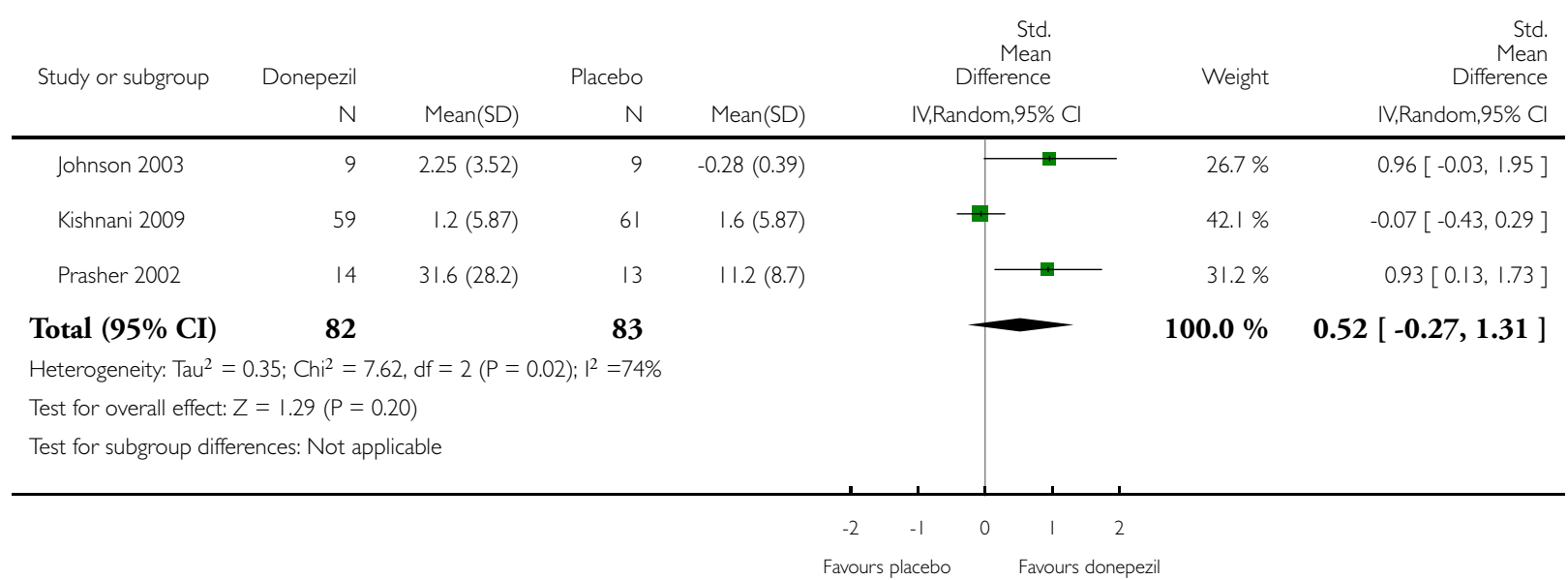




\section{Analysis I.2. Comparison I Comparison I: donepezil versus placebo, Outcome 2 Behavioural problems}

(various scales) 12 to 24 weeks.

Review: Pharmacological interventions for cognitive decline in people with Down syndrome

Comparison: I Comparison I: donepezil versus placebo

Outcome: 2 Behavioural problems (various scales) 12 to 24 weeks

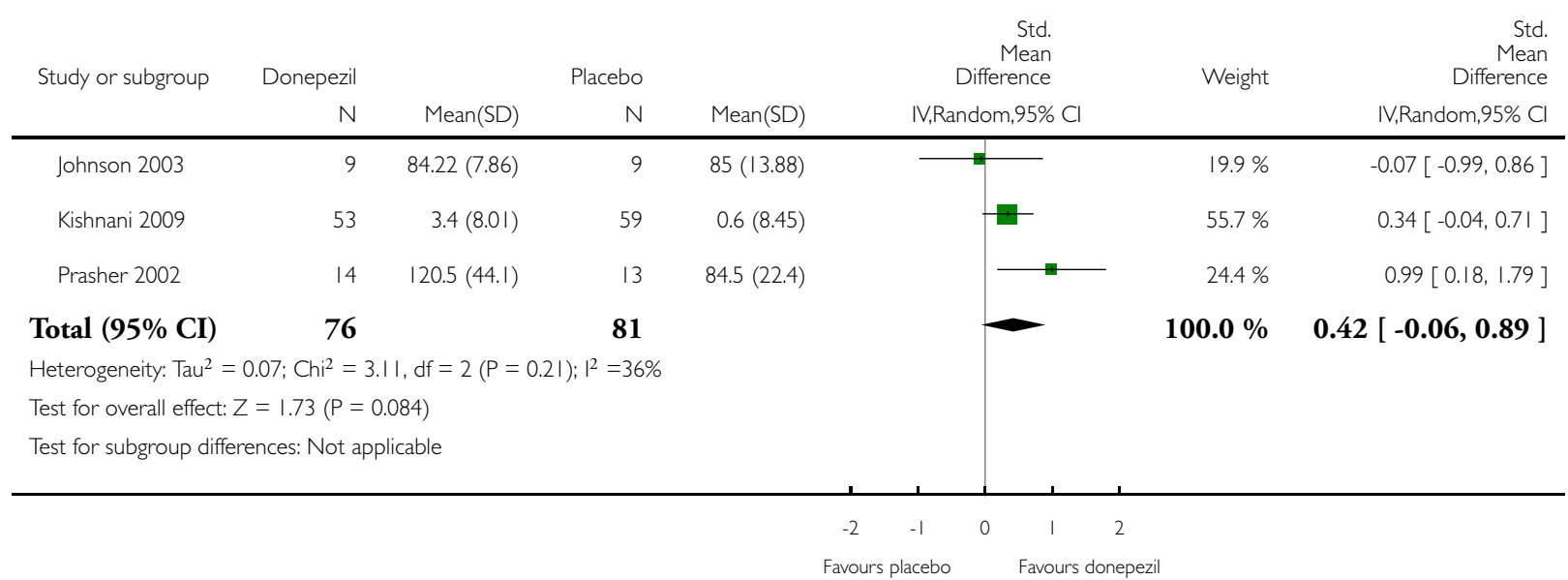


Analysis I.3. Comparison I Comparison I: donepezil versus placebo, Outcome 3 Adverse events (I 2 to 24 weeks).

Review: Pharmacological interventions for cognitive decline in people with Down syndrome

Comparison: I Comparison I: donepezil versus placebo

Outcome: 3 Adverse events ( 12 to 24 weeks)

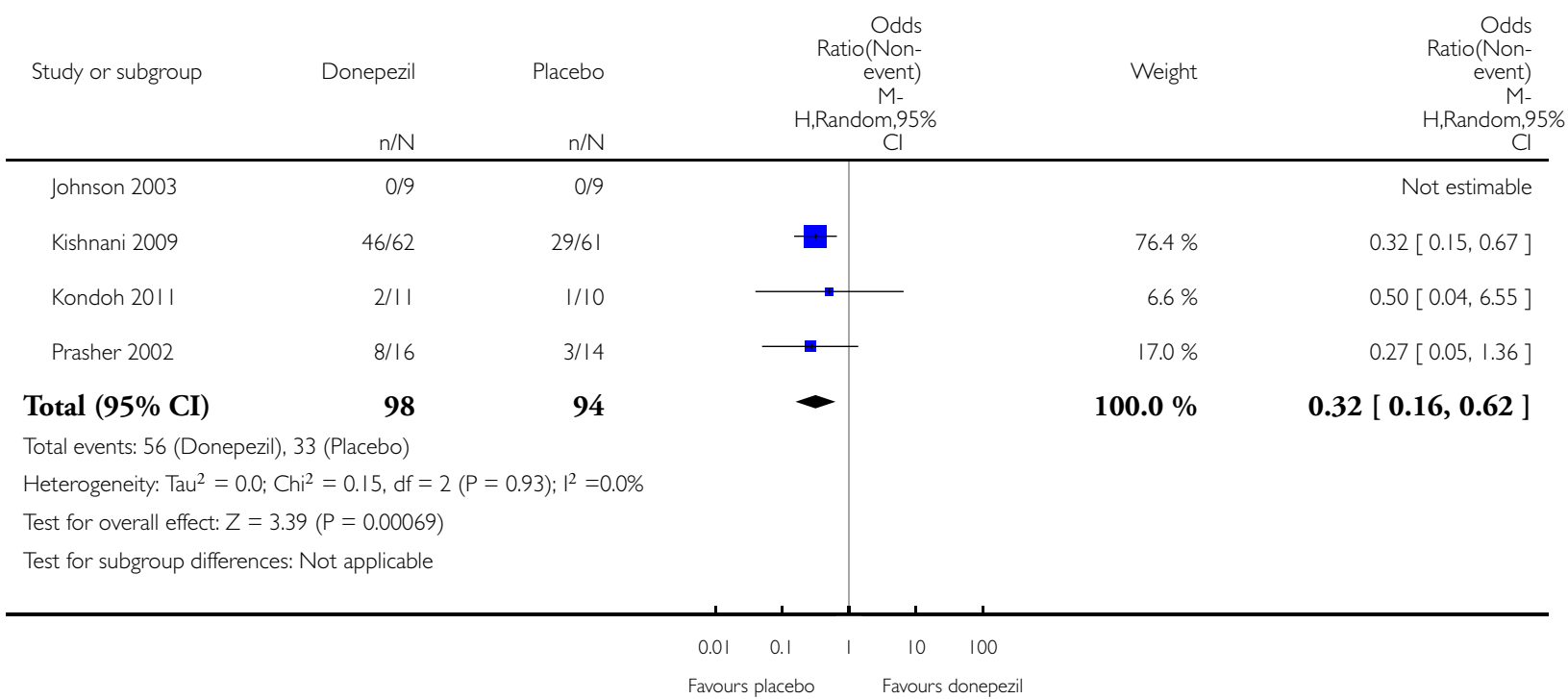


Analysis 2.I. Comparison 2 Comparison 2: memantine versus placebo, Outcome I Cognitive abilities (various scales) 16 to 52 weeks.

Review: Pharmacological interventions for cognitive decline in people with Down syndrome

Comparison: 2 Comparison 2: memantine versus placebo

Outcome: I Cognitive abilities (various scales) 16 to 52 weeks

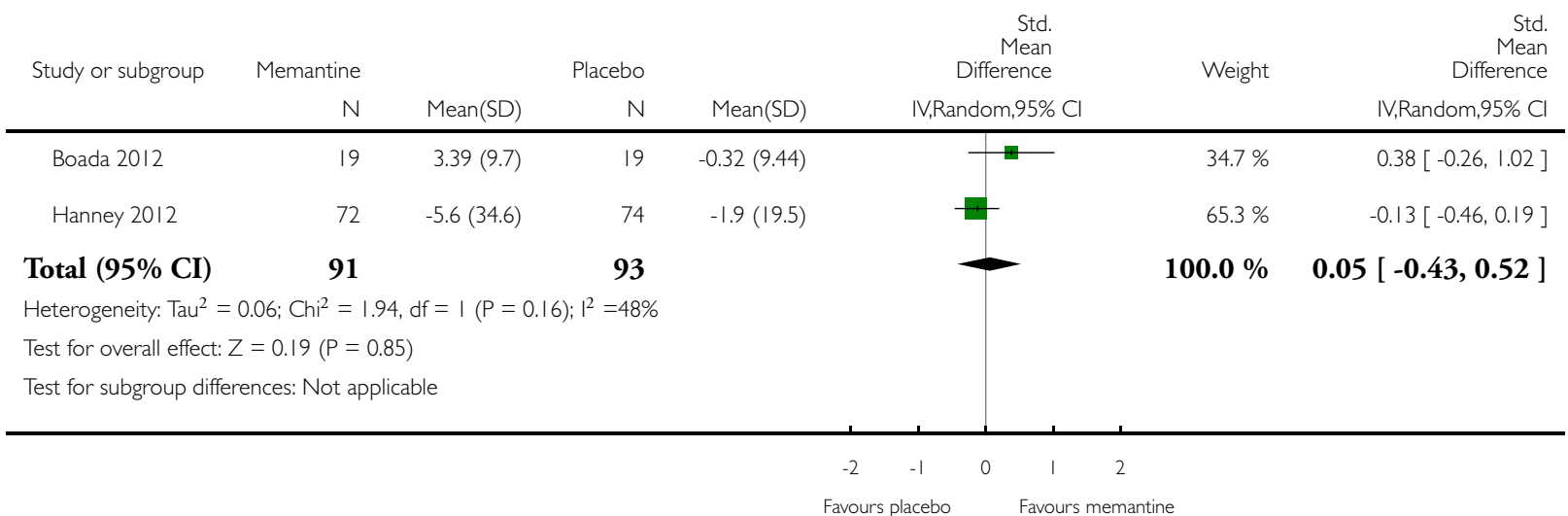

Analysis 2.2. Comparison 2 Comparison 2: memantine versus placebo, Outcome 2 Behavioural problems (various scales) 16 to 52 weeks.

Review: Pharmacological interventions for cognitive decline in people with Down syndrome

Comparison: 2 Comparison 2: memantine versus placebo

Outcome: 2 Behavioural problems (various scales) 16 to 52 weeks

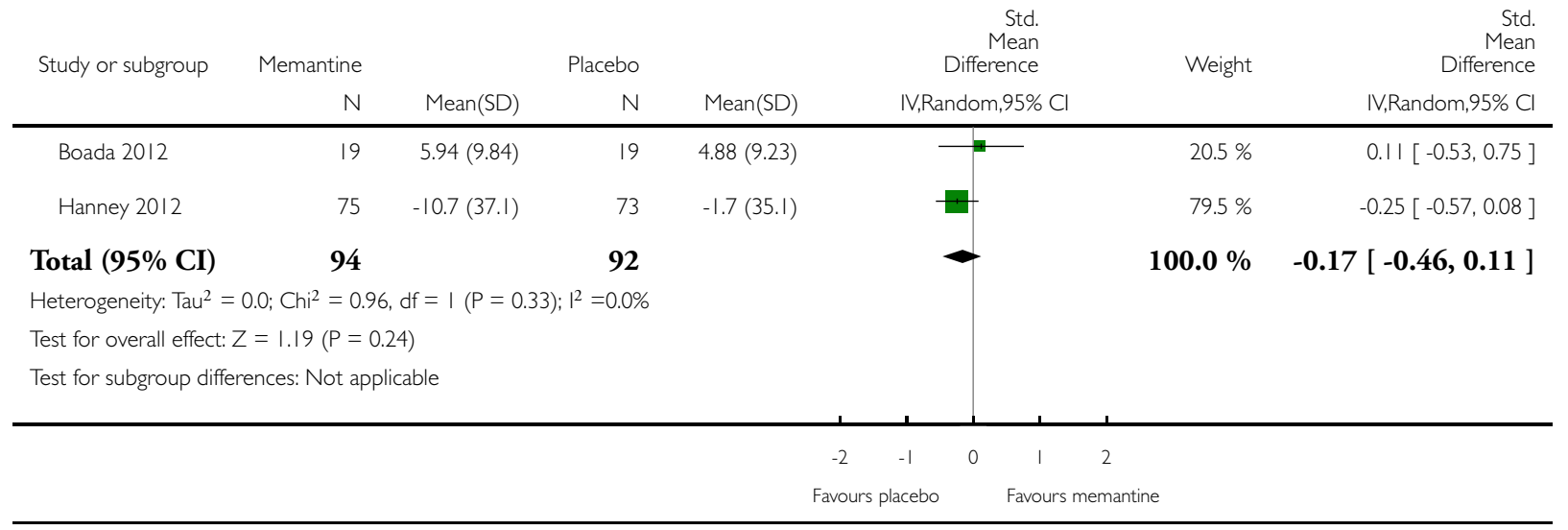

Pharmacological interventions for cognitive decline in people with Down syndrome (Review) 


\section{Analysis 2.3. Comparison 2 Comparison 2: memantine versus placebo, Outcome 3 Adverse events (16 to} 52 weeks).

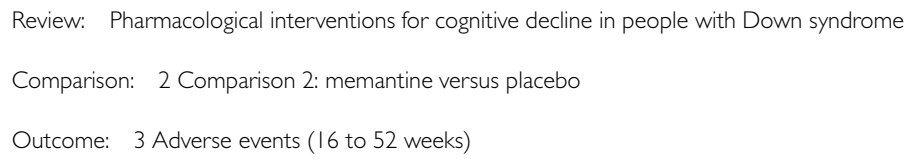

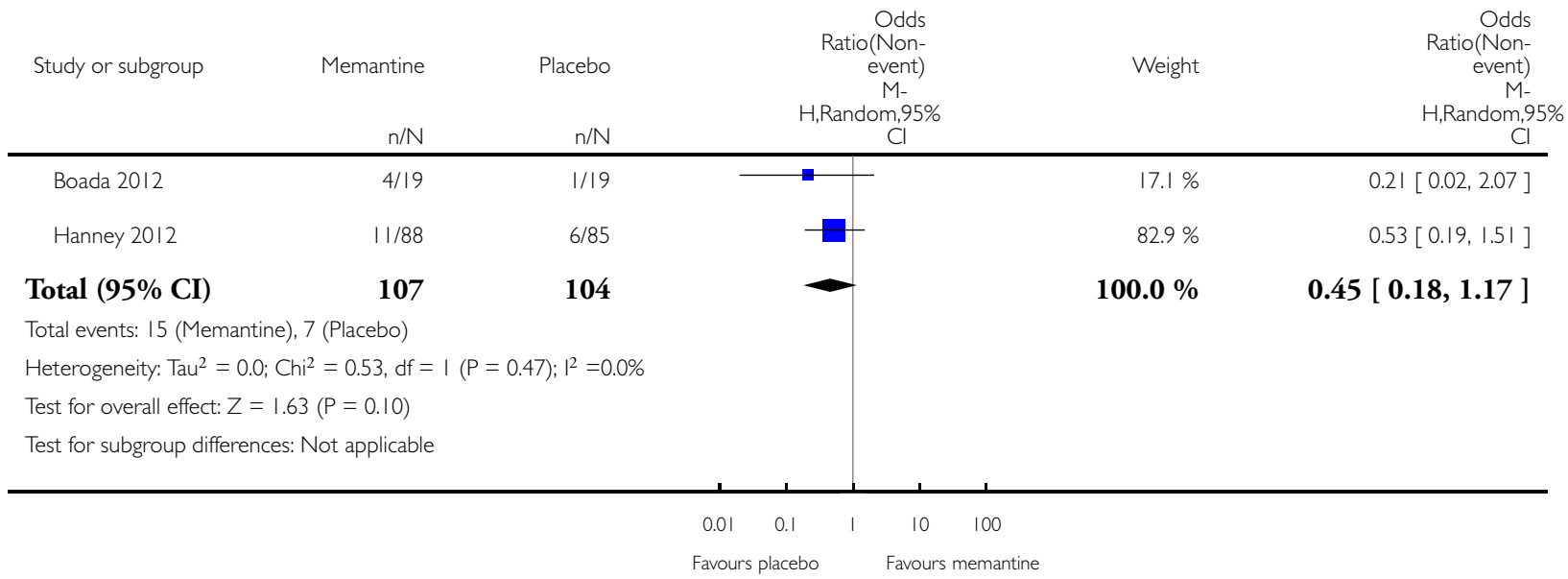

\section{ADDITIONAL TABLES}

Table 1. Levels of quality of a body of evidence in the GRADE approach

\begin{tabular}{l|l}
\hline Underlying methodology & Quality rating \\
\hline Randomized trials; or double-upgraded observational studies & High \\
\hline Downgraded randomized trials; or upgraded observational studies & Moderate \\
\hline Double downgraded randomized trials; or observational studies & Low \\
\hline $\begin{array}{l}\text { Triple downgraded randomized trials; or downgraded observa- } \\
\text { tional studies, or case series/case reports }\end{array}$ & Very low \\
\hline $\begin{array}{l}\text { Pharmacological interventions for cognitive decline in people with Down syndrome (Review) } \\
\text { Copyright @ } 2015 \text { The Cochrane Collaboration. Published by John Wiley \& Sons, Ltd. }\end{array}$ \\
\hline
\end{tabular}


Copy of Table 12.2.a from Schünemann 2011

GRADE: Grades of Recommendation, Assessment, Development and Evaluation

Table 2. Factors that may decrease the quality level of a body of evidence

1. Limitations in the design and implementation of available studies suggesting high likelihood of bias

2. Indirectness of evidence (indirect population, intervention, control, outcomes)

3. Unexplained heterogeneity or inconsistency of results (including problems with subgroup analyses)

4. Imprecision of results (wide confidence intervals)

5. High probability of publication bias

Copy of Table 12.2.b from Schünemann 2011

Table 3. Factors that may increase the quality level of a body of evidence

1. Large magnitude of effect

2. All plausible confounding would reduce a demonstrated effect or suggest a spurious effect when results show no effect

3. Dose-response gradient

Copy of Table 12.2.c from Schünemann 2011

Table 4. Studies not eligible for the synthesis

\begin{tabular}{|c|c|}
\hline Study name & Eisenburg 1984 \\
\hline Methods & $\begin{array}{l}\text { Randomised, double blinded, placebo-controlled trial } \\
\text { Cross-over trial with 3-week washout }\end{array}$ \\
\hline Participants & $\begin{array}{l}\text { - } 9 \text { participants randomised (5 intervention, } 4 \text { control) } \\
\text { - Age range of participants: } 10 \text { to } 42 \text { years. Information on recruitment provided in the paper suggests that at } \\
\text { least three participants were under } 18 \text { years of age (" } 3 \text { subjects came from two different special education schools } \\
\text { and were living with their parents" (p 144) } \\
\text { - Gender of participants: "Three subjects were girls" (p 144) }\end{array}$ \\
\hline Interventions & $\begin{array}{l}\text { Intervention group } \\
\text { - Vasopressin ( } 40 \mu \mathrm{g} \text { daily for } 10 \text { days) } \\
\text { Control group } \\
\text { - Placebo }\end{array}$ \\
\hline
\end{tabular}


Table 4. Studies not eligible for the synthesis (Continued)

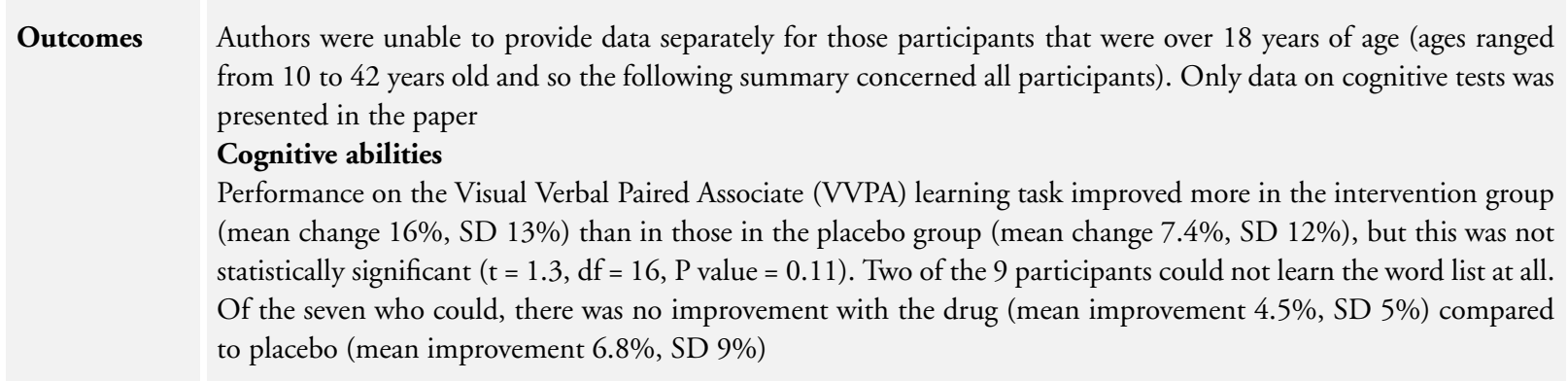

Notes

We contacted the authors of this study to request data for participants aged 18 to 42 years only. The author replied stating that it would not be possible to access any information beyond what was available in the published paper

$\mathrm{df}$ - degrees of freedom

SD - standard deviation

\section{A P P E N D I C E S}

\section{Appendix I. Search strategies}

\section{Cochrane Central Register of Controlled Trials (CENTRAL, which includes the Specialised Register of the Cochrane Developmental, Psychosocial and Learning Problems Group)}

CENTRAL, part of the Cochrane Library, 2014, Issue 12. Searched 21 January 2015 [46 records]

\#1 MeSH descriptor: [Dementia] explode all trees

\#2 MeSH descriptor: [Cognition Disorders] explode all trees

\#3 MeSH descriptor: [Delirium, Dementia, Amnestic, Cognitive Disorders] this term only

\#4 ((cognit* or cerebr*) near/3 (declin* or deteriorat* or degenerat* or disorder* or impair* or function*))

\#5 (dementia or demented)

\#6 MeSH descriptor: [Memory] this term only

\#7 MeSH descriptor: [Memory Disorders] explode all trees

\#8 (memory near/3 (declin* or deteriorat* or degenerat* or disorder* or impair* or function* or loss*))

\#9 MeSH descriptor: [Confusion] this term only

\#10 (forgetful* or confused or confusion)

\#11 Alz*eimer*

\#12 Huntington*

\#13 Lewy next bod*

\#14 Creutzfeldt next Jakob or CJD

\#15 MeSH descriptor: [Delirium] this term only

$\# 16$ deliri*

$\# 17$ \{or \#1-\#16\}

\#18 MeSH descriptor: [Down Syndrome] this term only

\#19 down* next syndrome

\#20 downs next disease

Pharmacological interventions for cognitive decline in people with Down syndrome (Review)

Copyright $\Subset 2015$ The Cochrane Collaboration. Published by John Wiley \& Sons, Ltd. 
\#21 trisomy next 21

\#22 chromosome next 21

\#23 (mongol or mongols or mongoloid or mongolism)

\#24 \{or \#18-\#23\}

\#25 \#17 and \#24 in Trials

\section{ALOIS: Specialised register of the Cochrane Dementia and Cognitive Improvement Group}

This register covers a number of sources, including the major bibliographic healthcare databases and trials register. To find out more see: About ALOIS.

ALOIS. Up to date as of 1 January 2015. Searched 21 January 2015 [10 records]

"down* syndrome" OR "down* disease" OR “trisomy 21" OR “chromosome 21" OR mongol or mongoloid OR mongolism

\section{Ovid MEDLINE(R)}

Ovid MEDLINE 1946 to January Week 2 2015. Searched 20 January 2015 [477 records]

1 exp Dementia/

2 exp cognition disorders/

3 Delirium, Dementia, Amnestic, Cognitive Disorders/

4 ((cognit\$ or cerebr\$) adj3 (declin\$ or deteriorat\$ or degenerat\$ or disorder\$ or impair\$ or function\$)).tw.

5 alz?eimer\$.tw.

6 (dementia or demented).tw.

7 huntington $\$$.tw.

8 Lewy bod\$.tw.

9 (Creutzfeldt-Jakob or cjd).tw.

10 Memory/

11 memory disorders/

12 Confusion/

13 (memory adj3 (declin\$ or deteriorat\$ or degenerat $\$$ or disorder $\$$ or impair $\$$ or function $\$$ or loss $\$$ )).tw.

14 (forgetful $\$$ or confused or confusion).tw.

15 Delirium/

16 deliri\$.tw.

17 or/1-16

18 Down Syndrome/

19 (down\$ adj syndrome).tw.

20 Downs disease.tw.

21 trisomy 21.tw.

22 chromosome 21.tw.

23 (mongol or mongols or mongoloid or mongolism).tw.

24 or/18-23

25 randomized controlled trial.pt.

26 controlled clinical trial.pt.

27 randomi\#ed.ab.

28 placebo\$.ab.

29 drug therapy.fs.

30 randomly.ab.

31 trial.ab.

32 groups.ab.

33 or $/ 25-32$

34 exp animals/ not humans.sh.

3533 not 34

3617 and 24 and 35

Pharmacological interventions for cognitive decline in people with Down syndrome (Review)

Copyright $\odot 2015$ The Cochrane Collaboration. Published by John Wiley \& Sons, Ltd. 


\section{Ovid MEDLINE(R) In-Process \& Other Non-Indexed Citations}

Ovid MEDLINE(R) In-Process \& Other Non-Indexed Citations. January 19, 2015. Searched 20 January 2015 [47 records]

1 ((cognit\$ or cerebr\$) adj3 (declin\$ or deteriorat\$ or degenerat $\$$ or disorder $\$$ or impair $\$$ or function\$)).mp.

2 alz? eimer\$.mp.

3 (dementia or demented).mp.

4 huntington $\$ . \mathrm{mp}$.

5 Lewy bod $\$ . m p$.

6 (Creutzfeldt-Jakob or cjd).mp.

7 (memory adj3 (declin\$ or deteriorat\$ or degenerat\$ or disorder\$ or impair\$ or function\$ or loss\$)).mp.

8 (forgetful\$ or confused or confusion).mp.

9 deliri\$.mp.

10 or/1-9

11 (down\$ adj syndrome).mp.

12 trisomy $21 . \mathrm{mp}$.

13 chromosome $21 . \mathrm{mp}$.

14 (mongol or mongols or mongoloid or mongolism).mp.

15 downs disease.mp.

16 or/11-15

17 (random $\$$ or trial $\$$ or control\$ or group $\$$ or blind $\$$ or placebo $\$$ or prospective).mp.

1810 and 16 and 17

\section{Embase (Ovid)}

EMBASE 1974 to 2015 Week 3. Searched 20 January 2015 [548 records]

1 exp Dementia/

2 exp memory disorder/

3 memory/

4 exp confusion/

5 cognitive defect/

6 ( (cognit\$ or cerebr\$) adj3 (declin\$ or deteriorat\$ or degenerat\$ or disorder\$ or impair\$ or function\$)).tw.

7 (memory adj3 (declin $\$$ or deteriorat $\$$ or degenerat $\$$ or disorder $\$$ or impair $\$$ or function $\$$ or loss $\$$ )).tw.

8 (forgetful\$ or confused or confusion).tw.

9 (dementia or demented).tw.

10 Huntington $\$ . t w$.

11 Alz?eimer\$.tw.

12 Lewy bod\$.tw.

13 (Creutzfeldt-Jakob or cjd).tw.

14 delirium/

15 deliri\$.tw.

16 or/1-15

17 Down syndrome/

18 (down\$ adj syndrome).tw.

19 Downs disease.tw.

20 trisomy 21.tw.

21 chromosome 21.tw.

22 (mongol or mongols or mongoloid or mongolism).tw.

23 or/17-22

2416 and 23

25 Randomized controlled trial/

26 controlled clinical trial/

27 Single blind procedure/

28 Double blind procedure/

29 triple blind procedure/

Pharmacological interventions for cognitive decline in people with Down syndrome (Review)

Copyright @ 2015 The Cochrane Collaboration. Published by John Wiley \& Sons, Ltd. 
30 Crossover procedure/

31 (crossover or cross-over).tw.

32 ((singl\$ or doubl\$ or tripl\$ or trebl\$) adj1 (blind\$ or mask\$)).tw.

33 Placebo/

34 placebo.tw.

35 prospective.tw.

36 factorial\$.tw.

37 random\$.tw.

38 assign $\$ . a b$.

39 allocat\$.tw.

40 volunteer $\$ . a b$.

41 groups $\$ . \mathrm{ab}$.

42 or $/ 25-41$

4324 and 42

44 exp animals/ or exp invertebrate/ or animal experiment/ or animal model/ or animal tissue/ or animal cell/ or nonhuman/ 45 human/ or normal human/ or human cell/

4644 and 45

4744 not 46

4843 not 47

\section{PsycINFO (OVID)}

PsycINFO 1806 to January Week 2 2015. Searched 20 January 2015 [76 records]

1 exp dementia/

2 cognitive impairment/

3 exp memory disorders/

4 memory/

5 delirium/

6 mental confusion/

7 Huntingtons Disease/

8 delirium/

9 ( (cognit\$ or cerebr\$) adj3 (declin\$ or deteriorat\$ or degenerat\$ or disorder\$ or impair\$ or function\$)).tw.

10 (memory adj3 (declin $\$$ or deteriorat $\$$ or degenerat $\$$ or disorder $\$$ or impair $\$$ or function $\$$ or loss $\$$ )).tw.

11 (forgetful\$ or confused or confusion).tw.

12 (dementia or demented).tw.

13 Huntington\$.tw.

14 Lewy Bod\$.tw.

15 (Creutzfeldt-Jakob or cjd).tw.

$16 \mathrm{Alz}$ ?eimer\$.tw.

17 or/1-16

18 down's syndrome/

19 (down\$ adj syndrome).tw.

20 Downs disease.tw.

21 trisomy $21 . t w$.

22 chromosome 21.tw.

23 (mongol or mongols or mongoloid or mongolism).tw.

24 or $/ 18-23$

2517 and 24

26 clinical trials/

27 random\$.tw.

28 (allocat\$ or assign\$).tw.

29 ((clinic $\$$ or control\$) adj trial\$).tw.

30 ((singl\$ or doubl\$ or trebl\$ or tripl\$) adj3 (blind\$ or mask\$)).tw.

Pharmacological interventions for cognitive decline in people with Down syndrome (Review)

Copyright $\odot 2015$ The Cochrane Collaboration. Published by John Wiley \& Sons, Ltd. 
31 (crossover\$ or “cross over\$”).tw.

32 random sampling/

33 Experiment Controls/

34 Placebo/

35 placebo\$.tw.

36 exp program evaluation/

37 treatment effectiveness evaluation/

38 ((effectiveness or evaluat\$) adj3 (stud\$ or research\$)).tw.

39 exp experimental methods/

40 or/26-39

4125 and 40

\section{CINAHL (EBSCOhost)}

CINAHL 1937 to current. Searched 20 January 2015 [106 records]

S38 S22 AND S37

S37 S23 OR S24 OR S25 OR S26 OR S27 OR S28 OR S29 OR S30 OR S31 OR S32 OR S33 OR S34 OR S35 OR S36

S36 (MH "Treatment Outcomes")

S35 (MH "Program Evaluation")

S34 (MH "Quantitative Studies")

S33 TX("cross over")

S32 TX (clinic* n1 trial*)

S31 PT Clinical trial

S30 TX placebo*

S29 (MH "Placebos")

S28 TX ( (singl* n1 blind*) or (singl* $n 1$ mask*) ) or TX ( (doubl* n1 blind*) or (doubl* n1 mask*) ) or TX ( (tripl* n1 blind*) or $\left(\right.$ tripl$^{*} \mathrm{n} 1$ mask $\left.\left.^{*}\right)\right)$ or TX $\left(\left(\operatorname{trebl}^{*} \mathrm{n} 1\right.\right.$ blind $\left.^{*}\right)$ or $\left(\operatorname{trebl}^{*} \mathrm{n} 1\right.$ mask $\left.\left.^{*}\right)\right)$

S27 TX (randomi* control* $^{*}$ trial $\left.^{*}\right)$

S26 TX (random* N3 (allocat* or assign*))

S25 (MH "Meta Analysis")

S24 (MH "random assignment")

S23 (MH "Clinical Trials+")

S22 S14 AND S21

S21 S15 OR S16 OR S17 OR S18 OR S19 OR S20

S20 mongol*

S19 chromosome 21

S18 trisomy 21

S17 Downs disease

S16 Down* syndrome

S15 (MH "Down Syndrome")

S14 S1 OR S2 OR S3 OR S4 OR S5 OR S6 OR S7 OR S8 OR S9 OR S10 OR S11 OR S12 OR S13

S13 (memory N3 (declin* or deteriorat* or degenerat* or disorder* or impair* or function* or loss*))

S12 ((cognit* or cerebr*) N3 (declin* or deteriorat* or degenerat* or disorder* or impair* or function*))

S11 (forgetful* or confused or confusion or deliri*)

S10 (Creutzfeldt-Jakob or cjd)

S9 Lewy bod*

S8 Huntington*

S7 Alz*eimer*

S6 (MH "Memory Disorders+")

S5 (MH "Memory")

S4 (MH "Confusion+")

S3 (MH "Delirium, Dementia, Amnestic, Cognitive Disorders")

S2 (MH "Cognition Disorders+")

Pharmacological interventions for cognitive decline in people with Down syndrome (Review)

Copyright $\odot 2015$ The Cochrane Collaboration. Published by John Wiley \& Sons, Ltd. 
8 to I I. Science Citation Index (SCI), Social Sciences Citation Index (SSCl), Conference Proceedings Citation Index-Science (CPCI-S) (Web of Science), Conference Proceedings Citation Index-Social Science \& Humanities (CPCI-SS\&H)

SCI 1970 to 20 January 2015. Searched 21 January 2015 [219 records]

SSCI 1970 to 20 January 2015. Searched 21 January 2015 [50 records]

CPCI-S 1990 to 20 January 2015. Searched 21 January 2015 [10 records]

CPCI-SS\&H 1990 to 20 January 2015. Searched 21 January 2015 [1 record]

\#20 \#19 AND \#13

DocType=All document types; Language=All languages;

\#19 \#18 OR \#17 OR \#16 OR \#15 OR \#14

DocType=All document types; Language=All languages;

\#18 TS=(control* NEAR/1 trial $\left.{ }^{*}\right)$

DocType=All document types; Language=All languages;

\#17 TS=(placebo* ${ }^{*}$

DocType=All document types; Language=All languages;

\#16 TS=(single or double NEAR/1 (blind*)

DocType=All document types; Language=All languages;

\#15 TS=RCT

DocType=All document types; Language=All languages;

\#14 TS=(random* NEAR/1 (trial or allocat* or assign*))

DocType $=$ All document types; Language $=$ All languages;

\#13 \#12 AND \#7

DocType=All document types; Language=All languages;

\#12 \#11 OR \#10 OR \#9 OR \#8

DocType=All document types; Language=All languages;

\#11 TS=(“chromosome 21")

DocType=All document types; Language=All languages;

\#10 TS=(“trisomy 21")

DocType=All document types; Language=All languages;

\#9 TS=(mongol or mongols or mongoloid or mongolism)

DocType=All document types; Language=All languages;

\#8 TS=( "down* syndrome" or "downs disease" )

DocType=All document types; Language=All languages;

\#7 \#6 OR \#5 OR \#4 OR \#3 OR \#2 OR \#1

DocType=All document types; Language=All languages;

\#6 TS=(Alz*eimer* or Huntington* or CJD or "Creutzfeld Jacob" or "Lewy bod*")

DocType=All document types; Language=All languages;

\#5 TS=(deliri*)

DocType=All document types; Language=All languages;

\#4 TS=((cognit* or cerebr*) near/3 (declin* or deteriorat* or degenerat* or disorder* or impair* or function*))

DocType=All document types; Language=All languages;

\#3 TS=(memory near/3 (declin* or deteriorat* or degenerat* or disorder* or impair* or function* or loss*))

DocType=All document types; Language=All languages;

\#2 TS= (forgetful* or confused or confusion)

DocType=All document types; Language=All languages;

\#1 TS=(dementia or demented)

DocType=All document types; Language=All languages;

\section{Cochrane Database of Systematic Reviews (CDSR)}

Pharmacological interventions for cognitive decline in people with Down syndrome (Review)

Copyright $\odot 2015$ The Cochrane Collaboration. Published by John Wiley \& Sons, Ltd. 
CDSR, part of the Cochrane Library, 2015, Issue 1. Searched 21 January 2015 [5 records]

\#1 MeSH descriptor: [Dementia] explode all trees

\#2 MeSH descriptor: [Cognition Disorders] explode all trees

\#3 MeSH descriptor: [Delirium, Dementia, Amnestic, Cognitive Disorders] this term only

\#4 ((cognit* or cerebr*) near/3 (declin* or deteriorat* or degenerat* or disorder* or impair* or function*)):ti,ab,kw

\#5 (dementia or demented):ti,ab,kw

\#6 MeSH descriptor: [Memory] this term only

\#7 MeSH descriptor: [Memory Disorders] explode all trees

\#8 (memory near/3 (declin* or deteriorat* or degenerat* or disorder* or impair* or function* or loss*)):ti,ab,kw

\#9 MeSH descriptor: [Confusion] this term only

\#10 (forgetful* or confused or confusion):ti,ab,kw

\#11 Alz*eimer*:ti,ab,kw

\#12 Huntington*:ti,ab,kw

\#13 (Lewy next bod*):ti,ab,kw

\#14 (Creutzfeldt next Jakob or CJD):ti,ab,kw

\#15 MeSH descriptor: [Delirium] this term only

\#16 deliri*:ti,ab,kw

\#17 \{or \#1-\#16\}

\#18 MeSH descriptor: [Down Syndrome] this term only

\#19 (down* next syndrome):ti,ab,kw

\#20 (downs next disease):ti,ab,kw

\#21 (trisomy next 21):ti,ab,kw

\#22 (chromosome next 21):ti,ab,kw

\#23 (mongol or mongols or mongoloid or mongolism):ti,ab,kw

\#24 \{or \#18-\#23\}

\#25 \#17 and \#24 in Cochrane Reviews (Reviews and Protocols)

\section{Database of Abstracts of Reviews of Effects (DARE)}

DARE, part of the Cochrane Library, 2014, Issue 4. Searched 21 January 2015 [1 record]

\#1 MeSH descriptor: [Dementia] explode all trees

\#2 MeSH descriptor: [Cognition Disorders] explode all trees

\#3 MeSH descriptor: [Delirium, Dementia, Amnestic, Cognitive Disorders] this term only

\#4 ((cognit* or cerebr*) near/3 (declin* or deteriorat* or degenerat* or disorder* or impair* or function*)):ti,ab,kw

\#5 (dementia or demented):ti,ab,kw

\#6 MeSH descriptor: [Memory] this term only

\#7 MeSH descriptor: [Memory Disorders] explode all trees

\#8 (memory near/3 (declin* or deteriorat* or degenerat* or disorder* or impair* or function* or loss*)):ti,ab,kw

\#9 MeSH descriptor: [Confusion] this term only

\#10 (forgetful* or confused or confusion):ti,ab,kw

\#11 Alz*eimer*:ti,ab,kw

\#12 Huntington*:ti,ab,kw

\#13 (Lewy next bod*):ti,ab,kw

\#14 (Creutzfeldt next Jakob or CJD):ti,ab,kw

\#15 MeSH descriptor: [Delirium] this term only

\#16 deliri*:ti,ab,kw

\#17 \{or \#1-\#16\}

\#18 MeSH descriptor: [Down Syndrome] this term only

\#19 (down* next syndrome):ti,ab,kw

\#20 (downs next disease):ti,ab,kw

\#21 (trisomy next 21):ti,ab,kw

\#22 (chromosome next 21):ti,ab,kw

\#23 (mongol or mongols or mongoloid or mongolism):ti,ab,kw

Pharmacological interventions for cognitive decline in people with Down syndrome (Review)

Copyright $\odot 2015$ The Cochrane Collaboration. Published by John Wiley \& Sons, Ltd. 
\#24 \{or \#18-\#23\}

\#25 \#17 and \#24 in Other Reviews

\section{ClinicalTrials.gov}

ClinicalTrials.gov

ClinicalTrials.gov. Searched 21 January 2015 [24 records]

Basic search: "Down syndrome" AND ( dementia OR Alzheimers OR cognition OR cognitive OR memory ) | Interventional Studies

\section{World Health Organisation (WHO) International Clinical Trials Registry Platform (ICTRP)}

apps.who.int/trialsearch/Default.aspx

ICTRP. Searched 21 January 2015 [22 records]

Standard search: down syndrome AND cognition OR down syndrome AND Alzheimers OR down syndrome AND dementia OR down syndrome AND memory OR down syndrome AND cognitive

\section{Appendix 2. Correspondence with pharmaceutical manufacturers}

We contacted the following pharmaceutical manufacturers to request information about unpublished trial data.

1. Pfizer Ltd, the previous manufacturer for donepezil.

2. Eisai Co, Ltd the current manufacturer for donepezil.

3. Janssen-Cilag Ltd, the manufacturer of galantamine.

4. Lundbeck, the manufacturer of memantine.

5. Novartis, the manufacturer of rivastigmine.

6. $\mathrm{t} 21$ research society.

7. Jérôme Lejeune Foundation.

\section{Appendix 3. Methods to be used in future updates of this review}

\section{Measures of treatment effect}

We will extract both change scores (i.e. change from baseline) and final values. Studies with change-from-baseline outcomes will be combined in a meta-analysis with studies with final measurement outcomes by using the (unstandardised) mean difference method in RevMan (Review Manager 2012). We will present mean differences in change scores in one subgroup, mean differences in final values in another, and pool both subgroups for an overall analysis (Higgins 2011).

We will only include data in the meta-analysis when it is at least approximately normally distributed. We will check the data for skewness where possible by visual inspection of the histogram and calculating the observed mean minus the lowest possible value (or the highest possible value minus the observed mean), and dividing this by the standard deviation (Higgins 2011). In the event that data are identified as skewed, we will contact the study authors to request appropriate data summaries or acquisition of individual participant data, in order to present results on a transformed scale, usually a log scale. If this is not possible, the results from these studies will be presented narratively only.

\section{Continuous data}

When continuous outcome data are recorded using the same measurement scale, we will convert data into mean differences (MDs) and present these with $95 \%$ confidence intervals (CIs).

\section{Time-to-event data}

We will convert time-to-event data (e.g. time to institutionalisation) into hazard ratios (HR) with 95\% CIs.

Pharmacological interventions for cognitive decline in people with Down syndrome (Review) 


\section{Multiple outcomes}

When a study provides multiple, interchangeable continuous measures of the same construct at the same point in time (e.g. multiple measures of behavioural problems), we will calculate the average SMD across these outcomes, and the average of their estimated variances (Borenstein 2009). This will avoid the need to select a single measure, and any associated inflated precision in meta-analyses (i.e. studies which report on more outcome measures will not receive more weight in an analysis than comparable studies, which report on a single outcome measure). When a study provides multiple, interchangeable dichotomous measures of the same construct at the same point in time, the same approach will be taken, this time averaging on the log OR (Higgins 2014 [pers comm]).

\section{Economic issues}

We will provide a narrative summary of any available data on the costs of programmes within the studies under review.

\section{Unit of analysis issues}

\section{Cluster-randomised trials}

Cluster-randomised trials are possible in this area, as allocation to the intervention group may occur by hospital or by community as opposed to by individual participant. It is anticipated that should this occur, investigators will have controlled for a clustering effect in their results already. If necessary, we will contact authors for further information. If study authors failed to control for a clustering effect, we will request IPD in order to calculate an estimate of the intracluster correlation coefficient (ICC). If IPD are not available, we will obtain an external estimate of the ICC from similar studies or available resources. If an appropriate ICC cannot be found from any available resources, we will seek statistical advice to obtain an estimate of the ICC and use this to reanalyse the trial data to obtain approximately correct analyses. This reanalysed trial data will then be entered into the RevMan software using the generic inverse variance method to analyse effect sizes and CIs (Higgins 2011).

\section{Cross-over trials}

Cross-over trials are possible in this research area, as participants may receive both the control and intervention treatment but in a different order. We will include relevant eligible cross-over trials in the review, but we will only use data gathered during the first period of the study, up to the point of the first cross-over. This should avoid any problems associated with any carry-over effect from the first period to the second period of the study.

\section{Studies with multiple treatment groups}

Studies with multiple intervention groups are possible in this area. If a study compares two or more eligible interventions groups to one eligible control group, we will split the sample size for the shared comparator group evenly. This should prevent the same comparator participants from being included twice. If a study compares one eligible intervention group to two or more eligible control groups, each undergoing different yet equally eligible forms of 'placebo', we will combine the control groups to create a single pairwise comparison. For dichotomous outcomes, both the sample sizes and the numbers of people with events can be summed across groups. For continuous outcomes and time-to-event outcomes, means and standard deviations can be combined using methods described in the Cochrane Handbook for Systematic Reviews of Interventions (Higgins 2011). If this strategy poses a problem for investigation of heterogeneity, we will compare each group separately as part of the subgroup analyses (see Subgroup analysis and investigation of heterogeneity). We will outline clearly in the review all decisions made regarding unit-of-analysis issues.

\section{Dealing with missing data}

We will contact authors and ask them to supply data missing from included studies. If this is not feasible, we will then follow the recommendations of the Cochrane Handbook for Systematic Reviews of Interventions (Higgins 2011).

Data that are missing are likely to be missing for reasons related to the outcomes of the missing data. For example, if a participant agrees to take part in a trial, but experiences adverse events as a result of the medication, or fails to adhere to the medication throughout the course of the study, he/she will be less likely to complete any follow-up assessments. We will apply an intention-to-treat analysis for all missing data, and impute missing data wherever possible.

Pharmacological interventions for cognitive decline in people with Down syndrome (Review) 
When dichotomous data are judged not to be missing at random, we will assume that the participants experienced the less favourable outcome (e.g. 'participant was institutionalised'), and we will impute the data accordingly.

We will impute missing continuous data and time-to-event data using a 'last observation carried forward' (LOCF) approach, using individual patient data (IPD) if available. Where this is not possible, we will impute sample mean values based on predicted values from a regression analysis.

We will examine the impact on the results of changes in the assumptions made about missing data as part of the Sensitivity analysis. For example, where dichotomous data cases are missing, we will impute data assuming that those missing experienced the positive outcome (e.g. 'participant was not institutionalised').

In the event of missing summary data, such as missing standard deviations, we will obtain these, where possible, using calculations provided in the Cochrane Handbook for Systematic Reviews of Interventions (Higgins 2011).

We will specify the methods used to address any missing data in the 'Characteristics of included studies' tables. If insufficient information is given regarding the exact number missing from each group, data imputation may not be possible, in which case, we will analyse only the available data. If imputation is not possible, we will outline the reasons for this in the text. When imputation is not possible, the results from these studies will be presented narratively.

\section{Assessment of reporting biases}

We will use visual inspections of funnel plots, along with trim and fill analyses, to assess publication and other reporting biases, providing outcome data are available from a sufficient number of included studies (usually around 10). We will also use Egger's regression intercept (Egger 1997), and Begg's rank correlation test to assess the asymmetry of the funnel plots (Begg 1994). Funnel plot asymmetry may be due to publication bias or be attributable to a real relationship between trial size and effect size (e.g. when larger trials have lower compliance, and compliance is positively related to effect size). In the event that we find such a relationship, we will examine clinical variation of the studies (Higgins 2008; section 10.4). As a direct test for publication bias, we will compare results extracted from published journal reports with results obtained from other sources (including correspondence).

\section{Data synthesis}

For some analyses, it may be necessary to incorporate IPD. In this event, we will use the IPD to generate estimates of effectiveness (aggregate data) for each study separately and then combine these summary statistics using a two-stage approach (Stewart 2015). Any IPD that are used in the data synthesis will be subject to data checking (such as adequate randomisation, selective outcome reporting, and completeness of follow-up) by contacting the original study authors with open-ended questions about their study design and conduct, as recommended by the Cochrane Handbook for Systematic Reviews of Interventions (Higgins 2011; section 8.3.4).

\section{Subgroup analysis and investigation of heterogeneity}

Providing that there is a sufficient number of studies, subgroup analyses will examine the differential effects of:

1. the different types of pharmacological intervention (e.g. donepezil versus galantamine);

2. baseline cognitive functioning (mild-to-moderate intellectual disability at baseline versus moderate-to-severe intellectual disability at baseline versus diagnosis of dementia at baseline);

3. interventions by stage of dementia (e.g. mild versus moderate versus severe); and

4. interventions by the age of the participant (e.g. young adults (18 to 30 years) versus mature adults (31 to 50 years) versus older adults (50 years plus).

\section{Sensitivity analysis}

We will assess whether the findings of this review are robust to the decisions made in the process of obtaining them through the use of sensitivity analysis. We will perform sensitivity analyses by conducting the following reanalyses:

1. excluding studies with issues regarding their study quality, excluding those with high risk of bias, or high attrition and dropout rate;

2. without imputing data for the missing participants; and

3. using alternative outcomes from studies providing multiple measures of the same construct.

Pharmacological interventions for cognitive decline in people with Down syndrome (Review) 


\section{H I S T O R Y}

Protocol first published: Issue 2, 2015

Review first published: Issue 10, 2015

\begin{tabular}{|c|c|c|}
\hline Date & Event & Description \\
\hline 4 September 2015 & Amended & $\begin{array}{l}\text { This is an amended version of a previously published protocol. The scope of the review has been } \\
\text { broadened to include participants without a diagnosis of dementia, and a wider range of pharma- } \\
\text { cological and nutritional interventions }\end{array}$ \\
\hline
\end{tabular}

\section{CONTRIBUTIONSOFAUTHORS}

All four authors contributed to the development of the review. Livingstone conducted the literature searches in collaboration with the CDPLPG Trials Search Co-ordinator. Livingstone and Hanratty screened the results for eligibility, extracted data independently, entered data into a piloted data extraction form, assessed each study for risk of bias, summarised each study, and drafted the methods and results sections. All four authors contributed to resolving any disagreements in screening or data extraction. Livingstone conducted the meta-analyses. All four authors contributed to the writing of the review.

Nuala Livingstone has overall responsibility for the review.

\section{DECLARATIONSOF INTEREST}

This review has been commissioned by the National Institute for Health Research (NIHR), Health Technology Assessment (HTA) Prioritisation Group.

Nuala Livingstone - is an Editor for the Cochrane Developmental, Psychosocial and Learning Problems Group and the Cochrane Editorial Unit.

Jennifer Hanratty - none known.

Rupert McShane - is the Co-ordinating Editor for the Cochrane Dementia and Cognitive Improvement Group. He is involved in a study unrelated to this review, which is sponsored by Janssen.

Geraldine Macdonald - is the Co-ordinating Editor for the Cochrane Developmental, Psychosocial and Learning Problems Group.

\section{SOURCES OF SUPPORT}

\section{Internal sources}

- Queen's University Belfast, UK. Salary 


\section{External sources}

- National Institute for Health Research (NIHR), Health Technology Assessment (HTA) Prioritisation group, UK. Funding to perform this review

\section{DIFFERENCES BETWEEN PROTOCOLANDREVIEW}

Due to insufficient number of studies in the memantine pooled analysis, it was not possible to make comparisons at the pre-specified follow-up periods (short term (less than three months), medium term (three to 12 months), and long term (over one year)). Instead, we have pooled results from the 16-week follow-up and the 52-week follow-up.

Regarding the section 'Measures of treatment effect, multiple outcomes', in a deviation from protocol, cognitive outcomes reported by Cooper 2012 were not combined as described. This is because Cooper 2012 served as a pilot trial with one aim being to select the most appropriate measure. Therefore, we summarised cognitive outcomes from the primary measure selected by Cooper 2012 as being most sensitive to change and easily completed by participants narratively.

A post protocol decision was made to use the Mantel-Haenszel method for analysis of dichotomous outcomes, as It has been shown that this method has better statistical properties when few events are available.

\section{N D EX TERMS}

\section{Medical Subject Headings (MeSH)}

Acetylcarnitine [adverse effects; therapeutic use]; Antioxidants [ ${ }^{*}$ therapeutic use]; Cognition [drug effects]; Cognition Disorders [ ${ }^{*}$ drug therapy]; Down Syndrome [* complications]; Indans [adverse effects; therapeutic use]; Memantine [adverse effects; therapeutic use]; Nootropic Agents [adverse effects; * therapeutic use]; Piperidines [adverse effects; therapeutic use]; Randomized Controlled Trials as Topic; Simvastatin [adverse effects; therapeutic use]

\section{MeSH check words}

Adult; Humans; Middle Aged

Pharmacological interventions for cognitive decline in people with Down syndrome (Review) 